\title{
Current Biology \\ Odorant Receptor Inhibition Is Fundamental to Odor Encoding
}

\section{Graphical Abstract}

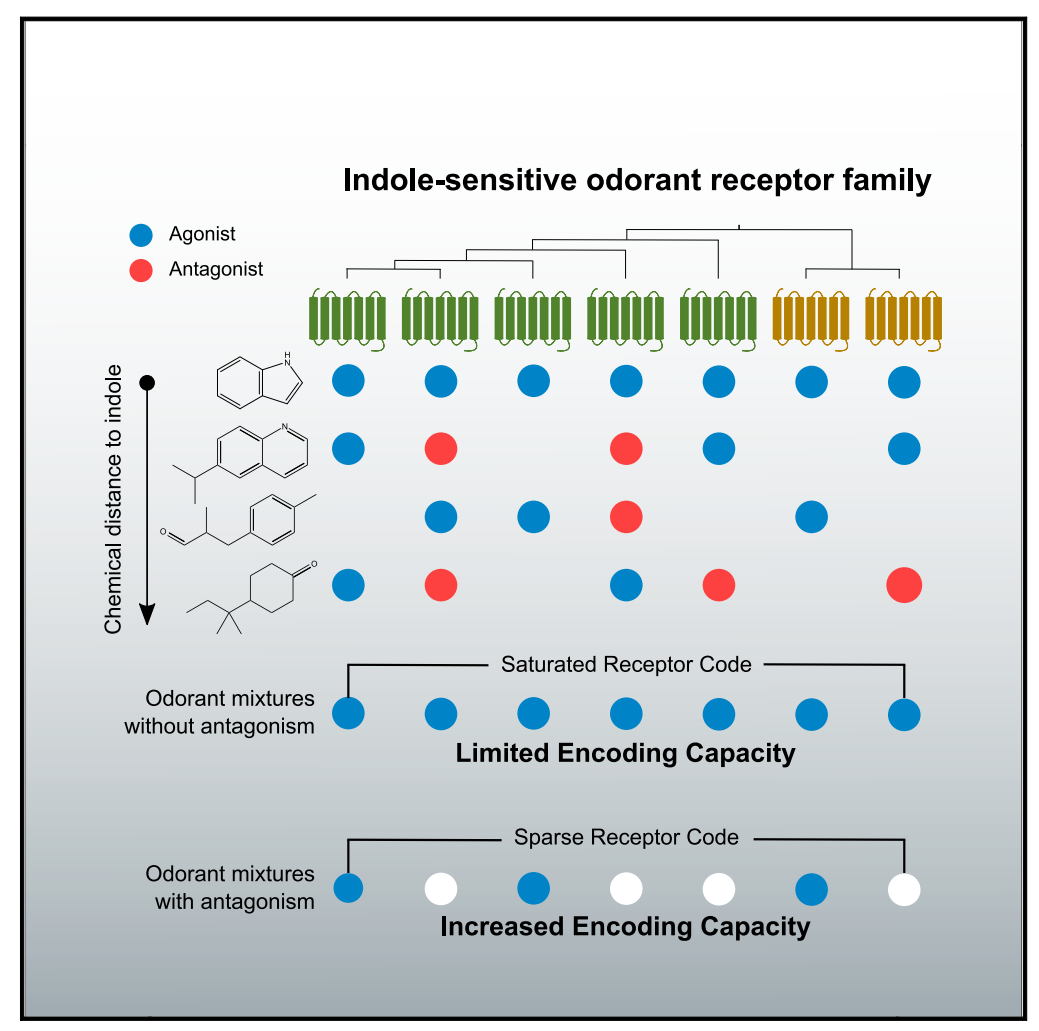

\section{Highlights}

- Odor mixture encoding requires extensive modulation of odorant receptor activity

- A combinatorial binding logic exists for antagonists, like agonists

- Widespread antagonism increases the encoding capacity of the olfactory system

- Divergent antagonism among paralogs diversifies odorant receptor repertoires

\section{Authors}

Patrick Pfister, Benjamin C. Smith, Barry J. Evans, ..., Zita Peterlin, Massimo Vergassola, Matthew E. Rogers

\section{Correspondence}

matthew.rogers@firmenich.com

\section{In Brief}

Odors activate and inhibit olfactory sensory neurons in the olfactory epithelium, modulating their representation at the point of detection. Pfister et al. show that neuronal inhibition is odorant-receptor mediated, widespread, combinatorial, and may represent a convergent evolutionary solution to the complexity of natural odors. 


\title{
Article \\ Odorant Receptor Inhibition Is Fundamental to Odor Encoding
}

\author{
Patrick Pfister, ${ }^{1,3}$ Benjamin C. Smith, ${ }^{1,3}$ Barry J. Evans, ${ }^{1}$ Jessica H. Brann, ${ }^{1}$ Casey Trimmer,${ }^{1}$ Mushhood Sheikh, ${ }^{1}$ \\ Randy Arroyave, ${ }^{1}$ Gautam Reddy, ${ }^{2}$ Hyo-Young Jeong, ${ }^{1}$ Daniel A. Raps, ${ }^{1}$ Zita Peterlin, ${ }^{1}$ Massimo Vergassola, ${ }^{2}$ \\ and Matthew E. Rogers ${ }^{1,4, *}$ \\ ${ }^{1}$ Firmenich Incorporated, 250 Plainsboro Road, Plainsboro, NJ 08536, USA \\ ${ }^{2}$ Department of Physics, UC San Diego, 9500 Gilman Dr., La Jolla, CA 92093, USA \\ ${ }^{3}$ These authors contributed equally \\ ${ }^{4}$ Lead Contact \\ *Correspondence: matthew.rogers@firmenich.com \\ https://doi.org/10.1016/j.cub.2020.04.086
}

\section{SUMMARY}

Most natural odors are complex mixtures of volatile components, competing to bind odorant receptors (ORs) expressed in olfactory sensory neurons (OSNs) of the nose. To date, surprisingly little is known about how OR antagonism shapes neuronal representations in the detection layer of the olfactory system. Here, we investigated its prevalence, the degree to which it disrupts OR ensemble activity, and its conservation across phylogenetically related ORs. Calcium imaging microscopy of dissociated OSNs revealed significant inhibition, often complete attenuation, of responses to indole-a commonly occurring volatile associated with both floral and fecal odors-by a set of 36 tested odorants. To confirm an OR mechanism for the observed inhibition, we performed single-cell transcriptomics on OSNs exhibiting specific response profiles to a diagnostic panel of odorants and identified three paralogous receptors-Olfr740, Olfr 741 , and Olfr743-which, when tested in vitro, recapitulated OSN responses. We screened ten ORs from the Olfr740 gene family with $\sim 800$ perfumery-related odorants spanning a range of chemical scaffolds and functional groups. Over half of these compounds (430) antagonized at least one of the ten ORs. OR activity fitted a mathematical model of competitive receptor binding and suggests normalization of OSN ensemble responses to odorant mixtures is the rule rather than the exception. In summary, we observed OR antagonism occurred frequently and in a combinatorial manner. Thus, extensive receptor-mediated computation of mixture information appears to occur in the olfactory epithelium prior to transmission of odor information to the olfactory bulb.

\section{INTRODUCTION}

Odorants represent a rich source of information about an organism's environment and are most frequently experienced as complex mixtures. Yet, odorant mixture encoding by the mammalian olfactory system remains poorly understood. Odorant detection is initiated when odorants interact with seven transmembrane domain G protein-coupled odorant receptors (ORs) expressed in olfactory sensory neurons (OSNs) lying in the nasal cavity [1, 2]. Known, putatively functional mammalian OR genes number between 58 and 2,514 depending on the species, with 390 in humans and 1,231 in mice [3]. Only one OR gene is expressed per OSN [4-7], a major feature underlying combinatorial odor encoding $[1,2,8,9]$. That is, a single OR can be activated by multiple odorants and a single odorant can activate multiple ORs [1017], leading to many possible combinations of active ORs, and thus the OSNs housing them. However, even with combinatorial encoding and a large family of receptors, recent theoretical work suggests substantial input normalization may be required to prevent saturation of the detection layer of the olfactory system and retain discriminatory ability even for moderately complex odors (>20 components) [18].

OR antagonism by odorants, a straightforward normalization solution, has been observed experimentally for a relatively small number of mammalian ORs [19-24] and likely plays an important role in how odorant mixtures may be encoded [25, 26]. More recent experimental work explored this hypothesis in the olfactory epithelium (OE) and olfactory bulb $(\mathrm{OB})$ in vivo and found evidence of mixture inhibition occurring in the peripheral olfactory system [27-29]. In particular, Xu et al. reported extensive OSN inhibition in intact OE when presented with complex odorant mixtures [27], while Inagaki et al. excluded that presynaptic inhibition in the OB was because of lateral inhibition from interneurons in double knockout mice for the $\mathrm{GABA}_{\mathrm{B} 1}$ and D2R dopamine receptors [28]. Yet limitations in probing ORs in heterologous expression systems and in silico [30] have impeded systematic exploration of the full range of possible receptor-ligand interactions. As such, it is not fully understood to what extent classical G protein-coupled receptors (GPCR) ligand types - like antagonists (ligands that 


\section{CellPress} OPEN ACCESS

A

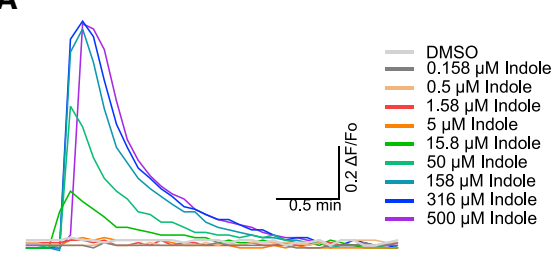

C

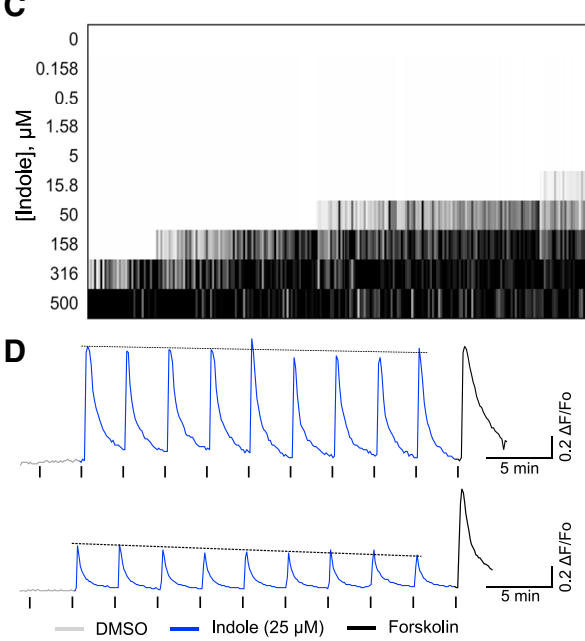

$\mathbf{F}$
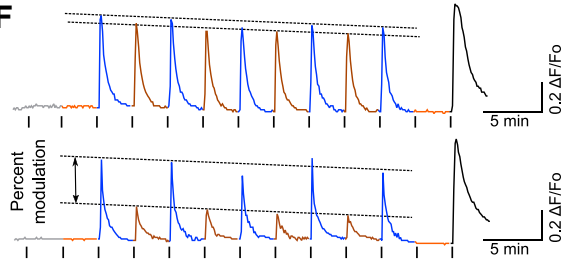

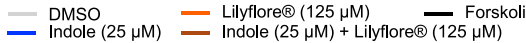

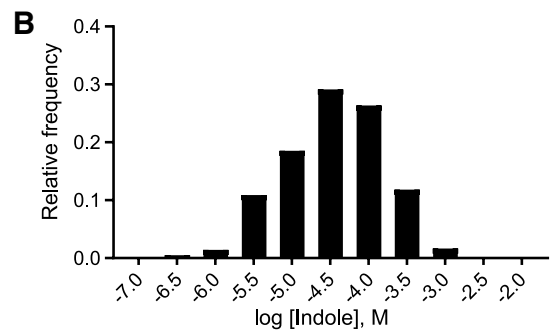
$\log$ [Indole], M
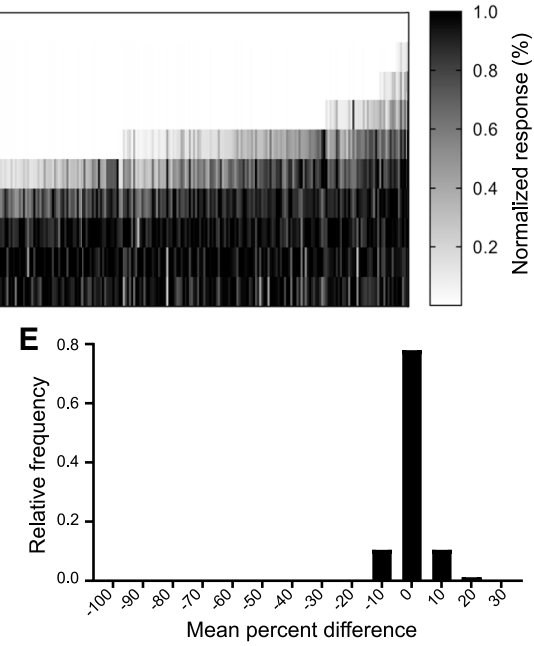

\section{G}

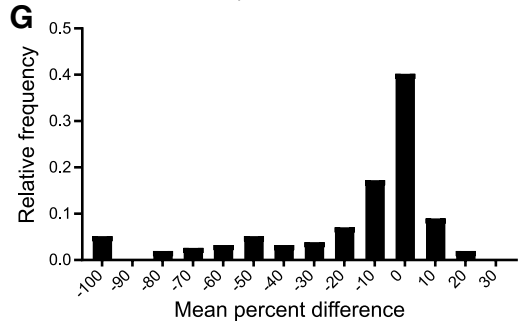

Current Biology Article
Figure 1. Characterization of Indole-Sensitive Dissociated OSNs

(A) A representative response of an individual OSN to increasing indole concentrations (ranging 0.158$500 \mu \mathrm{M})$. Saturation occurs at $158 \mu \mathrm{M}$ and above. Scale bar, $x$ axis represents time in minutes; $y$ axis represents $\Delta F / F_{0}$ fluorescence ratio.

(B) Population histogram of the $\mathrm{EC}_{50}$ distribution for indole-sensitive OSNs.

(C) Population heatmap of the concentrationdependent responses of 441 indole-sensitive OSNs $(n=3)$. Each column represents an individual OSN response normalized to its highest indole response.

(D) Response variability of two OSNs to $25 \mu \mathrm{M}$ indole (blue) repeated administration. Responses to $0.3 \%$ DMSO solvent (negative control, gray) and $40 \mu \mathrm{M}$ Forskolin (positive control, black) are also shown. Forskolin is an activator of Adenylyl Cyclase 3 (AC3) [33] and is used as a measure of maximal activation of the signal transduction cascade (see also Figure S1 for an AC3 inhibition experiment). Administration time points are indicated by vertical tick marks below the trace. Scale bar, $x$ axis represents time in minutes; $y$ axis represents $\Delta F / F_{0}$ fluorescence ratio.

(E) Population histogram of response variability shown in (D), measured as the mean percent difference between peak responses to evennumbered (interposing) administrations and a line of best fit across peak responses to odd-numbered (flanking) administrations (86 OSNs, $\mathrm{n}=3$ ).

(F) Responses of two OSNs to $25 \mu \mathrm{M}$ indole (blue) or to a mixture of $25 \mu \mathrm{M}$ indole and $125 \mu \mathrm{M}$ Lilyflore (orange). Scale bar, $x$ axis represents time in minutes; y axis represents $\Delta F / F_{0}$ fluorescence ratio.

(G) Population histogram of the mean percent difference between peak responses to the indole and Lilyfore mixture and a line of best fit across flanking indole administrations as described in $F(157$ OSNs; $n=4)$. bind but do not activate a receptor), partial agonists (ligands that cannot fully activate a receptor even at saturating concentrations), and inverse agonists (ligands that reduce constitutive receptor activity) - shape complex odor representations before they are propagated to the OB.

Using $\mathrm{Ca}^{2+}$ imaging of dissociated neurons, we first investigated inhibition of indole-sensitive OSNs by testing binary mixtures of indole and a diverse set of odorant compounds. We found that inhibition varied in magnitude, and most compounds inhibited many OSNs. The extent of inhibition was maintained when we imaged the binary mixture responses of intact OE that retained full connectivity to the OB, using SCAPE microscopy $[27,31]$. We then coupled $\mathrm{Ca}^{2+}$ imaging of dissociated OSNs with single-cell RNA sequencing (RNA-seq) to identify a subset of indole-sensitive paralogous ORs, which were then systematically probed with a large odorant library using highthroughput screening. Receptor-specific antagonism was, on average, at least as common as receptor activation and displayed diverse relative affinities and efficacies. Our data strongly support that antagonism is a typical outcome of ORligand binding and thus a fundamental aspect of olfaction, frequently leading to input normalization at the onset of odor mixture detection.

\section{RESULTS}

Prevalent Inhibition of Olfactory Sensory Neurons in Two-Component Odorant Mixtures

To investigate the extent of OSN inhibition, a standard calcium imaging method was developed, where thousands of dissociated mouse OSNs per experiment could be monitored with accurate concentrations of either monomolecular odorants or mixtures with specified odorant ratios [32] (STAR Methods). First, we characterized assay variability using the naturally occurring molecule, indole. Because previous experiments had shown indole activated a large proportion of OSNs (data not shown), it provided a good choice for subsequently studying inhibition breadth across an OSN population. The concentration of indole used herein was derived from indole dose-response experiments where 14,989 OSNs were challenged with increasing indole concentrations. Robust dose-dependent responses were observed, with 433 OSNs responding to indole with lognormally distributed potencies spanning approximately 3.5 orders of magnitude, with a mean $\mathrm{EC}_{50}$ of $36 \mu \mathrm{M}$ (Figures $1 \mathrm{~A}-$ 1C). Repeated administration of indole slightly below the mean $\mathrm{EC}_{50}(25 \mu \mathrm{M})$ yielded peak height variation in indole-sensitive OSNs of $0.79 \% \pm 4.9 \%$ (mean $\pm \mathrm{SD}$ ) (Figures $1 \mathrm{D}$ and $1 \mathrm{E}$ ), thus 


\section{Current Biology Article}

providing a robust yet sensitive condition to quantify the effects of two-component odorant mixtures.

To systematically measure OSN inhibition, we employed an experimental design in which $25 \mu \mathrm{M}$ indole delivery was interspersed with delivery of $25 \mu \mathrm{M}$ indole mixed with a test odorant at $125 \mu \mathrm{M}$. The peak $\mathrm{Ca}^{2+}$ signals evoked by the mixture were compared with indole alone, allowing for the measurement of relative response changes. The method was piloted with the structurally related odorant Lilyflore (Figure 1F; compound 20 in Figure 2). Indole + Lilyflore reduced indole responses in $43 \%$ of OSNs by $\geq 10 \%$, two standard deviations away from the assay's mean variability (Figures $1 \mathrm{E}$ and $1 \mathrm{G}$ ). Such a large response modulation indicated this odorant was an inhibitor of indole-sensitive OSNs and therefore a putative indole OR antagonist.

Previous work suggests OSN inhibitors and OR antagonists can be structurally related to agonists [19, 22-24]. To examine this relationship further, 36 structurally varied odorants were tested for their inhibitory effects on indole-sensitive OSNs using the experimental paradigm described above (Figure 2A). Chemical distances between indole and the 36 odorants were determined by calculating the Tanimoto coefficient of four recently developed molecular fingerprints commonly used in ligandbased search approaches (Table S1) [34, 35]. Inhibition was common and varied by OSN and odorant, with 32 compounds completely inhibiting a subset of indole-sensitive OSNs (Figure 2B). Almost half of the odorants (17) displayed median inhibition values greater than $10 \%$. Furthermore, several of the least chemically similar odorants (lowest Tanimoto coefficients) showed some of the strongest inhibition effects on the indolesensitive OSN population (e.g., compounds 1, 2, 3, 5, and 7 in Figure 2). Other previous work suggests that OR-independent mechanisms could result in comparable OSN response inhibition [36-39]. However, when pharmacologically blocking the olfactory transduction pathway [40, 41], we observed nearly complete attenuation of the indole response in all indole-sensitive OSNs recorded (Figure S1), in stark contrast to the highly specific inhibition patterns observed with odorants. The high but specific rate of odorant-mediated inhibition seen here across divergent chemical structures suggests that structural similarity is not necessarily a prerequisite for OSN inhibition.

The dose-dependence of odorant-mediated OSN inhibition was characterized by testing three inhibitors at concentrations between 2.5 and $500 \mu \mathrm{M}$ in mixture with $25 \mu \mathrm{M}$ indole (Figure $3 \mathrm{~A}$ ). These odorants, Lilyflore, Hivernal Neo, and Z95, were chosen to span a range of population effect sizes based on the screening results at $125 \mu \mathrm{M}$ (see Figure 2A). Lilyflore showed the smallest effect of the three with a median inhibition of $\sim 5 \%$, Hivernal Neo had a median inhibition of $\sim 12 \%$, and $Z 95$ showed the greatest effect with a median inhibition level of $\sim 45 \%$. In all cases, dose-dependent inhibition at the single OSN level could be fitted with the Hill equation and generated varying $\mathrm{IC}_{50} \mathrm{~S}$ and Hill coefficients, such that increasing doses inhibited the responses of successively larger numbers of OSNs with increasing strength (Figures 3B-3E).

Specificity of inhibition was further probed by functionally characterizing OSNs with a panel of agonists and then challenging the same population of indole-sensitive OSNs with the inhibitors Lilyflore, Hivernal Neo, and Z95 (Figures 3F and 3G).
The diagnostic panel of agonists consisted of indole and analogs 2-methylindole, 3-methylindole, 6-methylindole, and 2-methoxynaphthalene and segregated OSNs into ensembles with differing agonist response profiles. Following stimulation with the two-component mixtures, OSNs displayed further compound-specific differences in their responses and extensive input normalization.

To examine if the dissociation process could have impacted the observed OSN responses, we used SCAPE microscopy to monitor odor responses of mature OSNs via a genetically encoded calcium indicator, GCaMP6f, in a whole-mount preparation of the $\mathrm{OE}$ (Figure $3 \mathrm{H})$ [27, 31]. In this preparation, the structural integrity of the $\mathrm{OE}$ was maintained, projections to the $\mathrm{OB}$ were preserved, and odorants were delivered with the same delivery system used in dissociated preparations. Z95 was chosen for these experiments because it was the most potent and broadly acting inhibitor identified from our dissociated OSN experiments. The results obtained in intact OE mirrored those obtained in dissociated OSNs. Widespread inhibition of indole-sensitive OSNs was observed with Z95, ranging from no modulation to full inhibition of OSNs (Figures 3I-3K). Interestingly, the distribution of Z95 OSN inhibition in intact OE was shifted toward significantly higher values compared with that of dissociated OSNs (Figure 3K); the unpaired median difference between dissociated and intact OSNs was $60 \%(95.0 \% \mathrm{Cl} 18.8,81.2)$, the $p$ value of the two-sided permutation $t$ test was 0.007 [42], suggesting inhibition was significantly underestimated in the dissociated method. Taken together, these results imply that OSN inhibition can occur in vivo, shows sigmoidal dose-dependence, and is combinatorial like activation.

\section{Identification of Indole-Sensitive Odorant Receptors}

To demonstrate that OSN inhibition was a result of OR antagonism by specific odorants, we employed single-cell RNA-seq of indole-sensitive OSNs to identify indole-sensitive ORs for subsequent in vitro study. Indole and five related odorants (2-methylindole, 3-methylindole, 6-methylindole, 2-methoxynaphthalene, and Lilyflore) were sequentially delivered to dissociated OSNs, and six OSNs with three different response profiles were isolated for transcriptome analysis. RNA transcripts encoding Olfr740, Olfr741, and Olfr743 were retrieved, with high level expression of a single OR transcript in each OSN (Figures 4A4C), consistent with monogenic OR expression in OSNs 2,4-6 and coincident expression of mature OSN markers (Figure S3A) [43]. OSNs with similar response profiles expressed the same OR genes while OSNs with qualitatively distinct responses expressed different OR genes.

Olfr740, Olfr741, and Olfr 743 belong to a closely related gene family consisting of 12 members (Figure S2), providing an opportunity to probe combinatorial agonism and antagonism and how they relate to OR phylogenetic proximity. We characterized each OR's activation profile in a HEK293T-derived heterologous expression system (STAR Methods) by performing doseresponse experiments with the same diagnostic compounds used for identification. The compounds activated the ORs with varying potencies (measured by $\mathrm{EC}_{50}$ ) and efficacies (measured by maximum receptor activity) (Figures $4 \mathrm{D}-4 \mathrm{G}$ ). Importantly, the rank-order of in vitro OR potencies for the three identified ORs were consistent with the rank-order of OSN sensitivities of the 
A

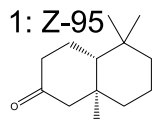<smiles>[Z10]C(C)C1CCC(CCC2CCC(C(C)(C)C)CC2)CC1</smiles><smiles>[Z]C(C)CCC(C)CCC(C)CCC(C)CC(C)C</smiles>

8<smiles>[C+]C1=CCC2CC(C)(C(C)C)CC2C1</smiles>

9<smiles>CCCCc1ccc2c(c1)CCC2(C)[N+]([O-])([O-])O</smiles><smiles>CC(C)/C=C/C1C(C)CCCC1(C)C</smiles>

12<smiles>CC(C)(C)C1CC2CCCC(C2)C1</smiles><smiles>CCCCCCCCCCCCC(C)C</smiles>

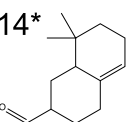

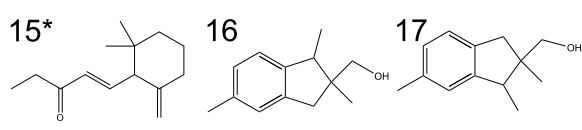

18<smiles>CCCc1ccccc1</smiles>

19

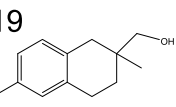

20*: Lilyflore ${ }^{\circledR} 19$

16
17
18
19
20<smiles>CCCCC1CCCC(C)C1CC(C)CC</smiles><smiles>CC1CC2CC(C)(C(C)C)CC2C1</smiles>

23<smiles>CC1(C)CC2CCCC2C1</smiles><smiles>[Z6]C(C)C1CCC(C(C)(C)C)CC1</smiles>

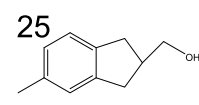<smiles>CC1(C)CCC2(C)CCC(C1)C2</smiles>

27<smiles>C=C(C)CCC1(C)CC2CCCCC2C1</smiles><smiles>CC1CC(C)C2CC3CCCCC3C2C1</smiles>

\section{9}<smiles>CC1CC2CCCCC2C1</smiles>

30<smiles>CCCc1ccccc1</smiles>

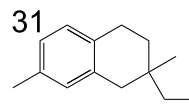

32

33

34<smiles>CCCC1(C)Cc2ccc(C)cc2C1</smiles><smiles>CCCCC1CCCCC1</smiles>

35: 2-MN

36

37: Indole<smiles>CCCCc1cccc(CCc2ccc3c(c2)CCC3)c1</smiles>

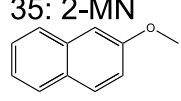

B

23

24

25

27

28

29

32

33

34

36

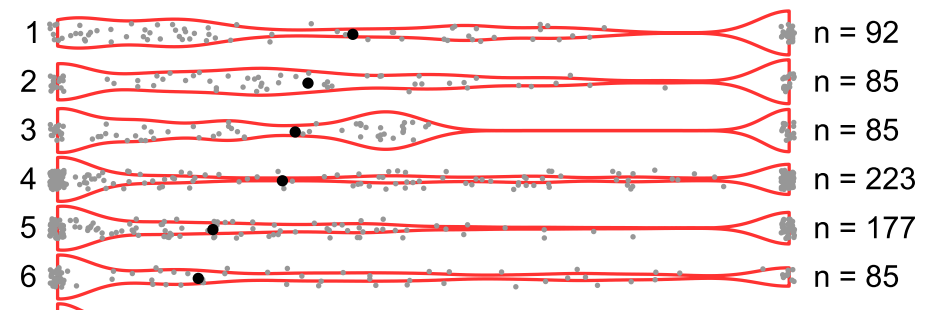

$70 \ldots n=148$

8 두두 $n=170$

9 ... $n=121$

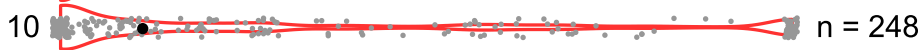

$1120 \mathrm{n}=99$

$120 \ldots \ldots+\therefore=121$

$13 \ldots n=121$

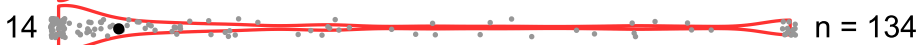

15 . . n $n=113$

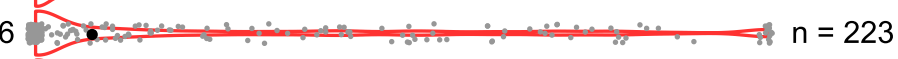

$17 \ldots n=2 \ldots$

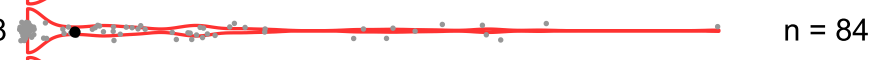

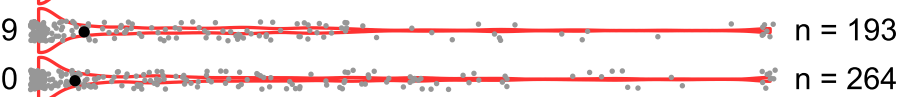
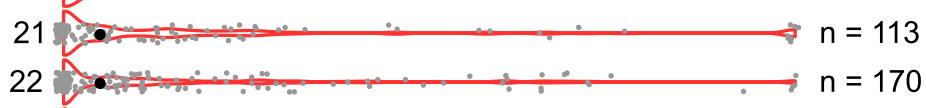

30

$\mathrm{n}=71$

$n=134$

$\mathrm{n}=168$

$\mathrm{n}=170$

$\mathrm{n}=85$

$\mathrm{n}=88$

$\mathrm{n}=167$

$\mathrm{n}=167$

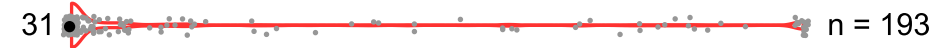

$\mathrm{n}=320$

$\mathrm{n}=95$

$n=438$

$\mathrm{n}=95$

$n=76$

0
25

50

75

100

Inhibition of indole response (\%)

Figure 2. Indole-Sensitive OSNs Are Inhibited by a Range of Odorants

(A) OSNs were presented with $25 \mu \mathrm{M}$ indole alone, or two-component mixtures of indole and $125 \mu \mathrm{M}$ of compounds $1-36$ (see Table S1 for chemical similarity). (B) Violin plots of indole response inhibition, wherein each gray dot represents modulation of a single OSN by that odorant, and the number to right indicates the total number of OSNs represented in each violin. Experiments were repeated at least twice in each case. The black dot denotes the median level of inhibition for the population sampled. The outer red line of the violin represents the probability density at a given inhibition value. 2-MN, 2-methoxynaphthalene. Asterisks (*) denote compounds tested as a mixture of isomers (see Table S3). 


\section{Current Biology}

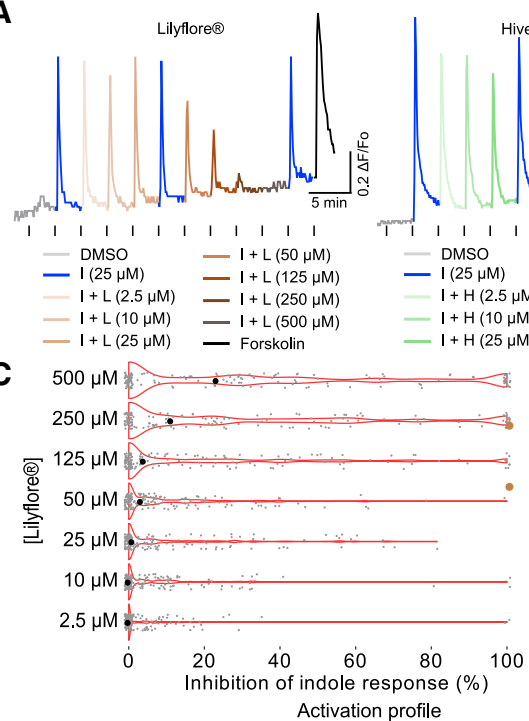

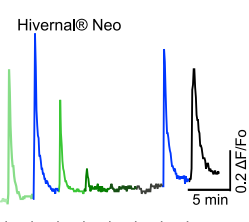

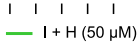

$-\mathrm{I}+\mathrm{H}(50 \mu \mathrm{M})$
$-\mathrm{I}+\mathrm{H}(125 \mu \mathrm{M})$ $\mathrm{I}+\mathrm{H}(125 \mu \mathrm{M})$
$\mathrm{I}+\mathrm{H}(250 \mu \mathrm{M})$ $\mathrm{I}+\mathrm{H}(500 \mu \mathrm{M})$ - Forskolin

D $500 \mu \mathrm{M}$

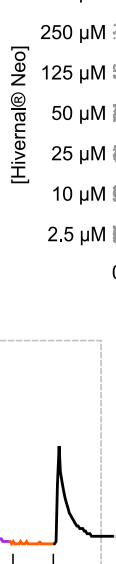

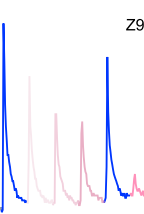

Z95

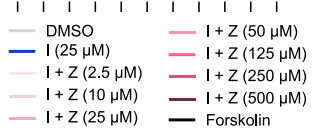
I $+Z(25 \mu \mathrm{M})$

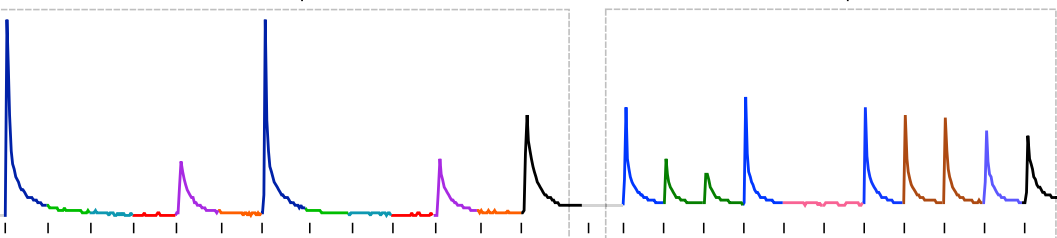

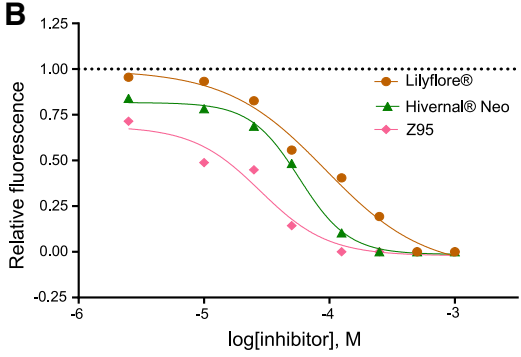

E

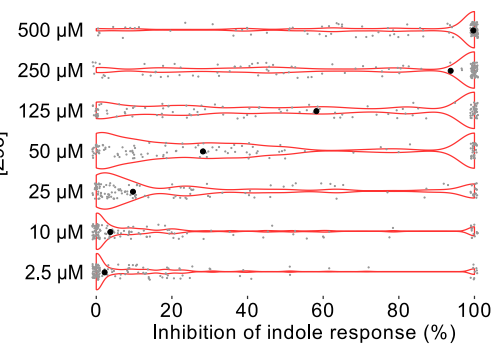

G

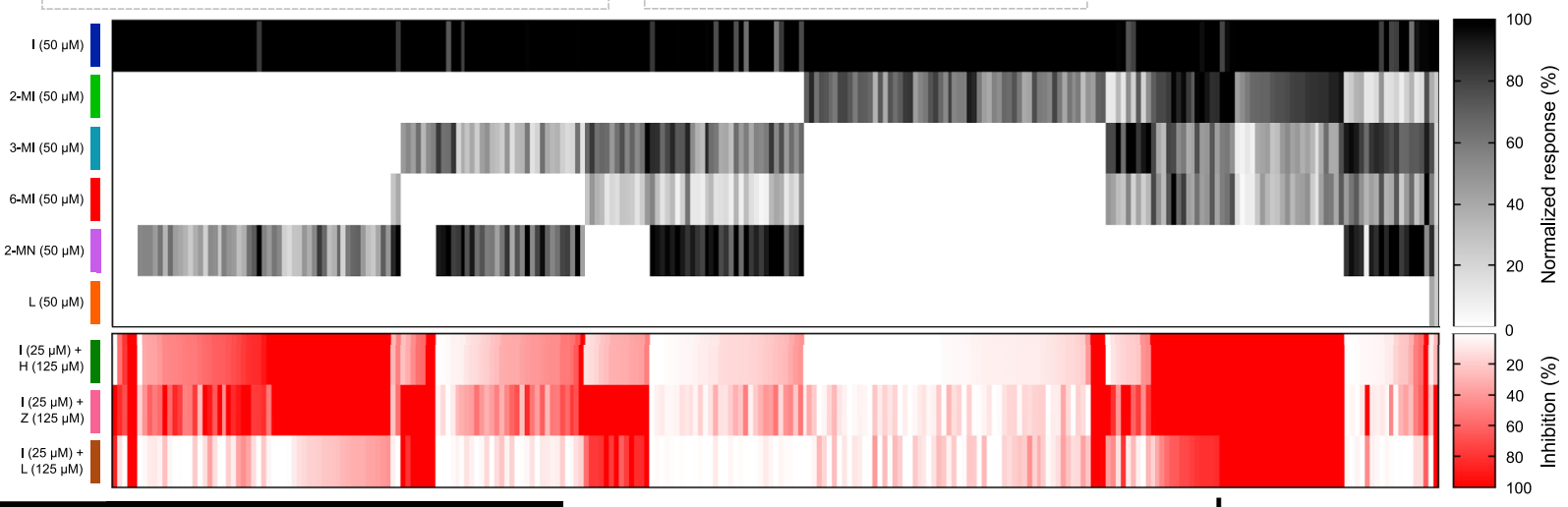

H
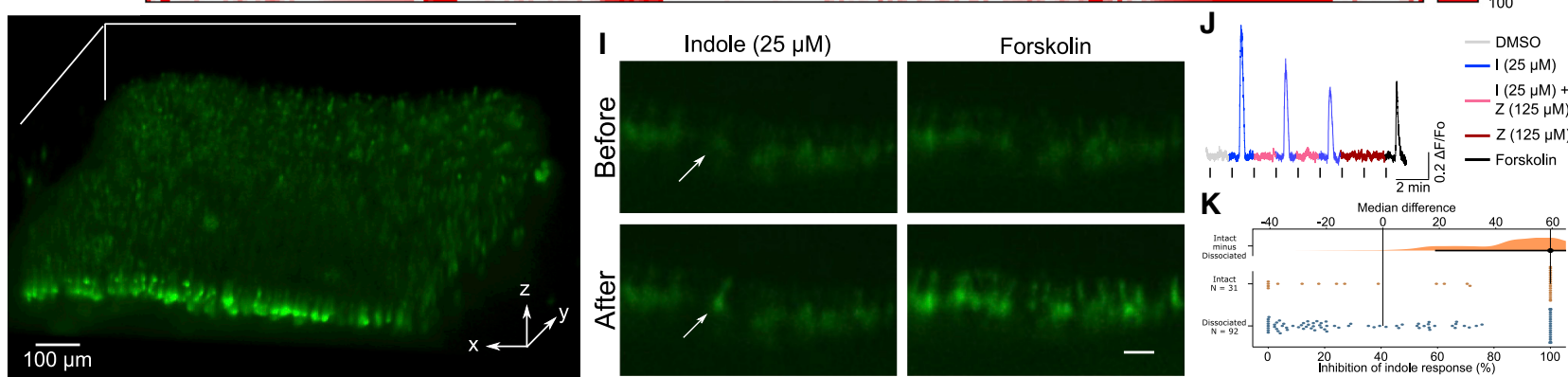

Figure 3. Lilyflore, Hivernal Neo, and Z95 Inhibited Indole-Sensitive OSNs in a Dose-Dependent and Specific Manner (A) Examples of dose-dependent inhibition of the indole response by Lilyflore (L), Hivernal Neo (H), and Z95 (Z) in OSNs challenged with $25 \mu \mathrm{M}$ indole alone (I; in triplicate) or in the presence of increasing concentrations of each inhibitor.

(B) Dose-response curves fitted to the Hill equation for OSNs in A to increasing concentrations of Lilyflore $\left(\right.$ circle, $\left.I_{50}=93 \mu \mathrm{M}\right)$, Hivernal Neo (triangle, IC $\mathrm{C}_{50}=$ $58 \mu \mathrm{M}$ ), or $\mathrm{Z} 95$ (diamond, $\mathrm{IC}_{50}=28 \mu \mathrm{M}$ ). Responses were normalized to the indole response line of best fit. Scale bar, $\mathrm{x}$ axis represents time in minutes; $\mathrm{y}$ axis represents $\Delta F / F_{0}$ fluorescence ratio.

(C-E) Violin plots of the inhibition distribution of indole-sensitive OSNs by increasing concentrations of Lilyflore (C), Hivernal Neo (D), and Z95 (E). Each gray dot represents modulation of a single OSN by that odorant delivered at the specified concentration and the black dot denotes the median level of inhibition for the 


\section{CellPress} OPEN ACCESS

\section{Current Biology Article}

cells of origin. This suggests that Olfr 740 , Olfr 741 , and Olfr743 activity drove the OSN responses and that OSN and heterologous OR assays are comparable. Furthermore, all ORs in the family showed robust responses to at least one member of the odorant panel (Figures $4 \mathrm{G}$ and S3B), confirming they functioned well in our assay system. The indole $\mathrm{EC}_{50}$ s ranged widely across the gene family, Olfr743 being the most sensitive receptor $\left(E_{50}=80 \mathrm{nM}\right)$ and Olfr745 and Olfr747 the least sensitive receptors $\left(\mathrm{EC}_{50}>600 \mu \mathrm{M}\right)$. Among paralogous ORs sharing almost $80 \%$ identity, indole's $\mathrm{EC}_{50}$ could still vary by more than two orders of magnitude (Olfr743 $\mathrm{EC}_{50}=80 \mathrm{nM}$; Olfr739 $\mathrm{EC}_{50}=32 \mu \mathrm{M}$ ). Efficacy also varied widely, encompassing inverse, partial, and full agonism (Figure S3). Thus, even across this small set of structurally related ligands, phylogenetically related ORs displayed diverse agonist specificity and receptor binding outcomes.

\section{Widespread and Combinatorial Antagonism of Indole-} Sensitive Odorant Receptors

The range of functional responses for this family was further examined with an 800-compound library, selected to comprise organoleptically and chemically diverse perfumery-related odorants including 5,6- and 6,6-bicyclic aromatics, macrocycles and polycycles, aliphatic chains, and multiple functional groups including alcohols, aldehydes, ketones, acids, lactones, and esters. We performed single-concentration agonist and antagonist screens (STAR Methods) with this library on the 10 ORs displaying full indole-dose response curves (Figure S3). We identified a total of 430 antagonists and 328 agonists that elicited a response in at least one OR, or 583 ligands in total when ignoring binding outcome. The number of antagonists and agonists varied widely by OR; in many cases, it appeared to be inversely related (Figure 5A). We used an Upset plot, a multidimensional Venn diagram [44], to examine the number of unique antagonists and agonists for each OR as well as the overlap among ORs (Figures 5B and S4B). A total of 149 antagonists and 123 agonists only impacted a single OR. However, most compounds were ligands for multiple ORs281 antagonists and 205 agonists - again indicating combinatorial ligand binding properties for both binding outcomes.

\section{Functional Diversification of OR Paralogs}

OR paralogs are observed to respond to diverse agonists, reflecting acquisition of new functions following OR gene duplication in order to have become fixed in the genome [45]. To investigate whether antagonism may be an additional driver of neofunctionalization, responses among the 10 paralogous ORs were compared in detail. Hierarchical clustering of pairwise Pearson correlation matrices broadly reflected phylogenetic proximity in both screens by segregating the two paralog OR gene clades (Figures 5C and S4C). Individual pairwise correlations ranged between 0.27 and 0.94 for antagonists and 0.23 and 0.94 for agonists. They were also similarly distributed for both assay types (Figure 5D), indicating wide overall functional variability. However, across all 40 pairwise comparisons for both assays, sequence similarity did not consistently correlate with similar screening results. For example, while Olfr741 and Olfr742 (94\% identity) were highly correlated (antagonist $r=$ 0.74 , agonist $r=0.71)$, Olfr739 and Olfr742 (90\% identity) were much less well correlated (antagonist $r=0.41$, agonist $r=$ 0.45). Conversely, an OR pair with relatively low identity, Olfr738 and Olfr749 (60\% identity), exhibited better correlation (antagonist $r=0.64$, agonist $r=0.71$ ). The overall correlations between percent amino acid identity and functional similarity were $r=0.50(p<0.001)$ for antagonism and $r=0.63 p<0.0001$ for agonism (Figure S4D).

Ligand binding appeared to be slightly more conserved across the family of ORs than the functional outcome of binding. In Figure S5, the Jaccard similarity coefficient (i.e., number of shared ligands divided by the number of total ligands) was slightly higher for binding (median $=0.35$ ) than for agonism (median $=0.27$ ) or antagonism (median $=0.28$ ). This implies that over evolutionary time, ligands switch binding outcomes (agonism or antagonism) slightly more frequently than switching between being able to bind or not. Taken together, the data suggest that upon gene duplication, OR paralogs diverge in functional outcome more rapidly than in their ability to bind specific ligands and that both dimensions can drive neofunctionalization.

\section{Specificity and Chemical Diversity of Indole-Sensitive OR Antagonists}

To further examine cross-target specificity, agonist potency $\left(E_{50}\right)$, antagonist potency (relative $\mathrm{IC}_{50}$ in the presence of an $\mathrm{EC}_{80}$ concentration of indole), and maximal efficacy were quantified by dose-response experiments of indole and the top five antagonists for each OR from the single-concentration screen

population sampled. The outer red line of the violin represents the probability density at a given inhibition value for Lilyflore $(115$ OSNs, $n=2)$, Hivernal Neo $(311$ OSNs, $n=9$ ), and Z95 (122 OSNs, $n=3$ ).

(F) Example of an OSN response to a series of singly administered odorants presented in duplicate (50 $\mu \mathrm{M})$, including indole (I; blue), 2-methylindole (2-MI; green), 3-methylindole (3-MI; teal), 6-methylindole (6-MI; red), 2-methoxynaphthalene (2-MN; purple), and Lilyflore (L; orange). Following this series to establish the activation profile, OSNs were challenged with indole alone ( $25 \mu \mathrm{M}$; light blue) or in combination with one of the three inhibitors (125 $\mu \mathrm{M})$. Scale bar, $\mathrm{x}$ axis represents time in minutes; $y$ axis represents $\Delta F / F_{0}$ fluorescence ratio.

(G) Top, heatmap of the activation profiles observed in the indole-sensitive population. Bottom, heatmap of inhibition profiles for the same population of OSNs. Colors along the left side of panel correspond to the singly administered odorants or binary mixtures shown in (F).

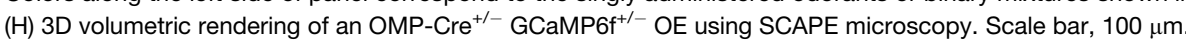

(I) Example of an OSN response (left; see arrow) in the intact OE before and after $25 \mu \mathrm{M}$ indole administration. The response to $40 \mu \mathrm{M}$ Forskolin is also shown (right). Scale bar, $20 \mu \mathrm{m}$.

(J) An example of indole response inhibition by Z95 in SCAPE calcium imaging. Scale bar, $x$ axis represents time in minutes; $y$ axis represents $\Delta F / F_{0}$ fluorescence ratio.

(K) The median difference between indole response inhibition by Z95 in Fura-2 loaded OSNs (dissociated) and SCAPE-imaged OSNs (intact) is shown in a Gardner-Altman estimation plot. The median difference is plotted on a floating axis on the top as a bootstrap sampling distribution, while the individual OSN values are depicted as a dot plot on the bottom axes; the $95 \%$ confidence interval is indicated by the ends of the horizontal error bar. The median difference was $60 \%$, the median inhibition in dissociated OSNs was 40\%, the median inhibition in intact OSNs was 100\% [42]. 
A

A
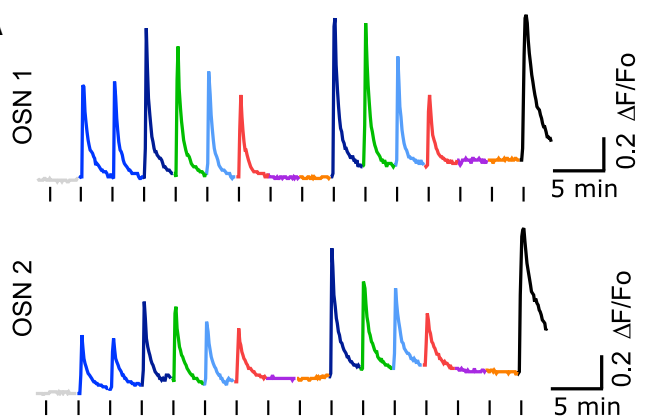

B

$B$
m
n
0

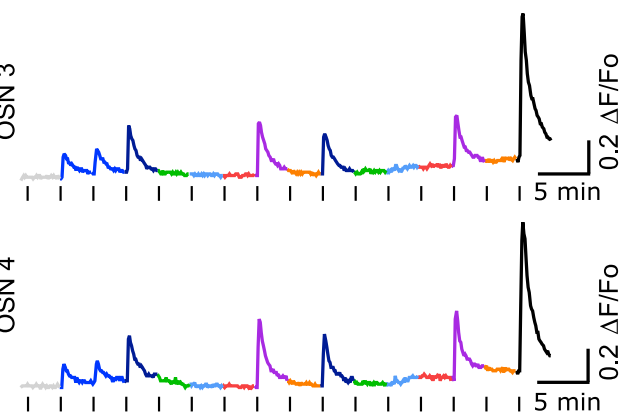

C
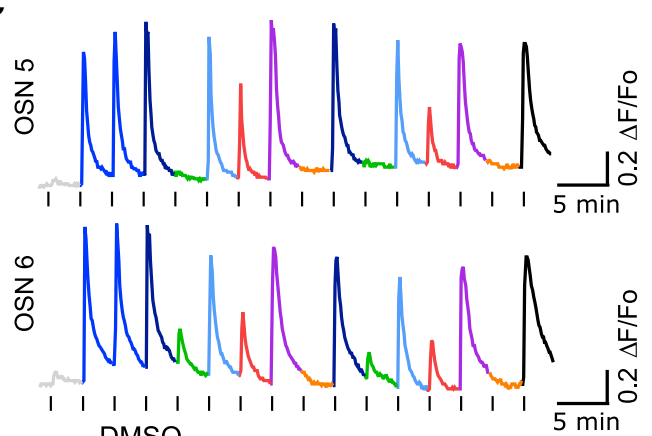

- DMSO

— Indole $(25 \mu \mathrm{M})$

- Indole $(50 \mu \mathrm{M})$

- 2-Methylindole $(50 \mu \mathrm{M})$

- 3-Methylindole $(50 \mu \mathrm{M})$
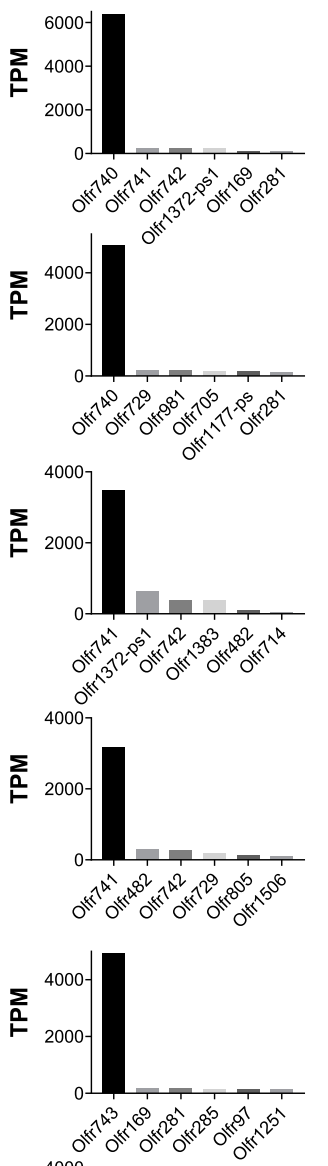

放 2000

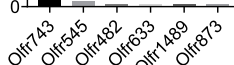

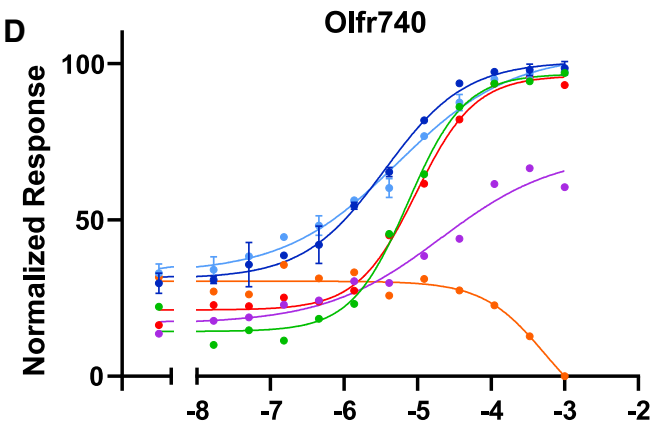

Olfr741

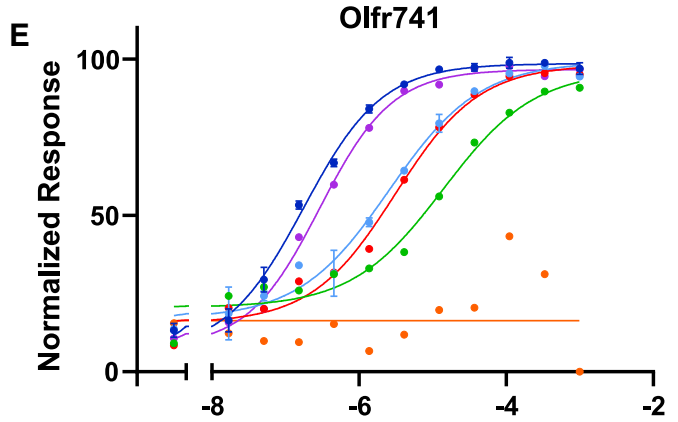

F Olfr743

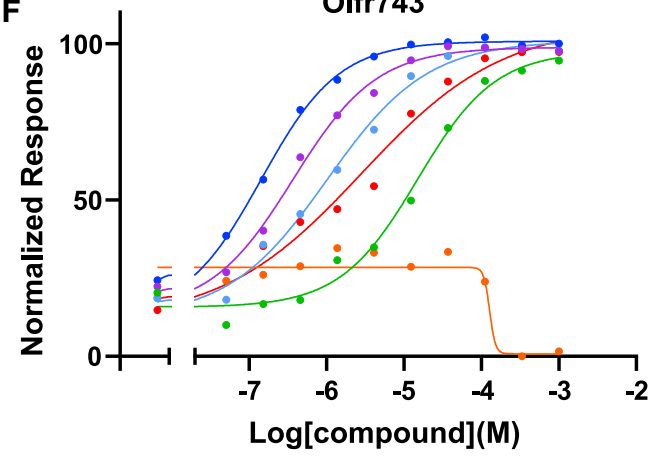

$\rightarrow$ Indole $\rightarrow$ 6-Methylindole

$\rightarrow$ 2-Methoxynaphthalene $\rightarrow$ 2-Methylindole

$\rightarrow$ 3-Methylindole $\quad \rightarrow$ Lilyflore

G

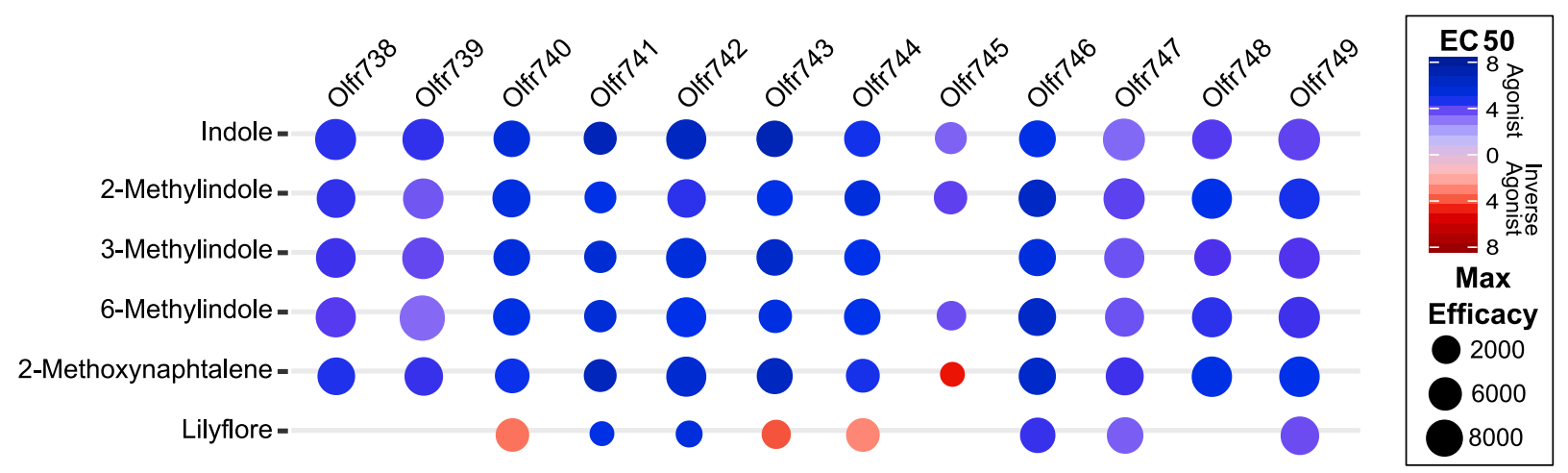

Figure 4. OR Identification from Functionally Characterized OSNs

(A-C) OSN responses to the diagnostic panel of odorants used in Figure 3F and their corresponding OR mRNA levels. Cells with similar response profiles were grouped OSN 1 and 2 (A), OSN 3 and 4 (B), and OSN 5 and 6 (C). Histograms of the most abundant OR mRNAs are shown to the right of each trace. One clearly abundant OR mRNA transcript was retrieved from each cell. TPM, transcripts per million reads. Scale bars for the OSN responses, $x$ axis represents time in minutes; $y$ axis represents $\Delta \mathrm{F} / \mathrm{F}_{0}$ fluorescence ratio. 


\section{$\infty$ CellPress}

OPEN ACCESS

\section{Current Biology Article}

A

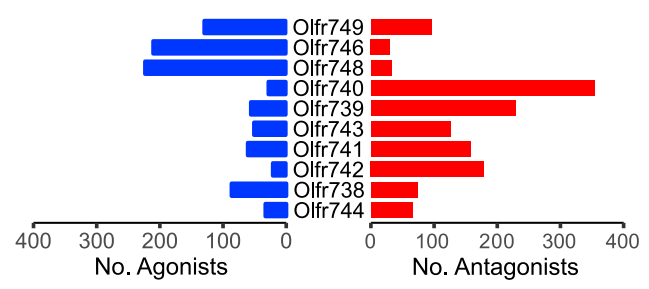

B$$
\text { 旁 }
$$

C

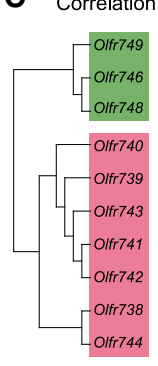

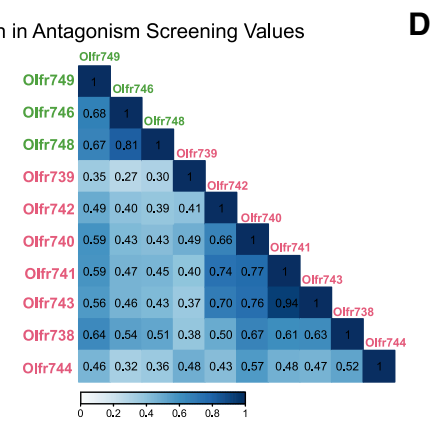

D Distributions of Correlation in Screening Values

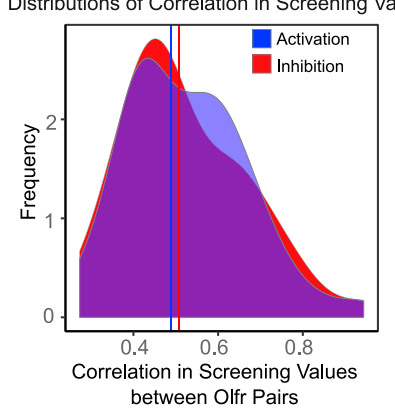

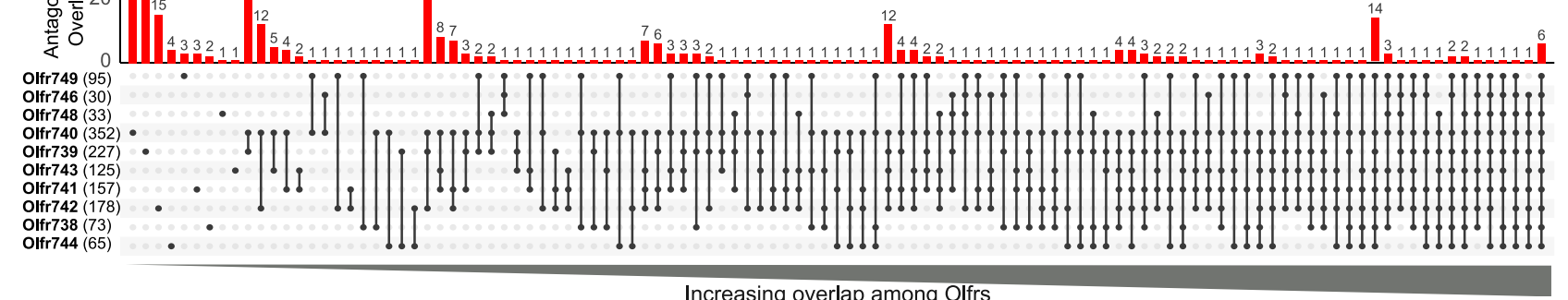

Increasing overlap among Olfrs

Figure 5. Large-Library Odorant Screens Revealed Combinatorial Antagonist Logic Among Closely Related Indole-Sensitive ORs (A) A bar plot of the number of agonists and antagonists identified from single-concentration compound library screening against the Olfr 740 family. 700 compounds were tested in agonist mode and an additional 100 were added (800 total) for antagonist mode.

(B) An Upset plot showing the number of antagonists (bar height) that were unique (single dots) or shared (linked dots) among Olfr740 family members.

(C) A cladogram representing the phylogenetic relationship between the ten indole-sensitive receptors screened (based on amino acid alignment) aligned with the pairwise Pearson correlation matrix obtained from antagonism screening results for each OR.

(D) Histograms of pairwise Pearson correlations between the single-concentration in vitro responses for all receptor pairs, for both agonist and antagonist screens. Vertical lines indicate median correlation for each screen. See Figure S4A for ROC analyses used to determine true positive thresholds. See Figures S4B-S4D for the agonist screening analyses. See Figure S5 for the Jaccard similarity coefficients of ligand binding.

(Figure 6A). A composite heatmap summarizes the diversity of outcomes we observed (Figure 6B). All 36 compounds inhibited more than one OR, eight compounds inhibited all 10 ORs despite pairwise amino acid sequence identities as low as 56\%, and 12 inhibited only a subset of ORs. 16 compounds (compounds 3,5 , 20,23 and 50-61) showed inhibition of some ORs and activation of others at the concentrations tested, consistent with their single-concentration results. Five of the 36 compounds had also been tested on dissociated OSNs and one had been further tested on intact OE (see Figures 2 and 3). Consistent with the results from dissociated and intact OSNs, Z95 (compound 1) was a strong antagonist on all in vitro ORs, while Lilyflore (compound 20) was a weaker and less frequent antagonist in OSNs and only inhibited five in vitro ORs.

The diversity of inhibitory responses observed in OSN Ca ${ }^{2+}$ imaging was paralleled by a noticeable chemical diversity. While some compounds had a clear structural relationship to indole (compounds 4, 6, 8, and 9; Figure 2; Table S1), several potent antagonists did not share obvious similarity $(2,3,5$, and 7; Figure 2; Table S1). The results obtained by probing ORs in vitro, through systematic screening of a chemically diverse odorant library, provided further evidence that antagonists can be structurally distinct from agonists. We assessed the chemical distance between indole and the 36 antagonists in Figure 6 by again calculating the Tanimoto coefficient of the four molecular fingerprints [34, 35]. Strong rank-order correlation (mean $r=0.80 \pm 0.13$ ) between the four methods was found, but none of the antagonists displayed high Tanimoto coefficients (i.e., above 0.85 [46]) in any method (Table S2). In addition, 18 compounds had a low coefficient (below 0.1 ) yet exhibited potent inhibition on multiple ORs.

\section{Binding Affinity Is Weakly Correlated with Functional Outcome}

Mathematical models suggest the correlation between binding affinity and activation efficacy (i.e., ability to induce OR downstream signaling once bound) plays an important role in odor identification and discrimination, assuming mixture interactions are primarily because of competitive binding at the receptor level $[18,47-49]$. If the binding affinity and activation efficacy are largely uncorrelated, agonism and antagonism across the receptor ensemble are balanced. This reduces the chances of

(D-F) Dose-response profiles of Olfr740 (D), Olfr741 (E), and Olfr743 (F) expressed in heterologous cells to the same panel of odorants. The rank-order of in vitro OR responses closely matched that of OSN responses. Normalized Response, cAMP HTRF ratio.

(G) 12 ORs (Olfr740, Olfr741, and Olfr743 and nine paralogs) were tested at a range of concentrations with the diagnostic ligand panel. Dose-response curves are shown in a heatmap with blue and red hues representing $\mathrm{EC}_{50} \mathrm{~s}(\mu \mathrm{M})$ of agonists and inverse agonists, respectively, given in units of - log ${ }_{10}(\mathrm{M})$. Activation efficacy (maximum change in HTRF ratio between baseline and receptor saturation) is indicated by the relative diameter of the circle. No circle indicates no detectable activation or inverse agonism but does not exclude neutral antagonism. See Figure S2 for the phylogenetic relationship between ORs identified. See Figure S3 for the mature OSN control mRNA transcripts and the dose-response curves. 
A

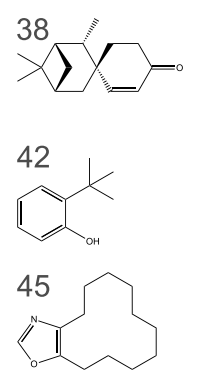

$47^{*}$<smiles>CCC1CCC(CCCC(C)(C)C)CC1</smiles>

50<smiles>CC(C)=CC1CC(C)CCO1</smiles><smiles>CC1CC(C)(c2ccccc2)CC1(C)[As]</smiles><smiles>CC(C)(C)c1ccc2c(c1)OCC(=O)CO2</smiles><smiles>CC(=O)/C=C/C1C(C)=CCCC1(C)C</smiles><smiles>CC1(C)CCCC2C1CCCC2(C)C</smiles>

48<smiles>CC1(C)CCC2(C)CCC[C@@H]2C2C1CCC2(C)C</smiles>

51<smiles>CC(CC=S)CCc1ccccc1</smiles><smiles>CC1CC2C3C=CC(C3)C2CC1=O</smiles>

62<smiles>CC1(C)C2=C(C(=[Se+])CCC2)C(C)(C)C1(C)C</smiles><smiles>CC(C)CCOC(=O)Cc1ccccc1</smiles><smiles>CC(=O)OCCc1ccccc1</smiles><smiles>O=C(OCCc1ccccc1)c1ccccc1O</smiles><smiles>CC(=O)OC(c1ccccc1)C(Cl)(Cl)Br</smiles><smiles>C=CCCC(=O)C1=CCCC(C)(C)C1</smiles><smiles>CC(C=O)Cc1ccc(C(C)(C)C)cc1</smiles>

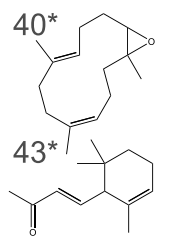<smiles>CC1(C)CCc2ccc(CCC=O)cc21</smiles>

49<smiles>CC(C)(C)c1ccc(CCC=O)cc1</smiles><smiles></smiles><smiles>CC(CC=S)c1ccccc1</smiles>

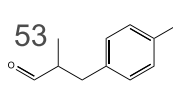<smiles>COC(=O)c1ccc(OC)cc1</smiles>

57<smiles>CC(C)(C)C1CCC(=O)CC1</smiles>

61<smiles>C1CCC2CCC2C1</smiles><smiles>CC(C)c1ccc2c(c1)OCC(=O)CO2</smiles>
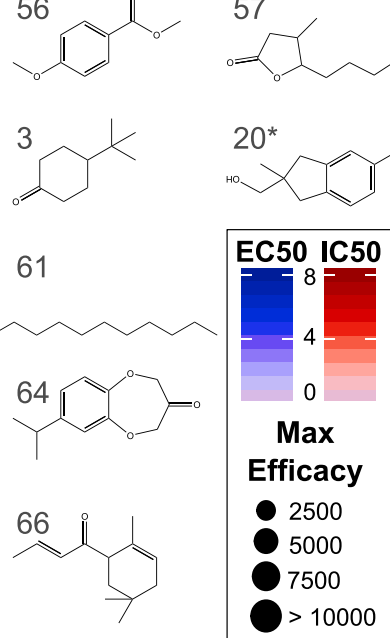

B

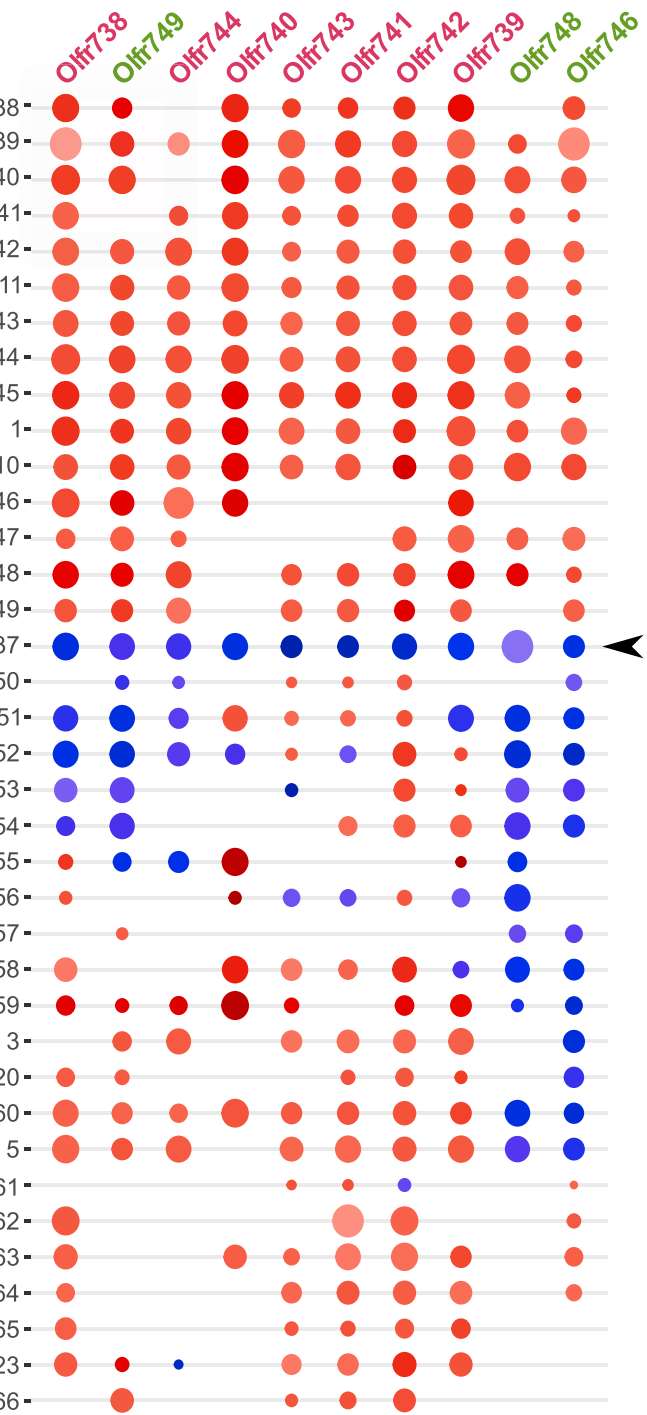

Figure 6. Combinatorial Inhibition and Activation of the Olfr740 Family

(A) The 35 strongest antagonists identified (top five non-redundant hits per OR), Lilyflore and indole were tested for dose-responses (see Table S2 for chemical similarity). Asterisks (*) denote compounds tested as a mixture of isomers (see Table S3).

(B) Composite heatmap summarizing full dose-response curves obtained for both the inhibition (red hue $\mathrm{IC}_{50}$ ) and activation (blue hue $\mathrm{EC}_{50}$ ) of the Olfr 740 family, with $\mathrm{EC}_{50}$ and $\mathrm{IC}_{50}$ color scales given in units of $-\log _{10}(\mathrm{M})$. Activation efficacy (maximum change in $\mathrm{HTRF}$ ratio between baseline and receptor saturation) is represented by the relative diameter of the circle; no circle indicates the absence of significant ligand binding for that OR. When a dose-response curve could be fitted in both inhibition and activation mode (i.e., partial agonists), the $\mathrm{IC}_{50}$ is shown.

saturating the OR repertoire in the presence of complex odor mixtures and may allow for greatly improved odor segmentation and discrimination.

The dose-response data (Figure 6) allowed quantitatively testing the above correlation on this family of ORs. We fit a two-step competitive binding (CB) model to the data (Figure 7A; STAR Methods). In this model, the activators and inhibitors compete to bind the receptor with binding affinities $\kappa^{-1}$ act and $\kappa^{-1}$ inh respectively. The bound compound then activates the receptor with an activation efficacy $\eta_{\text {act }}$ or $\eta_{\text {inh }}$, depending on whether the activator or inhibitor is bound (1 represents a perfect agonist $\left[\eta_{\text {act }}\right]$, i.e., the compound fully activates the receptor, whereas 0 represents no activation $\left[\eta_{\text {inh }}\right]$ ). To allow for inverse agonism, we added the possibility for spontaneous activation of the receptor, $\eta_{\mathrm{s}}$ (between 0 and 1 ), when no compound is bound (observed for Olfr740, Olfr743, and Olfr744; Figure S3). The key parameter that determines a compound's functional outcome is its activation efficacy. A compound is a partial agonist if its activation efficacy $\eta$ is less than 1 but greater than $\eta_{\mathrm{s}}$ and is an inverse agonist if $\eta$ is less than $\eta_{\mathrm{s}}$. If $\eta_{\text {act }}>\eta_{\text {inh }}$ and $\mathrm{c}_{\mathrm{act}} / \kappa_{\mathrm{act}}<\mathrm{c}_{\text {inh }} / \kappa_{\text {inh }}$, then the inhibitor "antagonizes" the activator. The model yielded an excellent fit to the data for two inhibitors tested in a two-way dose response (Figure 7B), using three parameters: the binding affinities of the activator and inhibitor, $\kappa^{-1}$ act and $\kappa^{-1}$ inh and the ratio of the subtracted activation efficacies $\left(\eta_{\text {inh }}-\eta_{\mathrm{s}}\right) /\left(\eta_{\text {act }}-\eta_{\mathrm{s}}\right)$ (STAR Methods). For these two 
A

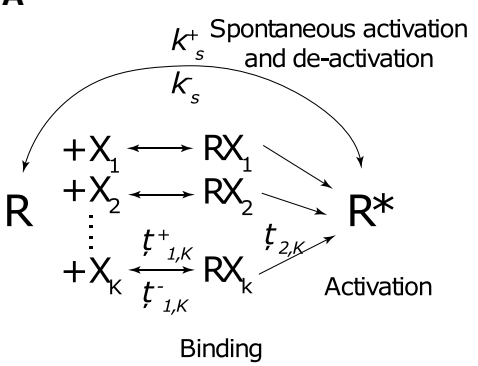

C

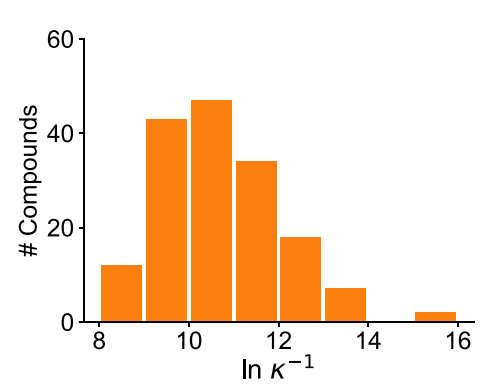

B

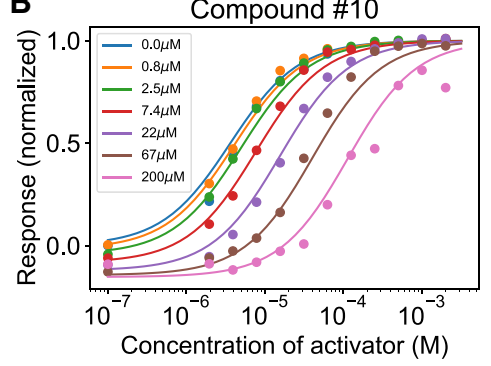

D

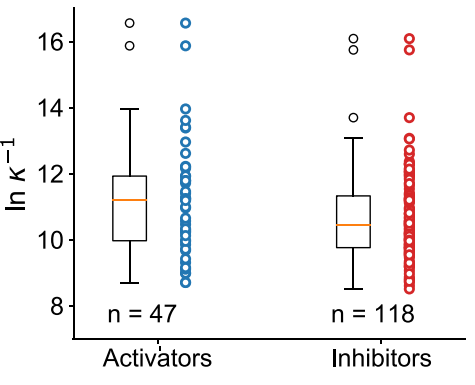

Compound \#1

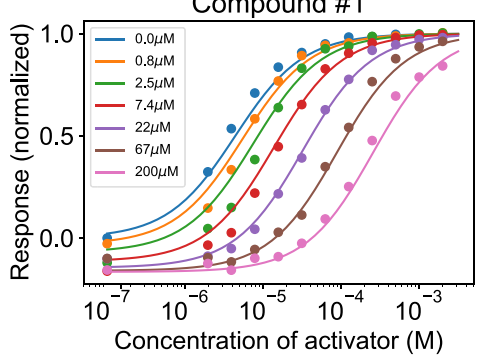

E

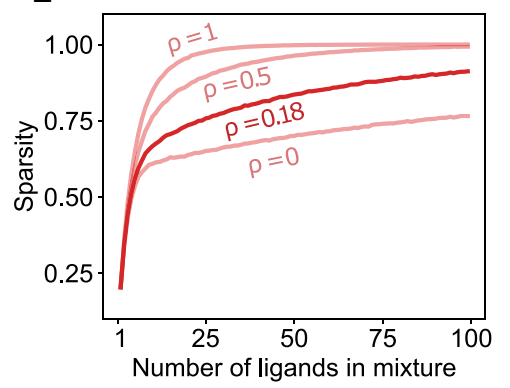

Figure 7. The Competitive Binding Model of Odorant Mixture Interactions and the Relationship between Binding Affinity and Functional Outcome

(A) A schematic of the competitive binding (CB) model with spontaneous activity.

(B) Data from a CB assay using Olfr740 with indole as the activator and compounds 10 and 1 as the inhibitors. Normalized data (solid circles) show the activation profiles for different concentrations of the inhibitors. The solid lines show the best fit curves using the CB model. Values below 0 indicate suppression of the constitutive activity by the inhibitor.

(C) Histogram of binding affinities obtained by fitting the model to activation and inhibition profiles for 37 compounds across the Olfr 740 family.

(D) Box and scatterplots showing the binding affinities for activators and inhibitors. While the distributions are largely overlapping, activators have a slightly higher binding affinity (median $=11.0$ ) compared with inhibitors (median $=10.5$ ) leading to a weak, but non-zero correlation between binding affinity and functional outcome.

(E) Receptor activation probability (sparsity) increased slower with mixture complexity when the correlation between binding affinity and functional outcome is weak compared to any additive model of mixture interactions $(\rho=1)$, and thus prevents saturation of the receptor ensemble.

inhibitors, a Schild regression revealed a linear relationship between inhibition levels and increasing doses of antagonist (Schild slope for compound $10=1.17$ and compound $1=0.8$ ) [50], further supporting competitive binding.

To test the affinity-efficacy correlation directly, the competitive binding model was fitted to the activation and inhibition (of $\mathrm{EC}_{80}$ indole) profiles of 37 unique compounds for each of the 10 indole-sensitive ORs. The distribution of $\ln \kappa^{-1}(n=165$; STAR Methods) was found to be close to a normal distribution (mean $=10.76, \mathrm{SD}=1.37$, i.e., $\kappa \sim 20 \mu \mathrm{M}$ ) with a few sensitive outliers (Figure $7 \mathrm{C}$ ). The two most potent agonist interactions were compounds 37 (indole) on both Olfr743 and Olfr741 $\left(E_{50} \mathrm{~s}=\right.$ $65 \mathrm{nM}$ and $127 \mathrm{nM}$, respectively), while the two most potent antagonist interactions were compounds 59 and 55 on Olfr740 $\left(\mathrm{IC}_{50} \mathrm{~S}=104 \mathrm{nM}\right.$ and $146 \mathrm{nM}$, respectively). Overall, we observed a weak Pearson correlation between the binding affinity of activators $\left(\eta \approx 1, n_{\text {act }}=47\right)$ and inhibitors $\left(\eta \approx 0, n_{\text {inh }}=118\right)$ of $\rho=0.18 \pm 0.03$ (mean \pm SD), where $\rho$ is the Pearson correlation coefficient between $\ln \kappa^{1}$ and $\eta$ (Figure 7D). To test whether the measured statistics lead to the receptor activity normalization predicted in theory [18], we computed the extent of saturation of a receptor ensemble with increasing mixture complexity, where mixture interactions were modeled using the CB model, and the receptor-ligand binding and activation parameters were drawn from the experimentally measured distributions (Figure $7 \mathrm{E}$ ). The fraction of activated receptors (sparsity) indeed increased at a slower rate compared to any additive model of mixture interactions $(\rho=1)$, reaching $90 \%$ saturation for $>100$ ligands compared with $\approx 25$ for an additive model. Thus, competitive binding could account for the widespread antagonism observed, and binding affinity and activation efficacy appeared largely decoupled ( $\rho \sim 0.18)$. These statistics would result in a meaningful expansion of the encoding capacity of the system compared with one in which antagonism was rare $(\rho \rightarrow 1)$ (Figure 7E).

\section{DISCUSSION}

Natural odors in the environment are typically complex chemical mixtures, but the precise mechanisms by which they are encoded by the OR repertoire are yet to be elucidated. In particular, the role of OR-specific antagonism in this regard has lacked extensive empirical characterization, which formed the primary focus of the current study. We found evidence for the full spectrum of competitive and non-cooperative GPCR interactions with no obvious bias toward agonism.

Indole was chosen as a target for antagonism, in part, as an example of a highly interesting yet representative odorant. It 
Please cite this article in press as: Pfister et al., Odorant Receptor Inhibition Is Fundamental to Odor Encoding, Current Biology (2020), https://doi.org/ 10.1016/j.cub.2020.04.086

\section{Current Biology Article}

occurs in nature, is present at substantial levels in some flowers, and is used regularly in perfumes for its floral and animalic character [51]. It is also present in latrine headspaces [52] and is reminiscent of feces if delivered at high concentrations. Using a robust $\mathrm{Ca}^{2+}$ imaging assay, we characterized the responses of dissociated OSNs to indole and other structurally related odorants and observed combinatorial activation and inhibition. For many odorants, complete OSN inhibition affected a large subset of the OSN population-a result recapitulated in intact OE with full connectivity to the $\mathrm{OB}$. This result would impact how complex mixtures are encoded at the detection layer of the olfactory system and raised the question of how frequently OSN inhibition may occur in general, and whether it is mediated by OR antagonism.

High-throughput screening of $\sim 800$ volatile compounds against the 10 ORs identified through single-cell transcriptomics and phylogenetics allowed us to probe the prevalence of both agonism and antagonism for a much larger chemical space. While this library is small compared with those typically found in drug screens (where compounds can number in the millions), it is large compared with what has previously been shown in the olfactory literature and is approximately $25 \%$ as large as all the odorants reportedly described in public databases $(\sim 3,100)$ [53]. Over half of the library was found to antagonize one or more ORs with about one third of those showing specificity to single ORs and the rest antagonizing multiple. These data thus supported an agonist-like combinatorial binding logic for antagonists, as proposed by others [25, 26]. It is possible the library used in this study over-represents the frequency of antagonism for odorants in general; however, they were selected to cover a wide range of qualities (musky, fruity, floral, etc.) and chosen to be chemically diverse within the realm of small organic molecules, making it unlikely. It is also possible the OR family investigated here is unusual in its potential to be antagonized. However, these ORs exhibited a typical behavior with respect to agonist selectivity suggesting the antagonist selectivity observed is typical too. It is thus possible that most ORs, like GPCRs in general, can be antagonized [25, 2729]. Furthermore, most antagonists were not structurally similar to indole, suggesting, even more provocatively, that most odorants may in fact antagonize ORs.

Liquid phase concentrations relevant in heterologous OR expression systems do not necessarily match those delivered by gas phase in vivo. Indeed, concentrations used in this study were often above saturating vapor pressure (Table S3), calling into question the relevance of the results. However, several studies have shown that micromolar in vitro OR sensitivity corresponded to nanomolar in vivo glomerular sensitivity [54] or picomolar in vivo behavioral sensitivity (compare [13] and [55]). This is consistent with a growing body of evidence showing the in vivo effects of fluid dynamics and absorption of odorants by the mucus [56-59]. Taking these into account, odorant concentrations in the nose in the vicinity of ORs are likely to increase substantially compared with their concentration in inhaled air (estimated to be 10- to 1,000-fold, depending on odorant-specific mucus absorption rates), which would reconcile the liquid-phase sensitivities observed here with gas-phase in vivo sensitivities. Furthermore, the similarity in antagonist and agonist binding affinity distributions (Figure 7D) imply that for any in vivo agonist, there is likely to be an equally potent in vivo antagonist.
Measurement of OR paralogs provided additional insights into OR repertoire evolution. With widespread antagonism, it appears ORs evolve along two important axes: binding affinity and binding outcome. Even the closest paralogs exhibited highly variable binding affinities while there were also shared ligands between all OR pairs that exhibited opposite binding outcomes. Indeed, changes in the sequence may affect not only the binding pocket but can also induce conformational changes altering transduction cascade efficiency (e.g., by modifying G protein affinity) [60-62]. In some cases, OR alleles with minimal sequence alterations, often a single SNP, outside of presumptive OR binding pockets [63] are responsible for dramatic shifts in potency and efficacy [10-12, 16, 17, 64]. As OR repertoires evolve along with speciation [3], antagonism likely contributes to the acquisition of novel gene functions in parallel with agonism, which will likely help both loci to be maintained following a gene duplication event. This remains consistent with current views that OR paralogs acquire new receptive fields and provide improved odor discrimination $[45,65]$.

All in vitro data with complete dose-response curves were consistent with a mathematical model of competitive binding, and for two odorants tested on one OR, antagonism was shown to be competitive by a Schild regression analysis. However, we cannot rule out that some antagonists may not bind competitively (e.g., allosteric binding). Although non-competitive binding of small volatile compounds to allosteric sites has not been widely reported for Class A GPCRs, there is a growing body of evidence that such interactions could occur for ORs [27, 47, $49,66]$. Even so, this would not affect the main implication of this study; that extensive, non-linear, OR-mediated computation of mixture information occurs prior to transmission of signal to the OB. Widespread combinatorial OR antagonism leads to a far richer mixture encoding logic for the system than one where antagonism is rare and responses are largely additive. This is convergent with insect olfactory systems, despite the differing nature of their ORs (heteromeric ion channels as opposed to metabotropic GPCRs) [26, 67, 68], suggesting that antagonism may be a requisite peripheral mechanism and a general feature of olfactory systems for encoding high dimensional natural odors.

\section{STAR $\star$ METHODS}

Detailed methods are provided in the online version of this paper and include the following:

- KEY RESOURCES TABLE

- RESOURCE AVAILABILTIY

○ Lead Contact

O Materials Availability

O Data and Code Availability

- EXPERIMENTAL MODEL AND SUBJECT DETAILS O Animal Care \& Sources

- METHOD DETAILS

○ Calcium Imaging

- SCAPE microscopy

O Single-Cell RNA-Seq

$\bigcirc$ Cell line generation

cAMP Functional Cell-Based Assay

High-Throughput Screening 


\section{CellPress} OPEN ACCESS

\section{Current Biology}

\author{
Competitive binding model with spontaneous receptor \\ activity \\ - Fitting activation and inhibition profiles to the compet- \\ itive binding model \\ O Correlation between binding affinity and functional \\ outcome \\ - QUANTIFICATION AND STATISTICAL ANALYSIS \\ O Calcium Imaging Analysis \\ O Statistical Analyses \\ O Molecular Fingerprints
}

\section{SUPPLEMENTAL INFORMATION}

Supplemental Information can be found online at https://doi.org/10.1016/j. cub.2020.04.086.

\section{ACKNOWLEDGMENTS}

This work was supported in part by a Simons Foundation grant 340106 (to G.R. and M.V.) and internal funding from Firmenich Incorporated (to M.E.R.). We would also like to thank members of the Firmenich R\&D division for their contributions. In particular, M. Reiter and J. Coulomb for chemical synthesis, J. Pika, M. Emberger and D. Hossain for compound analysis and management, M. Borisovska, D. Shcherbakov and J. Kim for additional analyses.

\section{AUTHOR CONTRIBUTIONS}

Conceptualization, P.P., B.C.S., J.H.B., and M.E.R.; Methodology, P.P., B.C.S., B.J.E., J.H.B., C.T., M.S., R.A., G.R., D.A.R., and Z.P.; Formal Analysis, B.C.S., C.T., and G.R.; Investigation, B.J.E., J.H.B., C.T., M.S., R.A., G.R., D.A.R., and Z.P.; Resources, H.-Y.J.; Writing - Original Draft, P.P., B.C.S., B.J.E., J.H.B., and G.R.; Writing - Review \& Editing, P.P., B.C.S., B.J.E., J.H.B., C.T., G.R., M.V., and M.E.R.; Visualization, B.C.S., J.H.B., B.J.E., C.T., G.R., and D.A.R.; Supervision, M.E.R and M.V.; Project Administration, P.P., B.C.S., J.H.B., C.T., and M.V.; Funding Acquisition, M.E.R. and M.V.

\section{DECLARATION OF INTERESTS}

All authors are corporate employees of Firmenich, with the exception of G.R. and M.V. Part of the work presented herein is covered in the following published patent applications: WO2014210585A2, WO2016201153A1, WO2017005571A1, and WO2018091686A1.

Received: August 26, 2019

Revised: March 31, 2020

Accepted: April 28, 2020

Published: May 28, 2020

\section{REFERENCES}

1. Buck, L., and Axel, R. (1991). A novel multigene family may encode odorant receptors: a molecular basis for odor recognition. Cell 65 , 175-187.

2. Malnic, B., Hirono, J., Sato, T., and Buck, L.B. (1999). Combinatorial receptor codes for odors. Cell 96, 713-723.

3. Hughes, G.M., Boston, E.S.M., Finarelli, J.A., Murphy, W.J., Higgins, D.G., and Teeling, E.C. (2018). The Birth and Death of Olfactory Receptor Gene Families in Mammalian Niche Adaptation. Mol. Biol. Evol. 35, 1390-1406.

4. Serizawa, S., Ishii, T., Nakatani, H., Tsuboi, A., Nagawa, F., Asano, M., Sudo, K., Sakagami, J., Sakano, H., ljiri, T., et al. (2000). Mutually exclusive expression of odorant receptor transgenes. Nat. Neurosci. 3, 687-693.

5. Chess, A., Simon, I., Cedar, H., and Axel, R. (1994). Allelic inactivation regulates olfactory receptor gene expression. Cell 78, 823-834.
6. Serizawa, S., Miyamichi, K., Nakatani, H., Suzuki, M., Saito, M., Yoshihara, Y., and Sakano, H. (2003). Negative feedback regulation ensures the one receptor-one olfactory neuron rule in mouse. Science 302, 2088-2094.

7. Monahan, K., and Lomvardas, S. (2015). Monoallelic expression of olfactory receptors. Annu. Rev. Cell Dev. Biol. 31, 721-740.

8. Kajiya, K., Inaki, K., Tanaka, M., Haga, T., Kataoka, H., and Touhara, K. (2001). Molecular bases of odor discrimination: Reconstitution of olfactory receptors that recognize overlapping sets of odorants. J. Neurosci. 21, 6018-6025.

9. Nara, K., Saraiva, L.R., Ye, X., and Buck, L.B. (2011). A large-scale analysis of odor coding in the olfactory epithelium. J. Neurosci. 31, 9179-9191.

10. Keller, A., Zhuang, H., Chi, Q., Vosshall, L.B., and Matsunami, H. (2007). Genetic variation in a human odorant receptor alters odour perception. Nature 449, 468-472.

11. Jaeger, S.R., McRae, J.F., Bava, C.M., Beresford, M.K., Hunter, D., Jia, Y., Chheang, S.L., Jin, D., Peng, M., Gamble, J.C., et al. (2013). A Mendelian trait for olfactory sensitivity affects odor experience and food selection. Curr. Biol. 23, 1601-1605.

12. McRae, J.F., Mainland, J.D., Jaeger, S.R., Adipietro, K.A., Matsunami, H., and Newcomb, R.D. (2012). Genetic variation in the odorant receptor OR2J3 is associated with the ability to detect the "grassy" smelling odor, cis-3-hexen-1-ol. Chem. Senses 37, 585-593.

13. Shirasu, M., Yoshikawa, K., Takai, Y., Nakashima, A., Takeuchi, H., Sakano, H., and Touhara, K. (2014). Olfactory receptor and neural pathway responsible for highly selective sensing of musk odors. Neuron 81 , 165-178.

14. Menashe, I., Abaffy, T., Hasin, Y., Goshen, S., Yahalom, V., Luetje, C.W. and Lancet, D. (2007). Genetic elucidation of human hyperosmia to isovaleric acid. PLoS Biol. 5, e284.

15. Glatz, R., and Bailey-Hill, K. (2011). Mimicking nature's noses: from receptor deorphaning to olfactory biosensing. Prog. Neurobiol. 93, 270-296.

16. McRae, J.F., Jaeger, S.R., Bava, C.M., Beresford, M.K., Hunter, D., Jia, Y., Chheang, S.L., Jin, D., Peng, M., Gamble, J.C., et al. (2013). Identification of regions associated with variation in sensitivity to food-related odors in the human genome. Curr. Biol. 23, 1596-1600.

17. Mainland, J.D., Keller, A., Li, Y.R., Zhou, T., Trimmer, C., Snyder, L.L., Moberly, A.H., Adipietro, K.A., Liu, W.L., Zhuang, H., et al. (2014). The missense of smell: functional variability in the human odorant receptor repertoire. Nat. Neurosci. 17, 114-120

18. Reddy, G., Zak, J.D., Vergassola, M., and Murthy, V.N. (2018). Antagonism in olfactory receptor neurons and its implications for the perception of odor mixtures. eLife 7, e34958.

19. Araneda, R.C., Kini, A.D., and Firestein, S. (2000). The molecular receptive range of an odorant receptor. Nat. Neurosci. 3, 1248-1255.

20. Spehr, M., Gisselmann, G., Poplawski, A., Riffell, J.A., Wetzel, C.H., Zimmer, R.K., and Hatt, H. (2003). Identification of a testicular odorant receptor mediating human sperm chemotaxis. Science 299, 2054-2058.

21. Araneda, R.C., Peterlin, Z., Zhang, X., Chesler, A., and Firestein, S. (2004). A pharmacological profile of the aldehyde receptor repertoire in rat olfactory epithelium. J. Physiol. 555, 743-756.

22. Shirokova, E., Schmiedeberg, K., Bedner, P., Niessen, H., Willecke, K., Raguse, J.D., Meyerhof, W., and Krautwurst, D. (2005). Identification of specific ligands for orphan olfactory receptors. G protein-dependent agonism and antagonism of odorants. J. Biol. Chem. 280, 11807-11815

23. Sanz, G., Schlegel, C., Pernollet, J.C., and Briand, L. (2005). Comparison of odorant specificity of two human olfactory receptors from different phylogenetic classes and evidence for antagonism. Chem. Senses 30, 69-80.

24. Peterlin, Z., Li, Y., Sun, G., Shah, R., Firestein, S., and Ryan, K. (2008). The importance of odorant conformation to the binding and activation of a representative olfactory receptor. Chem. Biol. 15, 1317-1327.

25. Oka, Y., Omura, M., Kataoka, H., and Touhara, K. (2004). Olfactory receptor antagonism between odorants. EMBO J. 23, 120-126. 


\section{Current Biology} Article

26. Su, C.Y., Menuz, K., and Carlson, J.R. (2009). Olfactory perception: receptors, cells, and circuits. Cell 139, 45-59.

27. Xu, L., Li, W., Voleti, V., Zou, D.J., Hillman, E.M.C., and Firestein, S. (2020). Widespread receptor-driven modulation in peripheral olfactory coding. Science 368, eaaz5390.

28. Inagaki, S., Iwata, R., and Takeshi, I. (2019). Widespread inhibitory responses in the mouse olfactory sensory neurons in vivo. bioRxiv. https:// doi.org/10.1101/803908.

29. Zak, J.D., Reddy, G., Vergassola, M., and Murthy, V.N. (2019). Antagonistic odor interactions in olfactory sensory neurons are widespread in freely breathing mice. bioRxiv. https://doi.org/10.1101/847525.

30. Peterlin, Z., Firestein, S., and Rogers, M.E. (2014). The state of the art of odorant receptor deorphanization: a report from the orphanage. J. Gen. Physiol. 143, 527-542.

31. Bouchard, M.B., Voleti, V., Mendes, C.S., Lacefield, C., Grueber, W.B. Mann, R.S., Bruno, R.M., and Hillman, E.M. (2015). Swept confocallyaligned planar excitation (SCAPE) microscopy for high speed volumetric imaging of behaving organisms. Nat. Photonics 9, 113-119.

32. Poivet, E., Tahirova, N., Peterlin, Z., Xu, L., Zou, D.J., Acree, T., and Firestein, S. (2018). Functional odor classification through a medicinal chemistry approach. Sci. Adv. 4, eaao6086.

33. Totsuka, Y., Ferdows, M.S., Nielsen, T.B., and Field, J.B. (1983). Effects of forskolin on adenylate cyclase, cyclic AMP, protein kinase and intermediary metabolism of the thyroid gland. Biochim. Biophys. Acta. 756, 319-327.

34. Riniker, S., and Landrum, G.A. (2013). Open-source platform to benchmark fingerprints for ligand-based virtual screening. J. Cheminform. 5, 26.

35. Bajusz, D., Rácz, A., and Héberger, K. (2015). Why is Tanimoto index an appropriate choice for fingerprint-based similarity calculations? J. Cheminform. 7, 20.

36. Bell, G.A., Laing, D.G., and Panhuber, H. (1987). Odour mixture suppression: evidence for a peripheral mechanism in human and rat. Brain Res. 426, 8-18.

37. Laing, D.G., Panhuber, H., and Slotnick, B.M. (1989). Odor masking in the rat. Physiol. Behav. 45, 689-694.

38. Kurahashi, T., Lowe, G., and Gold, G.H. (1994). Suppression of odorant responses by odorants in olfactory receptor cells. Science $265,118-120$.

39. Takeuchi, H., Ishida, H., Hikichi, S., and Kurahashi, T. (2009). Mechanism of olfactory masking in the sensory cilia. J. Gen. Physiol. 133, 583-601.

40. Grosmaitre, X., Vassalli, A., Mombaerts, P., Shepherd, G.M., and Ma, M. (2006). Odorant responses of olfactory sensory neurons expressing the odorant receptor MOR23: a patch clamp analysis in gene-targeted mice. Proc. Natl. Acad. Sci. USA 103, 1970-1975.

41. Chen, S., Lane, A.P., Bock, R., Leinders-Zufall, T., and Zufall, F. (2000). Blocking adenylyl cyclase inhibits olfactory generator currents induced by "IP(3)-odors". J. Neurophysiol. 84, 575-580.

42. Ho, J., Tumkaya, T., Aryal, S., Choi, H., and Claridge-Chang, A. (2019). Moving beyond $\mathrm{P}$ values: data analysis with estimation graphics. Nat. Methods 16, 565-566.

43. Saraiva, L.R., Ibarra-Soria, X., Khan, M., Omura, M., Scialdone, A., Mombaerts, P., Marioni, J.C., and Logan, D.W. (2015). Hierarchical deconstruction of mouse olfactory sensory neurons: from whole mucosa to single-cell RNA-seq. Sci. Rep. 5, 18178.

44. Lex, A., Gehlenborg, N., Strobelt, H., Vuillemot, R., and Pfister, H. (2014) UpSet: Visualization of Intersecting Sets. IEEE Trans. Vis. Comput. Graph. 20, 1983-1992.

45. Adipietro, K.A., Mainland, J.D., and Matsunami, H. (2012). Functional evoIution of mammalian odorant receptors. PLoS Genet. 8, e1002821.

46. Martin, Y.C., Kofron, J.L., and Traphagen, L.M. (2002). Do structurally similar molecules have similar biological activity? J. Med. Chem. 45, 4350-4358.
47. Rospars, J.P., Lansky, P., Chaput, M., and Duchamp-Viret, P. (2008) Competitive and noncompetitive odorant interactions in the early neural coding of odorant mixtures. J. Neurosci. 28, 2659-2666.

48. Cruz, G., and Lowe, G. (2013). Neural coding of binary mixtures in a structurally related odorant pair. Sci. Rep. 3, 1220.

49. Singh, V., Murphy, N.R., Balasubramanian, V., and Mainland, J.D. (2019). Competitive binding predicts nonlinear responses of olfactory receptors to complex mixtures. Proc. Natl. Acad. Sci. USA 116, 9598-9603.

50. Lew, M.J., and Angus, J.A. (1995). Analysis of competitive agonist-antagonist interactions by nonlinear regression. Trends Pharmacol. Sci. 16, 328-337.

51. Clark, G.S. (1995). An Aroma Chemical Profile: Indole. Perfum. Flavor. 20, 21-31.

52. Lin, J., Aoll, J., Niclass, Y., Velazco, M.I., Wünsche, L., Pika, J., and Starkenmann, C. (2013). Qualitative and quantitative analysis of volatile constituents from latrines. Environ. Sci. Technol. 47, 7876-7882.

53. Kumar, R., Kaur, R., Auffarth, B., and Bhondekar, A.P. (2015) Understanding the Odour Spaces: A Step towards Solving Olfactory Stimulus-Percept Problem. PLoS ONE 10, e0141263.

54. Oka, Y., Katada, S., Omura, M., Suwa, M., Yoshihara, Y., and Touhara, K. (2006). Odorant receptor map in the mouse olfactory bulb: in vivo sensitivity and specificity of receptor-defined glomeruli. Neuron 52, 857-869.

55. Dewan, A., Cichy, A., Zhang, J., Miguel, K., Feinstein, P., Rinberg, D., and Bozza, T. (2018). Single olfactory receptors set odor detection thresholds. Nat. Commun. 9, 2887.

56. Kurtz, D.B., Zhao, K., Hornung, D.E., and Scherer, P. (2004). Experimental and numerical determination of odorant solubility in nasal and olfactory mucosa. Chem. Senses 29, 763-773.

57. Schoenfeld, T.A., and Cleland, T.A. (2005). The anatomical logic of smell. Trends Neurosci. 28, 620-627.

58. Scott, J.W., Sherrill, L., Jiang, J., and Zhao, K. (2014). Tuning to odor solubility and sorption pattern in olfactory epithelial responses. J. Neurosci. 34, 2025-2036.

59. Coppola, D.M., Fitzwater, E., Rygg, A.D., and Craven, B.A. (2019). Tests of the chromatographic theory of olfaction with highly soluble odors: a combined electro-olfactogram and computational fluid dynamics study in the mouse. Biol. Open 8, bio047217

60. Kenakin, T. (2003). Ligand-selective receptor conformations revisited: the promise and the problem. Trends Pharmacol. Sci. 24, 346-354.

61. Gilchrist, A. (2007). Modulating G-protein-coupled receptors: from traditional pharmacology to allosterics. Trends Pharmacol. Sci. 28, 431-437.

62. Vaidehi, N., and Kenakin, T. (2010). The role of conformational ensembles of seven transmembrane receptors in functional selectivity. Curr. Opin. Pharmacol. 10, 775-781.

63. Man, O., Gilad, Y., and Lancet, D. (2004). Prediction of the odorant binding site of olfactory receptor proteins by human-mouse comparisons. Protein Sci. 13, 240-254.

64. Trimmer, C., Keller, A., Murphy, N.R., Snyder, L.L., Willer, J.R., Nagai, M.H., Katsanis, N., Vosshall, L.B., Matsunami, H., and Mainland, J.D. (2019). Genetic variation across the human olfactory receptor repertoire alters odor perception. Proc. Natl. Acad. Sci. USA 116, 9475-9480.

65. Niimura, Y. (2009). On the origin and evolution of vertebrate olfactory receptor genes: comparative genome analysis among 23 chordate species. Genome Biol. Evol. 1, 34-44

66. Chaput, M.A., El Mountassir, F., Atanasova, B., Thomas-Danguin, T., Le Bon, A.M., Perrut, A., Ferry, B., and Duchamp-Viret, P. (2012). Interactions of odorants with olfactory receptors and receptor neurons match the perceptual dynamics observed for woody and fruity odorant mixtures. Eur. J. Neurosci. 35, 584-597.

67. Cao, L.H., Yang, D., Wu, W., Zeng, X., Jing, B.Y., Li, M.T., Qin, S., Tang, C., Tu, Y., and Luo, D.G. (2017). Odor-evoked inhibition of olfactory sensory neurons drives olfactory perception in Drosophila. Nat. Commun. 8, 1357. 


\section{CellPress OPEN ACCESS}

68. Su, C.Y., Menuz, K., Reisert, J., and Carlson, J.R. (2012). Non-synaptic inhibition between grouped neurons in an olfactory circuit. Nature 492, 66-71.

69. Giovannucci, A., Friedrich, J., Gunn, P., Kalfon, J., Brown, B.L., Koay, S.A., Taxidis, J., Najafi, F., Gauthier, J.L., Zhou, P., et al. (2019). CalmAn an open source tool for scalable calcium imaging data analysis. eLife 8 , e38173.

70. Pnevmatikakis, E.A., and Giovannucci, A. (2017). NoRMCorre: An online algorithm for piecewise rigid motion correction of calcium imaging data. J. Neurosci. Methods 291, 83-94.

71. Pnevmatikakis, E.A., Soudry, D., Gao, Y., Machado, T.A., Merel, J., Pfau, D., Reardon, T., Mu, Y., Lacefield, C., Yang, W., et al. (2016). Simultaneous Denoising, Deconvolution, and Demixing of Calcium Imaging Data. Neuron 89, 285-299.

72. Hashimshony, T., Senderovich, N., Avital, G., Klochendler, A., de Leeuw, Y., Anavy, L., Gennert, D., Li, S., Livak, K.J., Rozenblatt-Rosen, O., et al.

\section{Current Biology}

(2016). CEL-Seq2: sensitive highly-multiplexed single-cell RNA-Seq. Genome Biol. 17, 77.

73. Langmead, B., and Salzberg, S.L. (2012). Fast gapped-read alignment with Bowtie 2. Nat. Methods 9, 357-359.

74. Zhang, J.H., Chung, T.D., and Oldenburg, K.R. (1999). A Simple Statistical Parameter for Use in Evaluation and Validation of High Throughput Screening Assays. J. Biomol. Screen. 4, 67-73.

75. Hintze, J.L.R.D.N. (1998). Violin plots: a box plot-density trace synergism. Am. Stat. 52, 181-184.

76. Wickham, H. (2017). tidyverse: Easily Install and Load the 'Tidyverse', R package version 1.2.1 (Vienna, Austria: R Core Team).

77. Hsieh, M.C. (2016). iNEXT: an R package for rarefaction and extrapolation of species diversity (Hill numbers). Methods Ecol. Evol. 7, 1451-1456.

78. (2017). Dassault Systèmes BIOVIA, Pipeline Pilot 18.1 .0 (Dassault Systèmes: San Diego). 


\section{Current Biology}

Article

\section{STAR $\star$ METHODS}

\section{KEY RESOURCES TABLE}

\begin{tabular}{|c|c|c|}
\hline REAGENT or RESOURCE & SOURCE & IDENTIFIER \\
\hline \multicolumn{3}{|c|}{ Chemicals, Peptides, and Recombinant Proteins } \\
\hline L15 medium & ThermoFisher & Cat\# 21083-027 \\
\hline DMEM/F12 (GIBCO BRL) & ThermoFisher & Cat\# 11039-021 \\
\hline Collagenase & Worthington/Fisher & Cat\# NC9482366 \\
\hline Dispase & Worthington/Fisher & Cat\# NC9199795 \\
\hline Forskolin & Sigma & Cat\# F3917 \\
\hline Insulin-transferrin-selenium & ThermoFisher & Cat\# 51500-056 \\
\hline Fura-2 AM & ThermoFisher & Cat\# F-1221 \\
\hline Concanavalin A & Sigma & Cat\#C2010 \\
\hline $\begin{array}{l}\text { DMEM, } 1 \text { X (Dulbecco's Modification of } \\
\text { Eagle's Medium) }\end{array}$ & Corning & Cat\# 10-013-CM \\
\hline Fetal Bovine Serum Qualified One Shot & Life Technologies & Cat\# A31606-01 \\
\hline Puromycin & GIBCO & Cat\# A11138-03 \\
\hline HBSS (Hanks' Balanced Salt Solution) & Corning & Cat\# 20-023-CV \\
\hline $\begin{array}{l}\text { HEPES (4-(2-hydroxyethyl)-1- } \\
\text { piperazineethanesulfonic acid) }\end{array}$ & Teknova & Cat\# H1030 \\
\hline Lipofectamine 2000 & Life Technologies & Cat\# 11668 \\
\hline IBMX (3-Isobutyl-1-methylxanthine) & Acros & Cat\# 28822-58-4 \\
\hline MDL-12,330A hydrochloride & Sigma & Cat\# M182 \\
\hline DMSO (Dimethyl Sulfoxide) & Sigma & Cat\# D2438 \\
\hline \multicolumn{3}{|l|}{ Critical Commercial Assays } \\
\hline SMART-Seq v3 Ultra Low Input RNA Kit & Takara & Cat\# 634851 \\
\hline Agencourt AMPure XP & Beckman & Cat\# 15026495 \\
\hline TruSeq RNA Sample Preparation v2 & Illumina & Cat\# 15026495 \\
\hline HTRF cAMP Dynamic 2 Kit & Cisbio & Cat\# 62AM4PEB \\
\hline GeneArt CRISPR Nuclease Vector Kit & Life Technologies & Cat\# A21175 \\
\hline \multicolumn{3}{|l|}{ Deposited Data } \\
\hline RNA-seq data & This paper & GEO: GSE149271 \\
\hline \multicolumn{3}{|l|}{ Experimental Models: Cell Lines } \\
\hline HEK293T & ATCC & Cat\# CRL-3216 \\
\hline Rtp1 expressing HEK293T & This paper & N/A \\
\hline \multicolumn{3}{|l|}{ Experimental Models: Organisms/Strains } \\
\hline C57BL/6J & The Jackson Laboratory & Cat\# JAX000664 \\
\hline OMP-Cre & The Jackson Laboratory & Cat\# JAX006668 \\
\hline tetO-GCaMP6f & The Jackson Laboratory & Cat\# JAX030328 \\
\hline \multicolumn{3}{|l|}{ Oligonucleotides } \\
\hline $\begin{array}{l}\text { gRNA Top Strand } \\
5^{\prime} \text {-GCC CTG AAC TGA GAT TGC AGG } \\
\text { TाT T-3' }\end{array}$ & This paper & N/A \\
\hline $\begin{array}{l}\text { gRNA bottom Strand } \\
5^{\prime} \text {-CTG CAA TCT CAG TTC AGG GCC } \\
\text { GGT G-3' }\end{array}$ & This paper & N/A \\
\hline $\begin{array}{l}5^{\prime} \text { Homology Arm primer } 1 \\
5^{\prime} \text {-CAT CAT CGA TGG GGT TIT ATG } \\
\text { GAA GAG TCT TAC TTC TCT T-3' }\end{array}$ & This paper & N/A \\
\hline
\end{tabular}




\begin{tabular}{|c|c|c|}
\hline \multicolumn{3}{|l|}{ Continued } \\
\hline REAGENT or RESOURCE & SOURCE & IDENTIFIER \\
\hline $\begin{array}{l}5^{\prime} \text { Homology Arm primer } 2 \\
\text { 5'- GCA GCG GCC GCG GGT CTA AAT } \\
\text { GAT CCA AGA CAG AGT GG-3' }\end{array}$ & This paper & N/A \\
\hline $\begin{array}{l}3^{\prime} \text { Homology Arm primer } 1 \\
5^{\prime} \text {-CTG TIT AAA CCT CTT CAG AGA CTC } \\
\text { CCT CCT CC-3' }\end{array}$ & This paper & N/A \\
\hline $\begin{array}{l}3^{\prime} \text { Homology Arm primer } 2 \\
5^{\prime} \text { - TTA ACT CGA GTT AAA TAG ATT TAA } \\
\text { ACC GGT CCC AGG ACC-3' }\end{array}$ & This paper & N/A \\
\hline \multicolumn{3}{|l|}{ Recombinant DNA } \\
\hline pPUR Vector & Clontech & Cat\# 631601 \\
\hline pGEM-T Easy Vector & Promega & Cat\# A1360 \\
\hline \multicolumn{3}{|l|}{ Software and Algorithms } \\
\hline Metamorph & Molecular Devices & https://www.moleculardevices.com/ \\
\hline Prism 7.04 & GraphPad & $\begin{array}{l}\text { https://www.graphpad.com/ } \\
\text { scientific-software/prism/ }\end{array}$ \\
\hline RStudio & Foundation for Open Access Statistics & https://rstudio.com/ \\
\hline Inkscape 0.92 .3 & Inkscape Project & https://inkscape.org/ \\
\hline BioEdit 7.2.6 & BioEdit & https://bioedit.software.informer.com/ \\
\hline EPISuite 4.11 & US Environmental Protection Agency & $\begin{array}{l}\text { https://www.epa.gov/ } \\
\text { tsca-screening-tools/ } \\
\text { epi-suitetm-estimation-program-interface }\end{array}$ \\
\hline MATLAB & Mathworks & $\begin{array}{l}\text { https://www.mathworks.com/products/ } \\
\text { matlab.html }\end{array}$ \\
\hline Caiman & Flatiron Institue & https://github.com/flatironinstitute/CalmAn \\
\hline Estimation Statistics beta & Adam Claridge-Chang and Joses Ho [42] & https://www.estimationstats.com/\#/ \\
\hline
\end{tabular}

\section{RESOURCE AVAILABILTIY}

\section{Lead Contact}

Further information and requests for resources and reagents should be directed to and will be fulfilled by the Lead Contact, Matthew E. Rogers (matthew.rogers@firmenich.com).

\section{Materials Availability}

Mouse lines utilized in this study are available at Jackson Laboratory: C57BL/6J (JAX000664), OMP-Cre line (JAX006668) and GCaMP6f reporter line (JAX030328).

A new Rtp1-expressing HEK293T cell line was generated, no other reagents. There are restrictions to the availability of this cell line due to existing IP (WO2016201153A1).

All other reagents are commercially available (see Key Resources Table).

Data and Code Availability

Requests for raw data and instrumentation and analysis code should be directed to the Lead Contact.

Analysis code is not provided because it is tailored to highly customized instrumentation.

The RNA-seq data used to generate Figure 4 in this paper is available on Gene Expression Omnibus: https://www.ncbi.nIm.nih. gov/geo/query/acc.cgi?acc=GSE149271.

\section{EXPERIMENTAL MODEL AND SUBJECT DETAILS}

\section{Animal Care \& Sources}

C57BL/6J male mice, aged 8 to 12 weeks, were obtained from the Jackson Laboratory. Two further mouse strains, OMP-Cre (JAX006668) with Ai148 (TIGRE-Ins-TRE2-LSL-GCaMP6f-Ins-CAG-LSL-tTA2CAG-GCaMP6f, JAX030328) were also purchased from the Jackson Laboratory and bred together to generate experimental animals that were used between 8 to 12 weeks of age. All experimental procedures were in compliance with $\mathrm{NIH}$ guidelines and were approved by the Mispro Biotech Services Institutional Animal Care and Use Committee. 
Please cite this article in press as: Pfister et al., Odorant Receptor Inhibition Is Fundamental to Odor Encoding, Current Biology (2020), https://doi.org/ 10.1016/j.cub.2020.04.086

\section{Current Biology Article}

\section{METHOD DETAILS}

\section{Calcium Imaging}

Tissue was prepared as described in Poivet et al., 2018 [32]. In brief, olfactory epithelia were placed into $5 \mathrm{~mL}$ L15 medium supplemented with $10 \%$ fetal bovine serum, $100 \mathrm{U} / \mathrm{mL}$ penicillin and $100 \mu \mathrm{g} / \mathrm{mL}$ streptomycin (GIBCO BRL, Grand Island, NY, USA), $0.5 \mathrm{U} \mathrm{ml}-1$ collagenase, $1 \mathrm{U} \mathrm{ml}-1$ dispase (Worthington Biochem, Lakewood, NJ, USA), $3.75 \mathrm{mM} \mathrm{CaCl} 2$ (Sigma-Aldrich, St-Louis, MO, USA), and $50 \mu \mathrm{g} \mathrm{ml}-1$ deoxyribonuclease II (Worthington Biochem).

The tissue was incubated at $37^{\circ} \mathrm{C}$ for $75 \mathrm{~min}$ on a rocker, subsequently dissociated by trituration with a siliconized pipette, and plated onto concanavalin-coated glass coverslips (Sigma-Aldrich, $10 \mathrm{mg} / \mathrm{mL}$ ) placed in $35 \mathrm{~mm}$ Petri dishes. Following plating for $30 \mathrm{~min}$ to permit cell adhesion, $2 \mathrm{~mL}$ of culture medium was added to each dish and the dishes were held at $37^{\circ} \mathrm{C}$ for at least $1 \mathrm{~h}$. Culture medium consisted of DMEM/F12 (GIBCO BRL) supplemented with $10 \%$ fetal bovine serum, $1 \mathrm{x}$ insulin-transferrin-selenium (GIBCO BRL), $100 \mathrm{U} / \mathrm{mL}$ penicillin and $100 \mu \mathrm{g} / \mathrm{mL}$ streptomycin (GIBCO BRL), and $100 \mu \mathrm{M}$ ascorbic acid (Sigma-Aldrich).

Cells were loaded with Fura-2 AM ( $5 \mu \mathrm{M}$; ThermoFisher, Waltham, MA, USA) at $31^{\circ} \mathrm{C}$ for $45 \mathrm{~min}$. After being washed with Hank's Balanced Salt Solution, the coverslips were mounted into a recording chamber. Imaging was carried out at room temperature on an IX83 inverted fluorescence microscope (Olympus, Center Valley, PA, USA) equipped with an Orca-R2 camera (C10600, Hamamatsu Photonics, Hamamatsu, Japan), Proscan III motorized stage (Prior Scientific, Rockland, MA, USA) a Lambda XL light source (Sutter Instrument, Novato, CA, USA), and Lamba-10B optical filter changer (Sutter Instrument). Odorants from Firmenich Incorporated were prepared as $1 \mathrm{mM}$ stocks and diluted to a final working concentration in HBSS 10mM HEPES pH 7.3, and bath applied using an Agilent 1100 series HPLC system (Agilent Technologies, Santa Clara, CA, USA). A final stimulation with $40 \mu \mathrm{M}$ Forskolin (Sigma-Aldrich; prepared as $40 \mathrm{mM}$ in DMSO and diluted in HBSS) was made to assess the viability of dissociated OSNs. Images were taken with Metamorph Premier software (Molecular Devices LLC, San Jose, CA, USA) at 340 and $380 \mathrm{~nm}$ excitation and $510 \mathrm{~nm}$ emission, approximately every $6 \mathrm{~s}$, and there was a 3 min delay between odor stimulation.

\section{SCAPE microscopy}

Mice were generated by crossing OMP-Cre (JAX006668) with Ai148 (TIGRE-Ins-TRE2-LSL-GCaMP6f-Ins-CAG-LSL-tTA2, JAX030328). Male 6 to 8-week old mice with a genotype of OMP-Cre+/- GCaMP6f+/- were used for Swept Confocally-Aligned Planar Excitation (SCAPE) imaging. Tissue was prepared as described in Xu et al., 2020 [27]. In brief, intact epithelia were mounted in a custom-designed chamber with an inlet from an Agilent 1100 series HPLC system and outlet to a vacuum flask to ensure consistent flow of HBSS, $10 \mathrm{mM}$ HEPES pH 7.3. Images were acquired using a custom SCAPE microscope [31] equipped with a $488 \mathrm{~nm}$ laser for GCaMP6f excitation. Each acquisition window was $75 \mathrm{~s}$, during which the OE was exposed to odorants from the HPLC using the same conditions as above, including a three-minute interstimulus interval. Images were taken using custom MATLAB code, and further processing carried out using the CalmAn computational toolbox [69], which implements NoRMCorre piecewise rigid motion correction [70], followed by constrained non-negative matrix factorization for segmentation, denoising, and detrending of the obtained data [71].

\section{Single-Cell RNA-Seq}

OSNs were dissociated from OMP-Cre+/- GCaMP6f+/- mice and plated on concanavillin-coated coverslips as above. OSNs with ligand response profiles of interest were retrieved using disposable capillaries with a $10 \mu \mathrm{m}$ tip diameter (Cat \# DCU ID 10, NeurolnDx, Torrance, CA, USA) controlled by a UniPick vacuum-assisted single-cell collection instrument (NeurolnDx).). Individual cells were expelled into an RNase-free $200 \mu \mathrm{l}$ tube containing poly-T primers that also bore cell-specific barcodes and unique molecular identifiers (UMI) to allow measurement of individual mRNA transcripts. Samples were then submitted to the Genome Technology Center (NYU Langone Health), where they were further processed for sequencing according to the Cel-Seq2 method [72]. Libraries were run on the Illumina NovaSeq 6000 using a SP100 flow cell in paired-end mode (read 2 carries transcript sequence; read 1 provides barcode and UMI information). Reads were mapped against the mouse reference genome (mm10) using Bowtie2 [73], and deduplicated UMls per gene were counted. Gene counts were normalized by dividing gene-specific UMls by the total number of UMIs from a cell, and multiplied by a million, to provide transcripts-per-million (TPMs) for each gene in each cell.

\section{Cell line generation}

A modified HEK293T cell line expressing the endogenous Rtp1 gene was generated for functional OR expression. A targeted insertion of the constitutively active CMV promoter $\left(\mathrm{P}_{\mathrm{CMV}}\right)$ was performed using CRISPR/Cas9 technologies followed by homologous directed DNA repair (HDR). A guide RNA (gRNA) was designed to target positions $148 \mathrm{bp}$ and $147 \mathrm{bp}$ upstream of the Rtp1 gene translation start site and induce a double-stranded DNA break, when combined with Cas9. Two oligo nucleotides (top and bottom target sequence strand) with $3^{\prime}$ overhangs were annealed and cloned into the vector the GeneArt ${ }^{\circledR}$ CRISPR Nuclease Vector Kit to generate the gRNA/Cas9 nuclease plasmid. $5^{\prime}$ and $3^{\prime}$ homology arms (amplified directly from HEK293T genomic DNA, see reagents for primer sequences) flanking the $P_{C M V}$ sequence attached to a puromycin resistance gene (from pPUR vector) were cloned into pGEM $\mathbb{B}-T$ Easy Vector to generate the HDR plasmid. HEK293T cells were transfected with 1:1 mixture of gRNA/Cas9 and HDR plasmids using Lipofectamine 2000. After selection in puromycin containing media, single colonies were isolated and tested for functional OR expression. A final clonal cell line was selected for use in this study. 


\section{Current Biology}

cAMP Functional Cell-Based Assay

All OR genes were synthesized and cloned into the modified expression vector PME18S-FL containing an SV40 promoter followed by a Flag-Rho tag at the $\mathrm{N}$-terminal end of the $\mathrm{OR}$. Expression vectors were co-transfected with the canonical olfactory $\mathrm{G}_{\text {protein }} \mathrm{G}_{\text {olf }}$ into the modified HEK293T cell line expressing the endogenous Rtp 1 gene using $5 \mu \mathrm{g}$ of DNA and $10 \mu \mathrm{I}$ Lipofectamine 2000 (Life Technologies, Cat. \#11668) in $6 \mathrm{~mL}$ DMEM per 120 wells. Cells were seeded at a density of 7500 cells/well in a volume of $50 \mu \mathrm{l}$ in $96-$ well white, opaque bottom plates (Corning, Cat \# 3688) in DMEM supplemented with $10 \%$ FBS without antibiotic. Plates were incubated at $37^{\circ} \mathrm{C}$ in $5 \% \mathrm{CO} 2$ overnight. Prior to the assay, cells were washed with $100 \mu \mathrm{lPBS}$ and incubated with $40 \mu \mathrm{l}$ of compound per well diluted in DMSO to a final concentration of $0.3 \%$ DMSO in assay buffer (HBSS, $10 \mathrm{mM} \mathrm{MgCl} 2,20 \mathrm{mM} \mathrm{HEPES,} 2 \mathrm{mM}$ CaCl2, $0.5 \mathrm{M}$ IBMX). For dose-response agonist experiments, compounds were diluted to 12 different concentrations between $10^{-8}$ and $10^{-3} \mathrm{M}$ at approximately half-log intervals as above. For antagonist experiments, the $\mathrm{EC}_{80}$ of indole was first determined in a duplicate doseresponse agonist experiment and then test compounds were prepared as before and mixed with a dilution of indole to achieve the $\mathrm{EC}_{80}$. In dose-response experiments in which both agonist and antagonist were varied, compounds were prepared as for the antagonist dose-response experiment but with indole diluted to range between $10^{-8}$ and $10^{-3} \mathrm{M}$ at half-log intervals as well. Cells were incubated with compound at $37^{\circ} \mathrm{C}$ in $5 \% \mathrm{CO} 2$ for $30 \mathrm{~min}$. OR activity was monitored using the HTRF (Homogeneous Time-Resolved Fluorescence) CAMP dynamic 2 kit (Cisbio, Cat \# 62AM4PEB, a competitive immunoassay between native cAMP produced by cells and the cAMP tracer molecule, labeled with proprietary CisBio fluorophore D2. cAMP-D2 bound to the cryptate-labeled anti-cAMP mouse generates fluorescence via a FRET signal. HTRF values indicate the fluorescence ratio of the cryptate emission wavelength at $620 \mathrm{~nm}$ to D2 acceptor emission at $665 \mathrm{~nm}$, values range between 0 and 10,000) following manufacturer protocols; HTRF assay plates were read on Pherastar (BMG labtech). Dose-response data were graphed in GraphPad Prism 7.04 to calculate EC $_{50}$, relative $\mathrm{IC}_{50}$, Hill coefficient, maxima and minima of the response signals, and to graph dose-response curves. Agonist dose-response experiments were carried out in duplicates. The standard errors of the mean were calculated and the data points and fitted to a fourparameter non-linear regression following the Hill equation (unconstrained Hill coefficient). Due to the competition-based nature of the HTRF assay, a decreasing HTRF ratio indicates cAMP accumulation and a corresponding activity increase. Here, dose-response data was scaled by subtracting the HTRF ratio from 7000 arbitrary units (encompassing the full assay window) to plot the data as agonism and antagonism by upward and downward curves respectively.

\section{High-Throughput Screening}

The same transfection and analysis conditions as above were applied to the library screening. A library of 800 odorants sourced internally was assembled in $100 \%$ solvent (DMSO) at a stock concentration of $300 \mathrm{mM}$ and stored at $-20^{\circ} \mathrm{C}$. For the activation assay, compounds were diluted to a final concentration of $300 \mu \mathrm{M}$ (DMSO concentration $0.1 \%$ final) in a 96 well plate format and delivered to the transfected cells. Agonism was assessed by stimulating each OR with $300 \mu \mathrm{M}$ of each compound, while antagonism was assessed by measuring the change in receptor activation elicited by $300 \mu \mathrm{M}$ of each compound in the presence of an $\mathrm{EC}_{80} \mathrm{Concen}$ tration of indole. This concentration was chosen to provide a larger assay window and a more stringent screening condition, selecting for stronger antagonists.

For the inhibition assay, an initial dose-response to indole was performed in triplicate for each receptor on the day of the assay to determine the $\mathrm{EC}_{80}$ used in each subsequent single-concentration modulation screen. Compounds were blended in a 96 well plate format to a final concentration of $300 \mu \mathrm{M}$ with indole $\mathrm{EC}_{80}$ at $0.2 \% \mathrm{DMSO}$ final (80 compounds per plate). Single-concentration activity measures were performed for 800 non-redundant binary mixtures and compared to the activity elicited by indole $\mathrm{EC}_{80}$ alone. Assay variability and reliability were evaluated by calculating the Z', a measure of the assay window and the standard deviations of minimum and maximum cAMP production per plate. The average ' ' value obtained across all experiments was 0.86 (SD $=0.03$ ) and 0.70 (SD = 0.09) for agonism and antagonism respectively, and surpassed minimal requirement above the standard quality limit of $Z$ ' $>0.5[74]$.

$$
Z^{\prime}=1-\frac{3 *\left(S D_{M a x}+S D_{\text {Min }}\right)}{\left|\operatorname{Mean}_{\operatorname{Max}}-\operatorname{Mean}_{\operatorname{Min}}\right|}
$$

Receiver Operating Characteristic (ROC) curves were used to assess the accuracy of the single-concentration screen to predict modulation at the dose-response level. Determination of whether an ingredient was considered an antagonist or agonist was made using cutoff values derived from ROC analyses (Figure S4A). All data points were considered for the Pearson correlation matrix analyses.

Competitive binding model with spontaneous receptor activity

We propose a model of competitive binding that includes spontaneous activation of the receptor as shown in Figure 7A. The on and off rates of the binding of ligand $X_{i}$ are denoted by $\kappa^{+}{ }_{1, i}$ and $\kappa_{1, i}^{-}$respectively. Once bound, there is a rate of activation of the receptor, which depends on the bound ligand. If $X_{i}$ is the bound ligand, we denote its rate of activating the receptor as $\kappa_{2, i \cdot}$ The activated receptor reverts to its native, unbound state with a rate $\mathrm{k}_{\mathrm{s}}^{-}$, which can in turn spontaneously activate with a rate $\mathrm{k}_{\mathrm{s}}^{+}$. The output of the experiment is assumed to be proportional to the total number of activated receptors. When the set of ligands $X_{1}, X_{2, \cdots,} X_{K}$ at concentrations $\mathrm{C}_{1}, \mathrm{C}_{2}, \ldots, \mathrm{C}_{\mathrm{K}}$ respectively are delivered, by writing down the set of coupled rate equations, we can calculate the total number of activated receptors of a particular type at steady state as 


\section{Current Biology Article}

\section{Cell|Press} OPEN ACCESS

$$
R=a_{2}+a_{1}\left\{\sum_{i} \eta_{i} \frac{C_{i}}{\kappa_{i}} /\left(1+\sum_{j} \frac{C_{j}}{\kappa_{j}}\right)+\eta_{s} /\left(1+\sum_{j} \frac{C_{j}}{\kappa_{j}}\right)\right\}
$$

where the sums are from 1 to $K, \kappa^{-1}{ }_{i}$ and $\eta_{i}$ are the binding affinity and activation efficacy respectively of ligand $X_{i}, \eta_{s}$ is the constitutive activity of the receptor and $a_{1}$ and $a_{2}$ are constants. In terms of the rate constants introduced previously, we have

$$
\eta_{s}=\frac{k_{s}^{+}}{k_{s}^{+}+k_{s}^{-}}, \kappa_{i}^{-1}=\frac{\kappa_{1, i}^{+}}{\kappa_{2, i}+\kappa_{1, i}^{-}} \frac{\kappa_{2, i}+k_{s}^{-}}{k_{s}^{+}+k_{s}^{-}}, \eta_{i}=\frac{\kappa_{2, i}}{\kappa_{2, i}+k_{s}^{-}} .
$$

Note that the definitions of $\eta_{i}$ and $\eta_{s}$ restrict their range between 0 and 1 . If there were no ligands present, all $C_{i}$ 's would be zero and the activity is then proportional to $\eta_{\mathrm{s}}$. At large concentrations, all receptors are bound, and all activity is due to ligand-induced activation rather than spontaneous activity. The constants $a_{1}$ and $a_{2}$ are independent of receptor-ligand interactions, and depend on cellular processes downstream of receptor activation, number of receptors, reporter properties and other factors.

Fitting activation and inhibition profiles to the competitive binding model

To obtain the plots in Figure 7B, we first normalized the data between zero and one, where zero corresponds to the HTRF ratio of the lowest concentration of the activator $(0.1 \mu \mathrm{M})$ and no inhibitor and one corresponds to the saturation level of the activator doseresponse profile with no inhibitor. Performing this normalization is equivalent to subtracting $a_{2}+a_{1} \eta_{s}$ and then dividing by $a_{1}\left(\eta_{\text {act }}\right.$ - $\eta_{\mathrm{s}}$ ) from the equation for $R$ from the previous STAR Methods section. Here $\eta_{\text {act }}$ is the unknown activation efficacy of the activator. If $\eta_{\text {inh }}$ is the activation efficacy of the inhibitor, we can write the normalized response in terms of the concentrations of the activator and inhibitor and their binding affinities as

$$
R_{\text {norm }}=\frac{\frac{\alpha C_{i n h}}{\kappa_{i n h}}+\frac{C_{a c t}}{\kappa_{a c t}}}{1+\frac{C_{\text {inh }}}{\kappa_{\text {inh }}}+\frac{C_{a c t}}{\kappa_{a c t}}}
$$

where $\alpha$ is the ratio $\left(\eta_{\text {inh }}-\eta_{\mathrm{s}}\right) /\left(\eta_{\text {act }}-\eta_{\mathrm{s}}\right)$. Note there are three free parameters: $\kappa_{\text {inh, }} \kappa_{\text {act }}$ and $\alpha$. We obtain the best fit curves in Figure $7 \mathrm{~B}$ by minimizing the RMSE between the CB model and the data from the competitive binding assay.

To obtain the values of the binding affinities in Figures 7C and 7D, we fit the CB model to the activation and inhibition profiles of 37 unique compounds delivered to the ten receptors from the Olfr740 family. For the activation assay, we first subtracted the HTRF ratio at the lowest concentration of the activator, which is equivalent to subtracting $a_{2}+a_{1} \eta_{\mathrm{s}}$ from the equation for $R$. We fit the dose-response curves to the Hill function with Hill coefficient 1 (as predicted by the CB model). We collected the best-fit binding affinities for the receptor-ligand pair which show a significant positive activation of the receptor (std. dev of the HTRF ratio across the ten concentrations $>80$ and positive best-fit saturation level) while excluding those which have a best-fit $\ln \kappa^{-1}>8.5, \kappa \sim 200 \mu \mathrm{M}$ (since the tested concentrations do not exceed much beyond this value). The screening above yielded the binding affinities for 47 activators from a total of $\sim 400$ activation profiles. For the inhibition assay, the activator was indole delivered at $\mathrm{EC}_{80}$, calibrated from an activation assay performed on the same batch of cells. We normalized the data like the analysis from the competitive binding assay. The normalized inhibition profiles are fit to the equation for $R_{\text {norm }}$ given above, where $\kappa_{\text {act }}$ is obtained from the activation assay for the activator and $C_{a c t}$ is the $E C_{80}$. The bestfit binding affinities which show significant inhibition (std. dev of the HTRF ratio across the ten concentrations $>80$, best-fit $\alpha$ value $<0.5$, and best-fit In $\kappa^{-1}{ }_{\text {inh }}>$ 8.5) were collected, yielding the binding affinities for 118 inhibitors.

Note that the best-fit curves from the CB model yield the activation efficacy $\eta$ in a continuum between 0 and 1 . In practice, however, most profiles do not saturate and the best-fit $\eta$ value is imprecise. In our dataset, we observed few partial agonists and thus we simplified our analysis by effectively projecting the activation efficacies into two broad categories: activators $(\eta \approx 1)$ and inhibitors $(\eta \approx 0)$.

\section{Correlation between binding affinity and functional outcome}

We calculated the Pearson correlation coefficient between the logarithm of the binding affinity and the binary variable activator/inhibitor. Using the expression for the correlation coefficient between a continuous and binary variable, we have

$$
\rho=\operatorname{Corr}\left(\ln \kappa^{-1}, \text { act } / \operatorname{inh}\right)=\frac{\left\langle\ln \kappa^{-1}\right\rangle_{\text {act }}-\left\langle\ln \kappa^{-1}\right\rangle_{\text {inh }}}{S} \sqrt{f_{\text {act }}\left(1-f_{\text {act }}\right)}
$$

where $S$ is the empirical standard deviation of $\ln \kappa^{-1}(=1.37)$, and $f_{\text {act }}$ is the probability that a compound that binds to a receptor is an activator. Using the data from the high-throughput screen of 800 odorants we estimated $f_{\text {act }} \sim 0.68$ (444 total activators out of 653 total binders), which gives $\rho=0.18$. To calculate the standard deviation of $\rho$, we repeat the entire analysis by first adding $6 \%$ noise to the dataset, where $6 \%$ is the average noise to signal ratio estimated from measurements of the HTRF ratio at the lowest concentration of each compound. The standard deviation of $\rho$ is then computed to be the standard deviation of the re-calculated $\rho$ values over 100 repetitions. Note that the correlation coefficient calculated here corresponds to the correlation between log-binding affinity and activation efficacy when the odorant and receptor are both independently drawn in each sample. One could instead calculate the correlation coefficient for each receptor, where the receptor is fixed and the correlation is calculated for sampled odorants. The latter would indeed contain more information about each receptor but requires enough data to compute $\rho$ for each receptor, which is not available with our current dataset.

To generate the plots in Figure 7E, we calculate the probability that a receptor is activated when an odorant mixture consisting of a particular number of ligands was delivered. We assume that the receptor-ligand interactions are independent across ligands, that if a ligand 


\section{Current Biology}

binds, it is either a perfect agonist $(\eta=1)$ or a perfect inhibitor $(\eta=0)$ and that each ligand is equiproportionate and delivered at saturating concentrations (the normalization effect is even stronger at weaker, unequal concentrations, see ref. 28). First, we assume the fraction of ligands that bind to a receptor (i.e., they either activate or inhibit the receptor) to be $\sim 30 \%$, as estimated from the data. Second, if the ligand binds, it is an activator with probability $f_{\text {act }}=0.68$. The logarithm of the binding affinity of an activator (inhibitor) is drawn from a normal distribution with mean $M_{a c t}\left(M_{i n h}\right)$ and standard deviation 1.37. $M_{a c t}=11.2$ and $M_{i n h}=10.62$ correspond to the experimentally obtained values, giving $\rho=0.18$. From the CB model, the activity of the receptor in the presence of a saturating, equiproportionate mixture is

$$
\eta_{\text {mix }}=\frac{\sum_{i} \eta_{i} \kappa_{i}^{-1}}{\sum_{j} \kappa_{j}^{-1}}
$$

where the sum is over the ligands in the mixture. If $\eta_{\text {mix }}>f_{a c t}$, the receptor is considered active. The sparsity for a fixed mixture complexity $\mathrm{K}$ is defined as the probability that $\eta_{\operatorname{mix}}>f_{\text {act }}$ over many samples of mixtures with $\mathrm{K}$ ligands. To obtain the sparsity versus $\mathrm{K}$ for other values of $\rho$ as shown in Figure $7 \mathrm{E}$, we tune the value of $M_{\text {act }}$ accordingly.

\section{QUANTIFICATION AND STATISTICAL ANALYSIS}

\section{Calcium Imaging Analysis}

Images were analyzed by a custom protocol built in Pipeline Pilot (BioVia Dassault Systèmes, San Diego, CA). Each image was tagged with a time point during acquisition, which could then be matched to the time of odorant administration. The frameset corresponding to the positive control (Forskolin) injection was isolated for image segmentation. A ratio was created of the $340 \mathrm{~nm} /$ $380 \mathrm{~nm}$ image pair for each time point, followed by the creation of a 3D stack of all the resulting images. This 3D image stack was projected into a 2-dimensional image where each pixel is equal to the $85^{\text {th }}$ percentile order statistic of that pixel location in the original 3D stack. Cell regions were then determined using adaptive thresholding of $15 \%$ above the mean for a window size of $16 \times 16$ pixels. The center of intensity peak for each region fed into a watershed segmentation to split clusters into individual cells. These individual cells were then filtered on contour eccentricity, creating a final segmentation image.

The ratios of the $340 \mathrm{~nm} / 380 \mathrm{~nm}$ images for the full experiment were then calculated, and the mean region intensities at every time point for each cell defined by the segmentation image was measured and scaled by a factor of 100 . The background (defined by the average intensity of the 5 frames prior to the subsequent injection) was then subtracted for each injection frame to give the delta values. Peak characteristics (slopes of peak and post-peak, fluctuation, post-peak upward deflection, area under the curve, and signal-to-noise ratio) of each cell for each injection window were fed into a trained Random Forests model to predict a PEAKTAG $(1,0,-1)$ relating to good, flat, or bad peaks, respectively. All injection frames for a given cell were then merged to give each cell a 'good' or 'bad' call based on PEAKTAGs, a delta value of at least 20 for the Positive control frame, and a PEAKTAG of 0 during the Negative control frame. A figure of merit (FOM) was calculated by the accumulation of bad peaks over the total number of injections per cell. All cells with a FOM greater than 0.0 were validated by hand to ensure data fidelity. Any cells that responded inconsistently to the same odorant were rejected from further analysis ( $2 \%$ of Forskolin-positive OSNs).

Cells that were validated as "good cells" were fed into a Modulation Analysis tool, custom built in Pipeline Pilot. Each cell that passed had a linear regression calculated to compensate for the natural attrition seen over the course of an experiment. A best fit line was drawn for the peaks corresponding to the agonist of interest. Cells with a slope that would cause an interception with the baseline before the Forskolin injection were rejected. The modulation value was calculated as the percent difference from the best fit line at that position. A negative modulation value indicates a reduction in the response when compared to the agonist of interest, and a positive modulation value shows an increased response. Where $\Delta \mathrm{f}$ is the maximum peak height of the agonist and potential antagonist mixture, $m$ is the slope of the best fit line, InjFr is the time point of the mixture injection, and $b$ is the intercept as determined by the best fit line, the modulation value can be determined as:

$$
\text { Modulation Value }=\frac{100 * \Delta f}{m * \operatorname{lnjFr}+b}-100
$$

\section{Statistical Analyses}

Figures were assembled with GraphPad Prism, Inkscape and RStudio software. Phylogenetic analyses were performed in BioEdit with the Protdist v3.5c application. Violin plots were made with Vioplot [75] and Tidyverse [76] R packages. Rarefaction analyses were carried out using iNEXT R package [77].

\section{Molecular Fingerprints}

Structural similarity between indole and 36 antagonist compounds was assessed by encoding compounds through circular (extended connectivity) and pharmacophoric (functional connectivity) molecular fingerprints. Tanimoto index was then used to calculate the similarity coefficient. The molecular similarity component of BIOVIA's Pipeline Pilot software was used to derive the fingerprints and compute the similarity [78]. 
Current Biology, Volume 30

Supplemental Information

\section{Odorant Receptor Inhibition Is}

\section{Fundamental to Odor Encoding}

Patrick Pfister, Benjamin C. Smith, Barry J. Evans, Jessica H. Brann, Casey Trimmer, Mushhood Sheikh, Randy Arroyave, Gautam Reddy, Hyo-Young Jeong, Daniel A. Raps, Zita Peterlin, Massimo Vergassola, and Matthew E. Rogers 
A

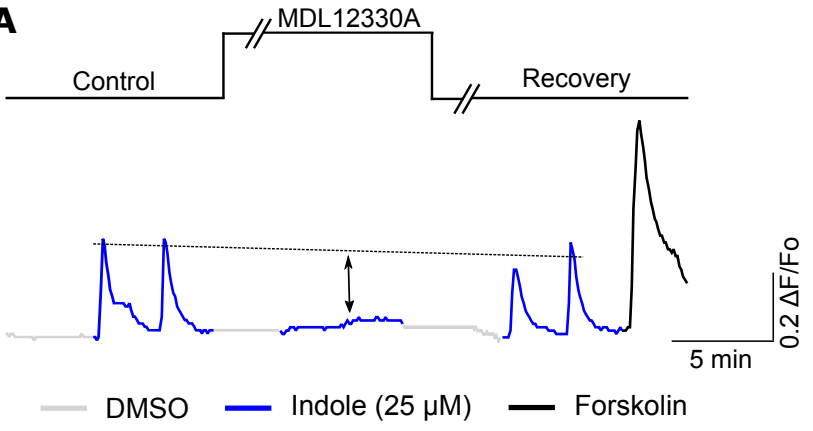

B

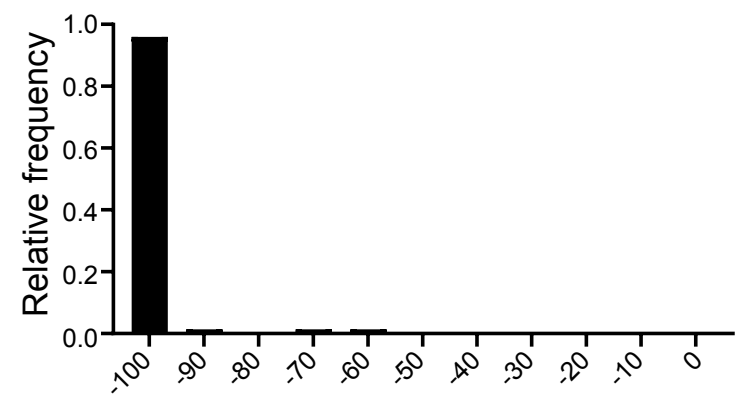

Percent modulation

Figure S1. Pharmacological inhibition of the olfactory transduction cascade generated non-specific OSN inhibition as opposed to the specific inhibition observed in Figure 1. (A) Inhibition of Adenylyl Cyclase 3 (AC3), the enzyme responsible for cAMP production in the olfactory transduction pathway downstream of OR activation, using the AC3 specific inhibitor MDL12330A. A 5 min pretreatment with MDL12330A (50 UM) abolished the indole response in an indole-activated OSN. This effect was reversible, and the indole response was recovered following a $5 \mathrm{~min}$ washout period. (B) Population histogram of the MDL12330A modulation of indole-activated OSNs as described in $\mathrm{A}(74 \mathrm{OSNs} ; \mathrm{N}=2)$. 
A

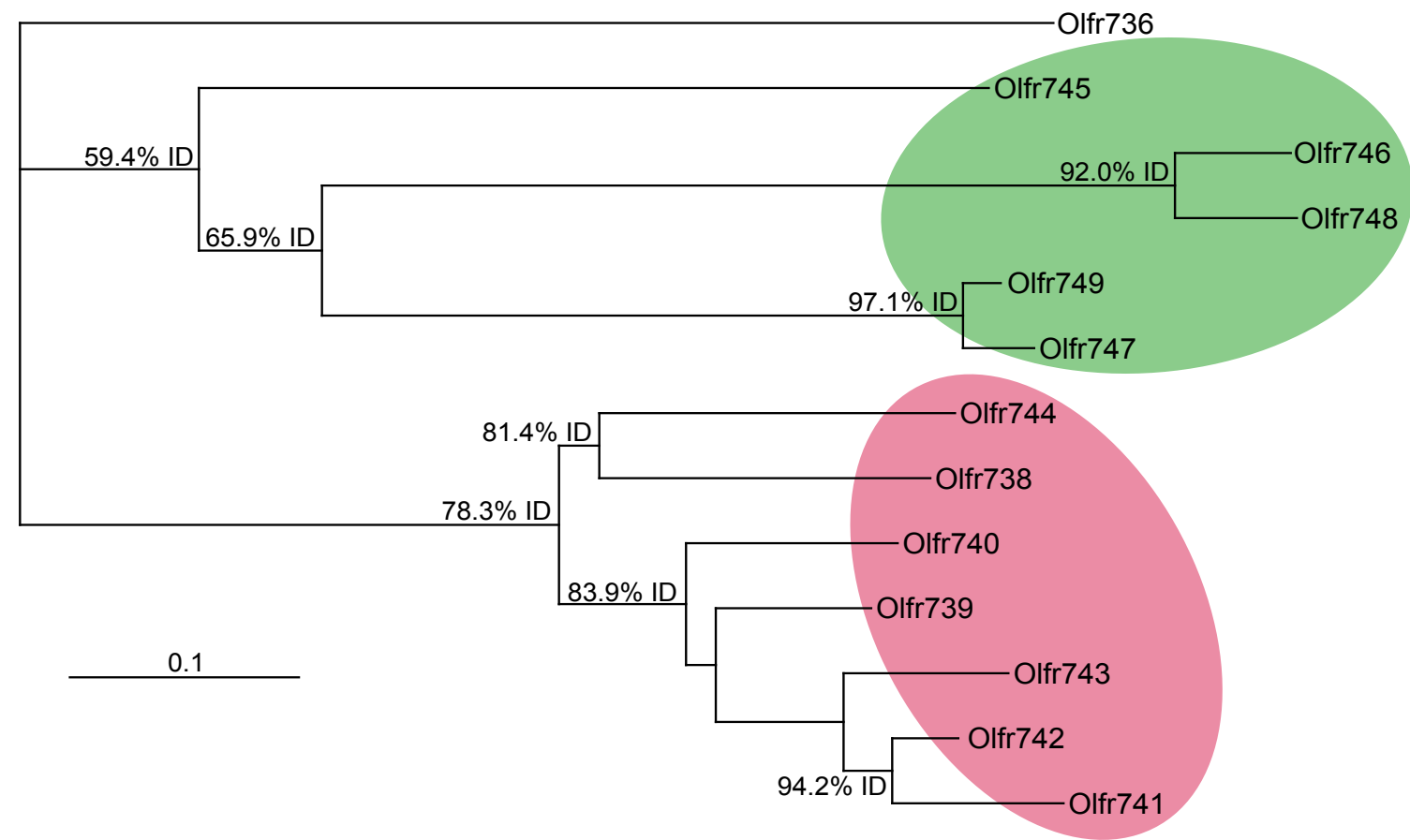

B

Figure S2. Phylogenetic relationship between 12 OR paralogs characterized in Figure 4 . Related to Figure 4. (A) A phylogenetic tree based on an amino acid alignment is shown with percent identity levels indicated for select nodes. Olfr736 represents a less conserved phylogenetic outgroup to the 12 OR genes and was used to root the tree. Olfr736 did not elicit a response from any test ligands, and so was removed from subsequent screens. Scale bar: average number of substitutions per site. (B) The full amino acid identity matrix is also shown. 
A
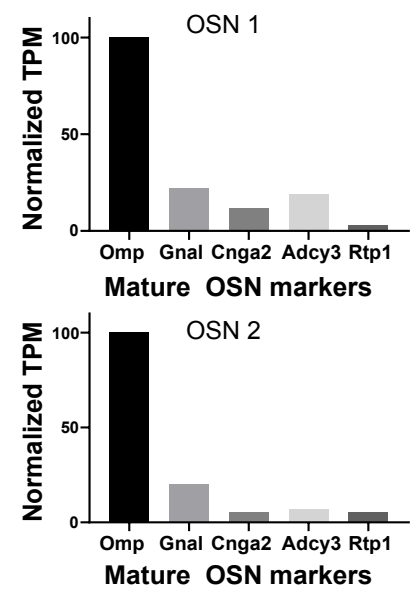
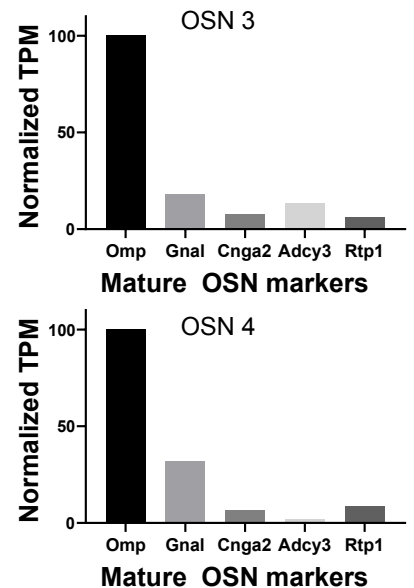
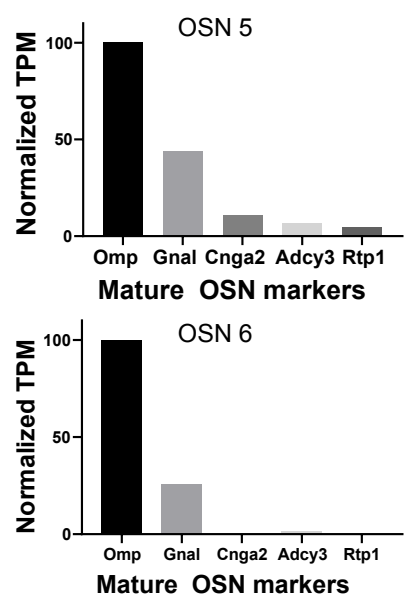

B
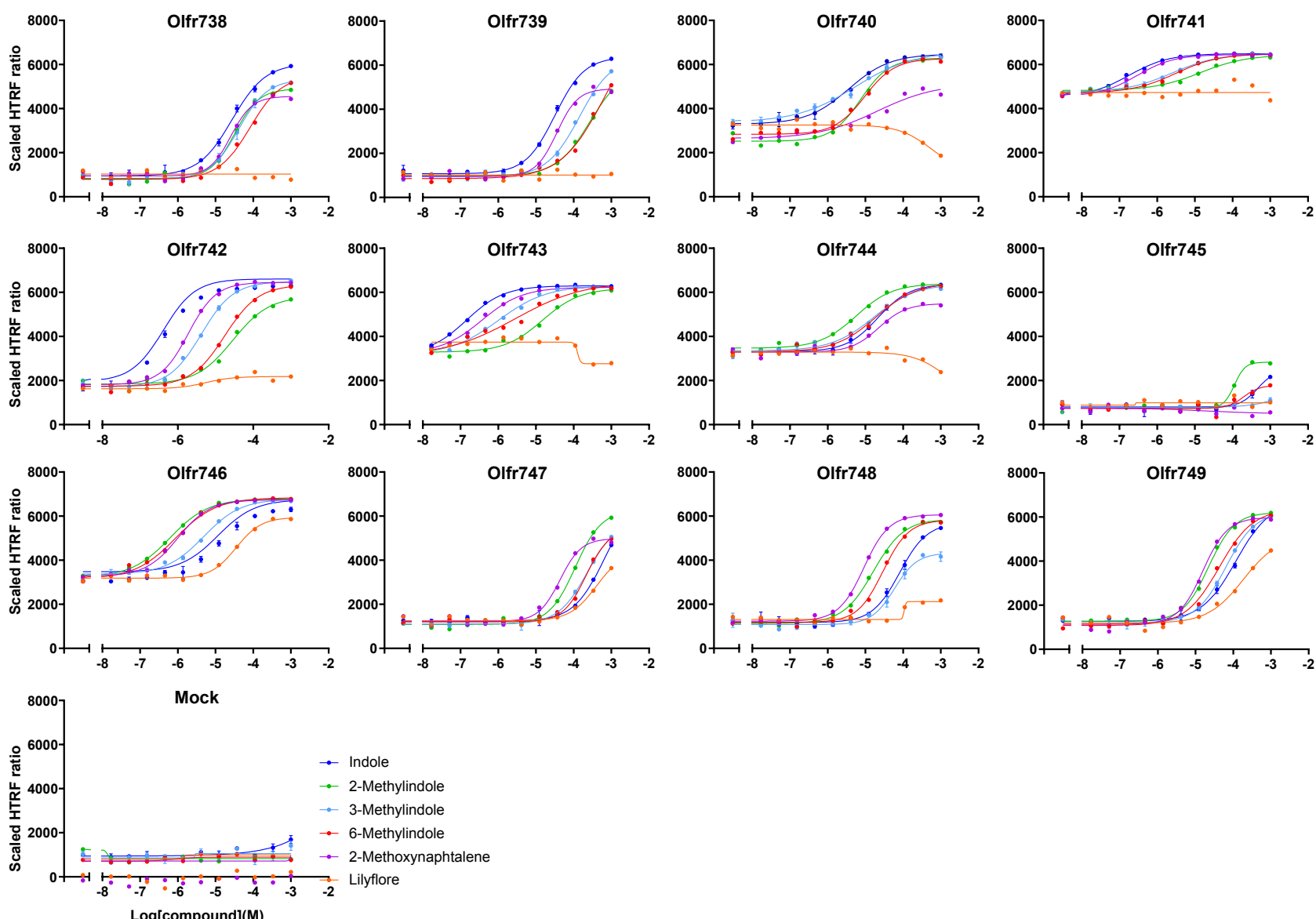

Figure S3. Functional diversity of OR paralog responses to indole-derived compounds summarized in Figure 4. Related to Figure 4. (A) Relative expression levels of mature OSN housekeeping genes: Olfactory Marker Protein (Omp), Golf (Gnal), Cyclic NucleotideGated Channel A2 (Cnga2), Adenylyl Cyclase 3 (Adcy3) and Receptor Transport Protein 1 (Rtp1) for the six cells characterized in Figure 4. Expression levels in transcripts per million reads (TPM) were normalized to OMP. (B) Dose-responses of the 12 OR paralogs with indole (dark blue), 2-methylindole (green), 3-methylindole (light blue), 6-methylindole (red), 2-methoxynaphthalene (purple), Lilyflore ${ }^{8}$ (orange). The empty vector control is shown. Both potencies and efficacies varied and revealed distinct activation levels among phylogenetically related ORs. 2-methoxynaphthalene partially activated Olfr738, Olfr739, Olfr740, and Olfr744 (71-75\% of the maximum indole response), and fully activated Olfr741, Olfr742, and Olfr743. Similarly, Lilyflore ${ }^{\circledR}$ displayed partial agonism across several ORs, and elicited clear inverse agonism on Olfr740, Olfr743 and Olfr744, indicating that these three receptors were constitutively active in our assay. Lilyflore $®$ also activated indole sensitive ORs only at high concentrations for receptors Olfr746 to Olfr749, consistent with the low OSN response overlap observed in Figure 3 between indole and Lilyflore ${ }^{\circledR}$ at several concentrations. Olfr745 and Olfr747 responded too weakly to indole to allow meaningful antagonism assays and so were omitted from subsequent screens. 
A

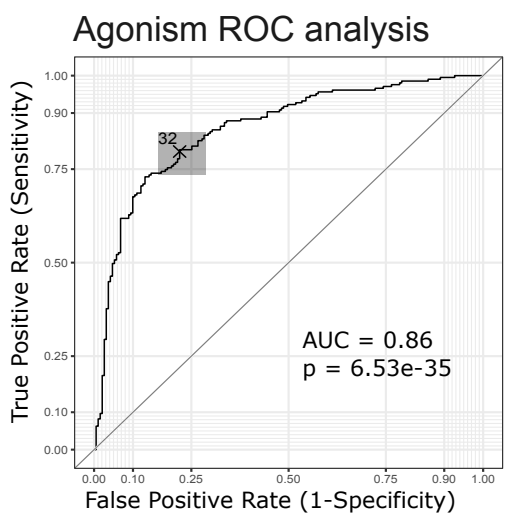

Antagonism ROC analysis

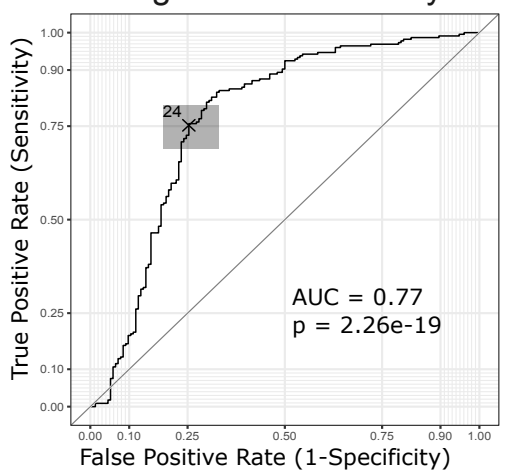

B
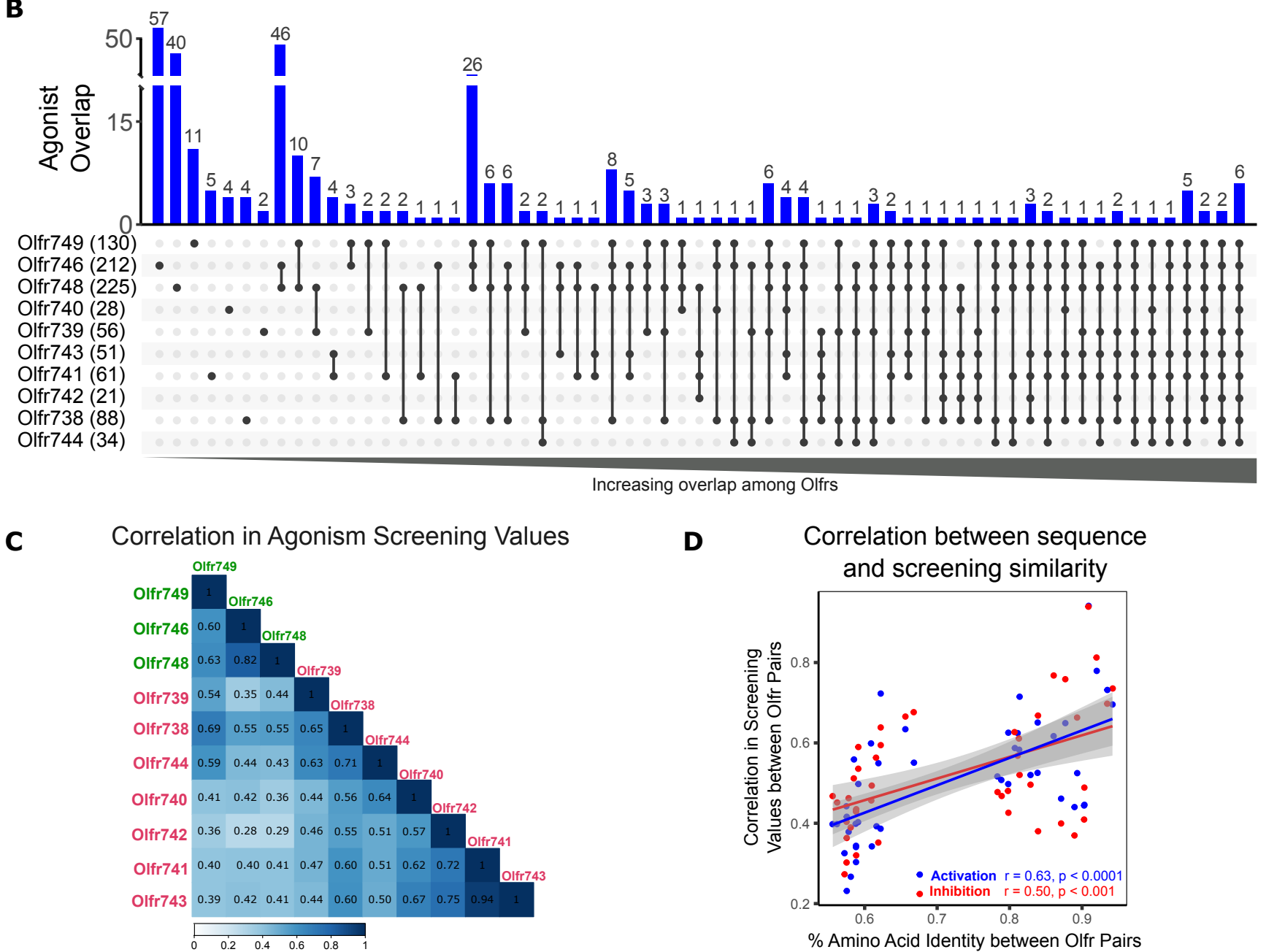

D

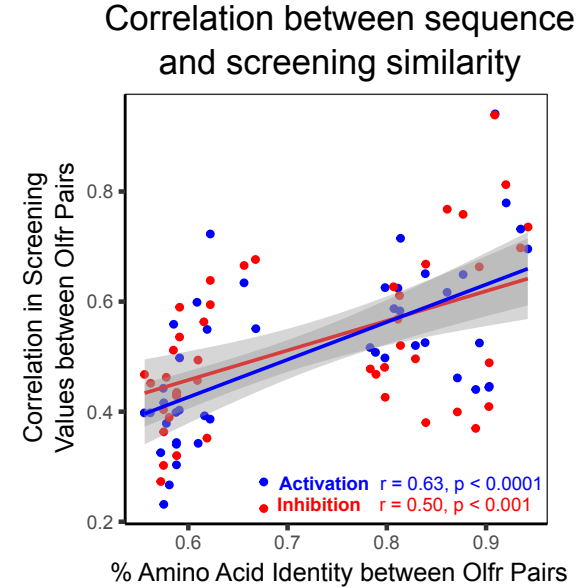

Figure S4. Large-library odorant screens revealed combinatorial agonist logic among closely related indole-sensitive ORs. Related to Figure 5. (A) Statistical Receiver Operating Characteristic (ROC) curves demonstrate that both single-concentration agonist and antagonist screens were able to predict whether compounds would pass an activation or inhibition dose-response experiment. $80 \%$ of true agonists showed activation greater than $32 \%$ for agonist screens and $75 \%$ of true antagonists showed inhibition greater than $24 \%$ for antagonist screens. Confidence interval for the threshold is shown in gray. AUC = area under the curve. (B) An Upset plot showing the number agonists (bar height) which were unique (single dots) or shared (linked dots) among the paralog ORs. (C) A cladogram representing the phylogenetic relationship between the ten indole-sensitive receptors screened is shown in parallel to the pairwise Pearson correlation matrix obtained from the full agonism screening results (all points considered). (D) Scatterplot of the correlation between pairwise percent amino acid identity and pairwise correlations in either inhibition (red points) or activation (blue points) screening results for each OR pair. 

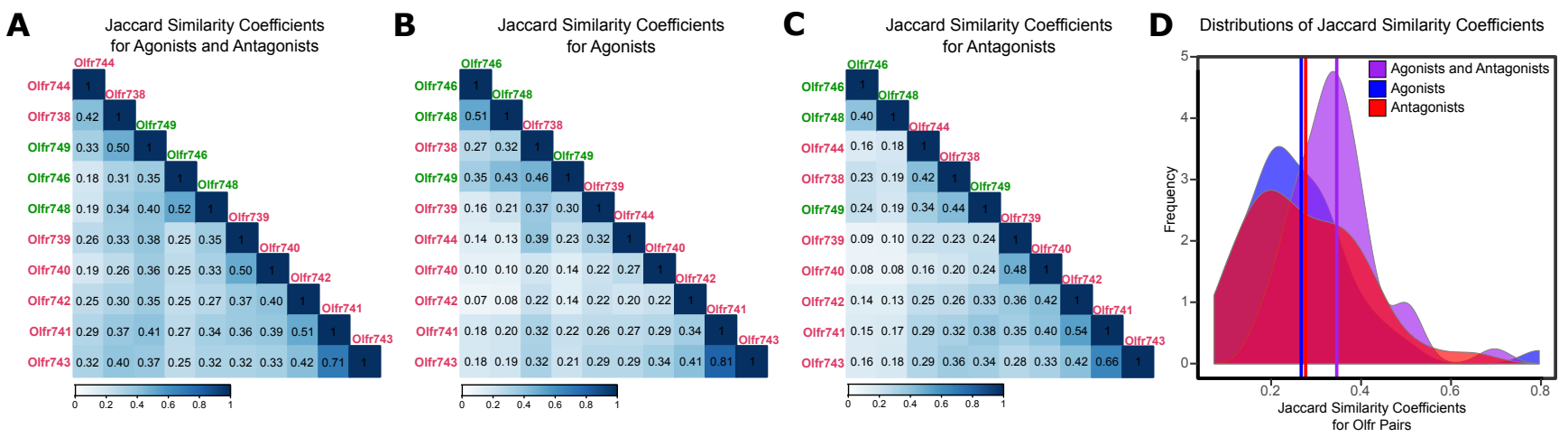

Figure S5. Analysis of function and binding conservation between paralogous ORs for the single-concentration in vitro OR screens shown in Figure 5 and 54 indicated ligand binding was more conserved than binding outcome. Related to Figure 5. The Jaccard similarity coefficients for (A) agonists and antagonists together (i.e. binders), (B) agonists only, or (C) antagonists only, for each pair of ORs. (D) Distributions of pairwise Jaccard similarity coefficients, for all OR pairs, for binders, agonists alone, and antagonists alone. Vertical lines show the median Jaccard similarity coefficient for each set. 


\begin{tabular}{|c|c|c|c|c|c|}
\hline \# Cmpd & Name & FCFC-4 & ECFC-4 & FCFP-4 & ECFP-4 \\
\hline 37 & $\begin{array}{l}\text { Fingerprint, Coefficient: Tanimoto } \\
\text { Indole }\end{array}$ & $\begin{array}{l}\text { Similarity } \\
\text { Target }\end{array}$ & $\begin{array}{l}\text { Similarity } \\
\text { Target }\end{array}$ & $\begin{array}{l}\text { Similarity } \\
\text { Target }\end{array}$ & $\begin{array}{l}\text { Similarity } \\
\text { Target }\end{array}$ \\
\hline 37 & Indole & 1.00 & 1.00 & 1.00 & 1.00 \\
\hline 35 & 2-methoxynaphthalene & 0.78 & 0.72 & 0.21 & 0.28 \\
\hline 30 & Phenethyl Alcohol & 0.71 & 0.59 & 0.17 & 0.18 \\
\hline 34 & Benzyl formate & 0.68 & 0.59 & 0.12 & 0.19 \\
\hline 36 & 3-phenylpropanal & 0.66 & 0.57 & 0.12 & 0.20 \\
\hline 32 & 3-phenyl-1-propanol & 0.66 & 0.55 & 0.12 & 0.17 \\
\hline 29 & Coumarin & 0.62 & 0.63 & 0.09 & 0.19 \\
\hline 18 & Alpha-methylcinnamaldehyde & 0.62 & 0.56 & 0.11 & 0.19 \\
\hline 25 & 5-METHYL-2-INDANMETHANOL & 0.43 & 0.32 & 0.07 & 0.11 \\
\hline 28 & Magnolan & 0.42 & 0.38 & 0.09 & 0.12 \\
\hline 6 & (2-METHYL-2-INDANYL)METHYL ACETATE & 0.41 & 0.41 & 0.06 & 0.15 \\
\hline 20 & Lilyflore & 0.40 & 0.30 & 0.06 & 0.11 \\
\hline 26 & 2,5-DIMETHYL-2-INDANECARBALDEHYDE & 0.40 & 0.31 & 0.09 & 0.16 \\
\hline 16 & (+-)-1,2,5-TRIMETHYL-2-INDANMETHANOL & 0.38 & 0.31 & 0.06 & 0.09 \\
\hline 17 & (+-)-1,2,6-TRIMETHYL-2-INDANMETHANOL & 0.38 & 0.30 & 0.06 & 0.09 \\
\hline 31 & (+-)(2,7-dimethyl-1,2,3,4-tetrahydro-2-napththalenyl)methanol & 0.37 & 0.29 & 0.06 & 0.10 \\
\hline 19 & (+-)-(2,6-dimethyl-1,2,3,4-tetrahydro-2-naphthalenyl)methanol & 0.37 & 0.29 & 0.06 & 0.10 \\
\hline 8 & (+-)-1-(2,5-dimethyl-2,3-dihydro-1H-inden-2-yl)ethanone & 0.36 & 0.29 & 0.10 & 0.13 \\
\hline 22 & 1-(2,5-DIMETHYL-2-INDANYL)-1-ETHANOL & 0.36 & 0.29 & 0.06 & 0.10 \\
\hline 33 & (+-)-2-METHOXYMETHYL-2,5-DIMETHYLINDAN & 0.36 & 0.28 & 0.13 & 0.10 \\
\hline 23 & Lilial & 0.34 & 0.34 & 0.07 & 0.10 \\
\hline 10 & Hivernal Neo & 0.33 & 0.29 & 0.06 & 0.11 \\
\hline 13 & (+-)-5-ISOPROPYL-2-METHYL-2-INDANMETHANOL & 0.32 & 0.27 & 0.06 & 0.10 \\
\hline 27 & (+-)-(2,5-dimethyl-2,3-dihydro-1H-inden-2-yl)methyl acetate & 0.32 & 0.27 & 0.09 & 0.11 \\
\hline 9 & 2-(2,5-DIMETHYL-2-INDANYL)-2-PROPANOL & 0.32 & 0.26 & 0.06 & 0.10 \\
\hline 4 & (+-)-(2,4,5-trimethyl-2,3-dihydro-1H-inden-2-yl)methanol & 0.32 & 0.24 & 0.06 & 0.10 \\
\hline 12 & (+-)-5-TERT-BUTYL-2-METHYL-2-INDANMETHANOL & 0.29 & 0.25 & 0.06 & 0.10 \\
\hline 11 & Alpha-ionone & 0.00 & 0.07 & 0.00 & 0.07 \\
\hline 21 & Methylionone Beta & 0.00 & 0.03 & 0.00 & 0.04 \\
\hline 1 & Z95 & 0.00 & 0.01 & 0.00 & 0.07 \\
\hline 2 & Mayol & 0.00 & 0.00 & 0.00 & 0.00 \\
\hline 5 & Orivone & 0.00 & 0.02 & 0.00 & 0.09 \\
\hline 24 & Dorisyl & 0.00 & 0.02 & 0.00 & 0.03 \\
\hline 3 & 4-t-butylcyclohexanone & 0.00 & 0.02 & 0.00 & 0.10 \\
\hline 14 & Cyclemone A & 0.00 & 0.06 & 0.00 & 0.07 \\
\hline 7 & Neral \& Geranial & 0.00 & 0.00 & 0.00 & 0.03 \\
\hline 15 & Galione & 0.00 & 0.00 & 0.00 & 0.04 \\
\hline
\end{tabular}

Table S1. Molecular fingerprints of compounds identified in Figure 2. Related to Figure 2 . The 36 antagonists tested in Figure 2 were analyzed with four molecular fingerprints: FCFC-4, ECFC-4, FCFP-4 and ECFP-4. The similarity Tanimoto coefficient to Indole is given for all compounds and rank-ordered according to the FCFC-4 similarity score. Darker shades indicate further structural distance from Indole. Approximately a quarter of the compounds exhibit a Tanimoto coefficient lower than 0.1 in all four molecular fingerprint models. 


\begin{tabular}{|c|c|c|c|c|c|}
\hline \# Cmpd & Name & FCFC-4 & ECFC-4 & FCFP-4 & ECFP-4 \\
\hline 37 & $\begin{array}{l}\text { Fingerprint, Coefficient: Tanimoto } \\
\text { Indole }\end{array}$ & $\begin{array}{l}\text { Similarity } \\
\text { Target }\end{array}$ & $\begin{array}{l}\text { Similarity } \\
\text { Target }\end{array}$ & $\begin{array}{l}\text { Similarity } \\
\text { Target }\end{array}$ & $\begin{array}{l}\text { Similarity } \\
\text { Target }\end{array}$ \\
\hline 37 & Indole & 1.00 & 1.00 & 1.00 & 1.00 \\
\hline 41 & Isopropyl Quinoline & 0.69 & 0.57 & 0.12 & 0.19 \\
\hline 52 & Trifernal & 0.62 & 0.57 & 0.11 & 0.18 \\
\hline 55 & Phenylethyl salicylate & 0.61 & 0.57 & 0.09 & 0.15 \\
\hline 52 & 2-Phenylethyl acetate & 0.60 & 0.54 & 0.10 & 0.17 \\
\hline 42 & tert-butylphenol, 2- & 0.58 & 0.48 & 0.11 & 0.17 \\
\hline 59 & Rosinol Cryst & 0.53 & 0.46 & 0.10 & 0.19 \\
\hline 58 & 3-methyl-5-phenylpentanal & 0.52 & 0.50 & 0.10 & 0.16 \\
\hline 54 & Rhubafuran & 0.52 & 0.51 & 0.10 & 0.16 \\
\hline 56 & Methyl anisate & 0.52 & 0.41 & 0.10 & 0.12 \\
\hline 53 & satinaldehyde & 0.47 & 0.43 & 0.07 & 0.11 \\
\hline 65 & Amyl Phenylacetate & 0.46 & 0.46 & 0.09 & 0.15 \\
\hline 20 & Lilyflore & 0.40 & 0.30 & 0.06 & 0.11 \\
\hline 49 & Bourgeonal & 0.38 & 0.36 & 0.07 & 0.11 \\
\hline 64 & Cascalone & 0.37 & 0.27 & 0.06 & 0.16 \\
\hline 23 & Lilial & 0.34 & 0.34 & 0.07 & 0.10 \\
\hline 39 & Transluzone & 0.34 & 0.25 & 0.06 & 0.16 \\
\hline 10 & Hivernal Neo & 0.33 & 0.29 & 0.06 & 0.11 \\
\hline 45 & Sclarene & 0.07 & 0.03 & 0.04 & 0.09 \\
\hline 38 & Wolfwood & 0.00 & 0.11 & 0.00 & 0.06 \\
\hline 40 & Cedroxyde & 0.00 & 0.10 & 0.00 & 0.05 \\
\hline 66 & Alpha-Damascone & 0.00 & 0.07 & 0.00 & 0.07 \\
\hline 11 & Alpha-ionone & 0.00 & 0.07 & 0.00 & 0.07 \\
\hline 47 & Lyral & 0.00 & 0.07 & 0.00 & 0.06 \\
\hline 63 & Neobutenone alpha & 0.00 & 0.07 & 0.00 & 0.06 \\
\hline 62 & Cashmeran & 0.00 & 0.04 & 0.00 & 0.05 \\
\hline 43 & Violet At & 0.00 & 0.03 & 0.00 & 0.05 \\
\hline 3 & 4-t-butylcyclohexanone & 0.00 & 0.02 & 0.00 & 0.10 \\
\hline 5 & Orivone & 0.00 & 0.02 & 0.00 & 0.09 \\
\hline 57 & Whiskey Lactone $\mathrm{K}$ & 0.00 & 0.02 & 0.00 & 0.05 \\
\hline 1 & Z95 & 0.00 & 0.01 & 0.00 & 0.07 \\
\hline 60 & Plicatone & 0.00 & 0.01 & 0.00 & 0.05 \\
\hline 44 & Caryophyllene oxide & 0.00 & 0.01 & 0.00 & 0.02 \\
\hline 48 & Cachalox & 0.00 & 0.00 & 0.03 & 0.00 \\
\hline 50 & Rose oxide & 0.00 & 0.00 & 0.00 & 0.03 \\
\hline 61 & Decyl acetate & 0.00 & 0.00 & 0.00 & 0.03 \\
\hline 46 & Z 11 Crude Dist & 0.00 & 0.00 & 0.00 & 0.02 \\
\hline
\end{tabular}

Table S2.Molecular fingerprint of compounds identified in Figure 6. Related to Figure 6 . The 36 antagonists tested in Figure 6 against all 10 indole-sensitive ORs were analyzed with four molecular fingerprints: FCFC-4, ECFC-4, FCFP-4 and ECFP-4. The similarity Tanimoto coefficient to indole is given for all compounds and rank-ordered according to the FCFC-4 similarity score. Darker shades indicate further structural distance from Indole. Approximately half the compounds exhibit a Tanimoto coefficient lower than 0.1 in all molecular four molecular fingerprint models. 


\begin{tabular}{|c|c|c|c|c|c|}
\hline \# Cmpd & Name & IUPAC & Smiles (Incl. mixtures) & $\begin{array}{l}\text { Vapor Pressure } \\
{[\mathrm{mmHg}]}\end{array}$ & $\begin{array}{l}\text { Saturation } \\
\text { Conc. [uM] }\end{array}$ \\
\hline 1 & Z95 & 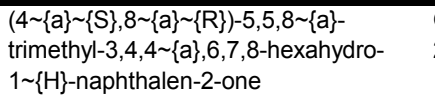 & $\begin{array}{l}\mathrm{O}=\mathrm{C}(\mathrm{CC}[\mathrm{C} @ @] 12[\mathrm{H}]) \mathrm{C}[\mathrm{C} @ @] 1(\mathrm{CCCC} \\
2(\mathrm{C}) \mathrm{C}) \mathrm{C}\end{array}$ & 0.0106 & 0.570 \\
\hline 2 & Mayol & (4-propan-2-ylcyclohexyl)methanol & $\mathrm{CC}(\mathrm{C})[\mathrm{C} @ \mathrm{H}] 1 \mathrm{CC}[\mathrm{C} @ @ \mathrm{H}](\mathrm{CO}) \mathrm{CC} 1$ & 0.0113 & 0.608 \\
\hline 3 & 4-t-butylcyclohexanone & 4- \{tert\}-butylcyclohexan-1-one & $\mathrm{CC}(\mathrm{C})(\mathrm{C}) \mathrm{C}(\mathrm{CC} 1) \mathrm{CCC} 1=\mathrm{O}$ & 0.173 & 9.304 \\
\hline 4 & $\begin{array}{l}\text { (+-)-(2,4,5-trimethyl-2,3-dihydro- } \\
\text { 1H-inden-2-yl)methanol }\end{array}$ & $\begin{array}{l}\text { (2,4,5-trimethyl-1,3-dihydroinden-2- } \\
\text { yl)methanol }\end{array}$ & $\mathrm{CC} 1=\mathrm{C}(\mathrm{C}) \mathrm{C} 2=\mathrm{C}(\mathrm{CC}(\mathrm{C})(\mathrm{CO}) \mathrm{C} 2) \mathrm{C}=\mathrm{C} 1$ & 3.12E-05 & 0.002 \\
\hline 5 & Orivone & $\begin{array}{l}\text { 4-(2-methylbutan-2-yl)cyclohexan-1- } \\
\text { one }\end{array}$ & $\mathrm{CC}(\mathrm{C}(\mathrm{CC} 1) \mathrm{CCC} 1=\mathrm{O})(\mathrm{CC}) \mathrm{C}$ & 0.121 & 6.508 \\
\hline 6 & $\begin{array}{l}\text { (2-METHYL-2- } \\
\text { INDANYL)METHYL ACETATE }\end{array}$ & $\begin{array}{l}\text { (2-methyl-1,3-dihydroinden-2-yl)methyl } \\
\text { acetate }\end{array}$ & $\mathrm{CC} 1(\mathrm{COC}(\mathrm{C})=\mathrm{O}) \mathrm{CC} 2=\mathrm{C}(\mathrm{C} 1) \mathrm{C}=\mathrm{CC}=\mathrm{C} 2$ & 0.00228 & 0.123 \\
\hline 7 & Citral & 3,7-dimethylocta-2,6-dienal & $\begin{array}{l}\mathrm{CC}(\mathrm{C})=\mathrm{CCC} / \mathrm{C}(\mathrm{C})=\mathrm{C} / \mathrm{C}=\mathrm{O} \cdot \mathrm{CC}(\mathrm{C})=\mathrm{CCC} / \\
\mathrm{C}(\mathrm{C})=\mathrm{ClC}=\mathrm{O}\end{array}$ & 0.0913 & 4.910 \\
\hline 8 & $\begin{array}{l}\text { (+-)-1-(2,5-dimethyl-2,3-dihydro- } \\
\text { 1H-inden-2-yl)ethanone }\end{array}$ & $\begin{array}{l}\text { 1-(2,5-dimethyl-1,3-dihydroinden-2- } \\
\text { yl)ethanone }\end{array}$ & $\mathrm{CC} 1=\mathrm{CC}(\mathrm{CC}(\mathrm{C}(\mathrm{C})=\mathrm{O})(\mathrm{C}) \mathrm{C} 2)=\mathrm{C} 2 \mathrm{C}=\mathrm{C} 1$ & 0.00303 & 0.163 \\
\hline 9 & $\begin{array}{l}\text { 2-(2,5-DIMETHYL-2-INDANYL)-2- } \\
\text { PROPANOL }\end{array}$ & $\begin{array}{l}\text { 2-(2,5-DIMETHYL-2-INDANYL)-2- } \\
\text { PROPANOL }\end{array}$ & $\mathrm{Cc} 1 \mathrm{ccc} 2 \mathrm{c}(\mathrm{c} 1) \mathrm{CC}(\mathrm{C})(\mathrm{C} 2) \mathrm{C}(\mathrm{C})(\mathrm{C}) \mathrm{O}$ & 7.32E-05 & 0.004 \\
\hline 10 & Hivernal Neo & $\begin{array}{l}\text { 3-(1,1-dimethyl-2,3-dihydroinden-4- } \\
\text { yl)propanal;3-(1,1-dimethyl-2,3- } \\
\text { dihydroinden-5-yl)propanal;3-(3,3- } \\
\text { dimethyl-1,2-dihydroinden-5- } \\
\text { yl)propanal }\end{array}$ & $\begin{array}{l}\mathrm{O}=\mathrm{CCCC} 1=\mathrm{CC} 2=\mathrm{C}(\mathrm{CCC} 2(\mathrm{C}) \mathrm{C}) \mathrm{C}=\mathrm{C} 1 . \mathrm{C} \\
\mathrm{C} 3(\mathrm{C}) \mathrm{CCC} 4=\mathrm{C} 3 \mathrm{C}=\mathrm{CC}=\mathrm{C} 4 \mathrm{CCC}=\mathrm{O} \cdot \mathrm{O}=\mathrm{C} \\
\mathrm{CCC} 5=\mathrm{CC}(\mathrm{CCC}(\mathrm{C}) \mathrm{C})=\mathrm{C} 6 \mathrm{C}=\mathrm{C} 5\end{array}$ & 0.000655 & 0.035 \\
\hline 11 & Alpha-ionone & $\begin{array}{l}\text { 4-(2,6,6-trimethylcyclohex-2-en-1-yl)but- } \\
\text { 3-en-2-one }\end{array}$ & $\mathrm{CC} 1(\mathrm{C}) \mathrm{C}(/ \mathrm{C}=\mathrm{C} / \mathrm{C}(\mathrm{C})=\mathrm{O}) \mathrm{C}(\mathrm{C})=\mathrm{CCC} 1$ & 0.0272 & 1.463 \\
\hline 12 & $\begin{array}{l}\text { (+-)-5-TERT-BUTYL-2-METHYL- } \\
\text { 2-INDANMETHANOL }\end{array}$ & $\begin{array}{l}\text { (+-)-5-TERT-BUTYL-2-METHYL-2- } \\
\text { INDANMETHANOL }\end{array}$ & $\mathrm{CC}(\mathrm{C})(\mathrm{C}) \mathrm{c} 1 \mathrm{ccc} 2 \mathrm{c}(\mathrm{c} 1) \mathrm{CC}(\mathrm{C})(\mathrm{CO}) \mathrm{C} 2$ & 1.00E-05 & 0.001 \\
\hline 13 & $\begin{array}{l}\text { (+-)-5-ISOPROPYL-2-METHYL-2- } \\
\text { INDANMETHANOL }\end{array}$ & $\begin{array}{l}\text { (+-)-5-ISOPROPYL-2-METHYL-2- } \\
\text { INDANMETHANOL }\end{array}$ & $\mathrm{CC}(\mathrm{C}) \mathrm{c} 1 \mathrm{ccc} 2 \mathrm{c}(\mathrm{c} 1) \mathrm{CC}(\mathrm{C})(\mathrm{CO}) \mathrm{C} 2$ & 2.33E-05 & 0.001 \\
\hline 14 & Cyclemone A & $\begin{array}{l}\text { 8,8-dimethyl-2,3,4,6,7,8 }\{\text { a }\} \text {-hexahydro- } \\
1 \sim\{\mathrm{H}\} \text {-naphthalene-2-carbaldehyde;8,8- } \\
\text { dimethyl-2,3,5,6,7,8 \{a\}-hexahydro- } \\
1 \sim\{\mathrm{H}\} \text {-naphthalene-2-carbaldehyde;8,8- } \\
\text { dimethyl-2,3,4,5,6,7-hexahydro-1 }\{\mathrm{H}\}- \\
\text { naphthalene-2-carbaldehyde;2,2- } \\
\text { dimethyl-octahydro-1 } \sim \mathrm{H}\}-2,4 \sim\{\mathrm{a}\}- \\
\text { methanonapthalen-8-one }\end{array}$ & $\begin{array}{l}\mathrm{CC} 1(\mathrm{C}) \mathrm{CCC}=\mathrm{C} 2 \mathrm{C} 1 \mathrm{CC}(\mathrm{C}=\mathrm{O}) \mathrm{CC} 2 . \mathrm{O}=\mathrm{C} \\
\mathrm{C} 3 \mathrm{CCC}(\mathrm{CCC} 4)=\mathrm{C}(\mathrm{C} 4(\mathrm{C}) \mathrm{C}) \mathrm{C} 3 . \mathrm{O}=\mathrm{CC} 5 \mathrm{C} \\
\mathrm{C}=\mathrm{C}(\mathrm{CCC} 6) \mathrm{C}(\mathrm{C} 6(\mathrm{C}) \mathrm{C}) \mathrm{C} 5 . \mathrm{O}=\mathrm{C}(\mathrm{C} 7 \mathrm{CCC} \\
\mathrm{C} 8(\mathrm{C}) \mathrm{C}) \mathrm{C} 9 \mathrm{CCC} 78 \mathrm{C} 9\end{array}$ & 0.00585 & 0.315 \\
\hline 15 & Galione & $\begin{array}{l}\text { 1-(2,2-dimethyl-6- } \\
\text { methylidenecyclohexyl)pent-1-en-3- } \\
\text { one;3-methyl-4-(2,6,6-trimethylcyclohex- } \\
\text { 2-en-1-yl)but-3-en-2-one;1-(2,6,6- } \\
\text { trimethylcyclohexen-1-yl)pent-1-en-3- } \\
\text { one;1-(2,6,6-trimethylcyclohex-2-en-1- } \\
\text { yl)pent-1-en-3-one }\end{array}$ & $\begin{array}{l}\mathrm{CC} 1(\mathrm{C}) \mathrm{C}(/ \mathrm{C}=\mathrm{C} / \mathrm{C}(\mathrm{CC})=\mathrm{O})=\mathrm{C}(\mathrm{C}) \mathrm{CCC} 1 . \mathrm{C} \\
\mathrm{C} 2(\mathrm{C}) \mathrm{C}(/ \mathrm{C}=\mathrm{C}(\mathrm{C}(\mathrm{C})=\mathrm{O}) \backslash \mathrm{C}) \mathrm{C}(\mathrm{C})=\mathrm{CCC} 2 . \mathrm{C} \\
=\mathrm{C}(\mathrm{CCCC} 3(\mathrm{C}) \mathrm{C}) \mathrm{C} 3 / \mathrm{C}=\mathrm{C} / \mathrm{C}(\mathrm{CC})=0 . C C 4 \\
(\mathrm{C}) \mathrm{CCC}=\mathrm{C}(\mathrm{C}) \mathrm{C} 4 / \mathrm{C}=\mathrm{C} / \mathrm{C}(\mathrm{CC})=\mathrm{O}\end{array}$ & 0.00449 & 0.241 \\
\hline 16 & $\begin{array}{l}\text { (+-)-1,2,5-TRIMETHYL-2- } \\
\text { INDANMETHANOL }\end{array}$ & $\begin{array}{l}\text { (+-)-1,2,5-TRIMETHYL-2- } \\
\text { INDANMETHANOL }\end{array}$ & $\mathrm{CC} 1 \mathrm{c} 2 \mathrm{ccc}(\operatorname{cc} 2 \mathrm{CC} 1(\mathrm{C}) \mathrm{CO}) \mathrm{C}$ & $4.86 \mathrm{E}-05$ & 0.003 \\
\hline 17 & $\begin{array}{l}\text { (+-)-1,2,6-TRIMETHYL-2- } \\
\text { INDANMETHANOL }\end{array}$ & $\begin{array}{l}\text { (+-)-1,2,6-TRIMETHYL-2- } \\
\text { INDANMETHANOL }\end{array}$ & $\mathrm{CC} 1 \mathrm{c} 2 \mathrm{cc}(\operatorname{ccc} 2 \mathrm{CC} 1(\mathrm{C}) \mathrm{CO}) \mathrm{C}$ & 4.86E-05 & 0.003 \\
\hline 18 & Alpha-methylcinnamaldehyde & 2-methyl-3-phenylprop-2-enal & $\mathrm{C} / \mathrm{C}(\mathrm{C}=\mathrm{O})=\mathrm{C} \backslash \mathrm{C} 1=\mathrm{CC}=\mathrm{CC}=\mathrm{C} 1$ & 0.025 & 1.345 \\
\hline 19 & $\begin{array}{l}(+-)-(2,6-\text { dimethyl-1,2,3,4- } \\
\text { tetrahydro-2- } \\
\text { naphthalenyl)methanol }\end{array}$ & $\begin{array}{l}\text { (2,6-dimethyl-3,4-dihydro-1 }\{\mathrm{H}\} \text { - } \\
\text { naphthalen-2-yl)methanol }\end{array}$ & $\mathrm{CC} 1=\mathrm{CC}=\mathrm{C} 2 \mathrm{CC}(\mathrm{CO})(\mathrm{C}) \mathrm{CCC} 2=\mathrm{C} 1$ & 3.21E-05 & 0.002 \\
\hline 20 & Lilyflore & $\begin{array}{l}\text { (2,5-dimethyl-1,3-dihydroinden-2- } \\
\text { yl)methanol }\end{array}$ & $\mathrm{CC} 1=\mathrm{CC}(\mathrm{CC}(\mathrm{C})(\mathrm{CO}) \mathrm{C} 2)=\mathrm{C} 2 \mathrm{C}=\mathrm{C} 1$ & 0.000112 & 0.006 \\
\hline 21 & Methylionone Beta & $\begin{array}{l}\text { 1-(2,6,6-trimethylcyclohexen-1-yl)pent-1. } \\
\text { en-3-one }\end{array}$ & $\mathrm{CC} 1(\mathrm{C}) \mathrm{C}(/ \mathrm{C}=\mathrm{C} / \mathrm{C}(\mathrm{CC})=\mathrm{O})=\mathrm{C}(\mathrm{C}) \mathrm{CCC} 1$ & 0.00449 & 0.241 \\
\hline 22 & $\begin{array}{l}\text { 1-(2,5-DIMETHYL-2-INDANYL)-1- } \\
\text { ETHANOL }\end{array}$ & $\begin{array}{l}\text { 1-(2,5-DIMETHYL-2-INDANYL)-1- } \\
\text { ETHANOL }\end{array}$ & $\mathrm{CC}(\mathrm{O}) \mathrm{C} 1(\mathrm{C}) \mathrm{Cc} 2 \mathrm{ccc}(\mathrm{cc} 2 \mathrm{C} 1) \mathrm{C}$ & 0.000106 & 0.006 \\
\hline 23 & Lilial & $\begin{array}{l}\text { 3-(4- \{tert\}-butylphenyl)-2- } \\
\text { methylpropanal }\end{array}$ & $\mathrm{CC}(\mathrm{C})(\mathrm{C}) \mathrm{C} 1=\mathrm{CC}=\mathrm{C}(\mathrm{CC}(\mathrm{C}=\mathrm{O}) \mathrm{C}) \mathrm{C}=\mathrm{C} 1$ & 0.00358 & 0.193 \\
\hline 24 & Dorisyl & (4- \{tert\}-butylcyclohexyl) acetate & $\begin{array}{l}\mathrm{CC}(\mathrm{C})(\mathrm{C})[\mathrm{C} @ \mathrm{H}] 1 \mathrm{CC}[\mathrm{C} @ \mathrm{H}](\mathrm{OC}(\mathrm{C})=\mathrm{O}) \mathrm{C} \\
\mathrm{C} 1 . \mathrm{CC}(\mathrm{C})(\mathrm{C})[\mathrm{C} @ \mathrm{H}] 2 \mathrm{CC}[\mathrm{C} @ @ \mathrm{H}](\mathrm{OC}(\mathrm{C} \\
=\mathrm{O}) \mathrm{CC} 2\end{array}$ & 0.0685 & 3.684 \\
\hline
\end{tabular}




\begin{tabular}{|c|c|c|c|c|c|}
\hline 25 & 5-METHYL-2-INDANMETHANOL & $\begin{array}{l}\text { (5-methyl-2,3-dihydro-1 }\{\mathrm{H}\} \text {-inden-2- } \\
\text { yl)methanol }\end{array}$ & $\mathrm{CC} 1=\mathrm{CC}(\mathrm{CC}(\mathrm{CO}) \mathrm{C} 2)=\mathrm{C} 2 \mathrm{C}=\mathrm{C} 1$ & 0.000231 & 0.012 \\
\hline 26 & $\begin{array}{l}\text { 2,5-DIMETHYL-2- } \\
\text { INDANECARBALDEHYDE }\end{array}$ & $\begin{array}{l}\text { 2,5-DIMETHYL-2- } \\
\text { INDANECARBALDEHYDE }\end{array}$ & $\mathrm{Cc} 1 \mathrm{ccc} 2 \mathrm{c}(\mathrm{c} 1) \mathrm{CC}(\mathrm{C})(\mathrm{C} 2) \mathrm{C}=\mathrm{O}$ & 0.0053 & 0.285 \\
\hline 27 & $\begin{array}{l}\text { (+-)-(2,5-dimethyl-2,3-dihydro-1 } \mathrm{H}- \\
\text { inden-2-yl)methyl acetate }\end{array}$ & $\begin{array}{l}\text { (+-)-(2,5-dimethyl-2,3-dihydro-1H-inden- } \\
\text { 2-yl)methyl acetate }\end{array}$ & $-\mathrm{CC}(=\mathrm{O}) \mathrm{OCC} 1(\mathrm{C}) \mathrm{Cc} 2 \operatorname{ccc}(\operatorname{cc} 2 \mathrm{C} 1) \mathrm{C}$ & 0.000845 & 0.045 \\
\hline 28 & Magnolan & $\begin{array}{l}\text { 2,4-dimethyl-4,4 \{a\},5,9 \{b\}-} \\
\text { tetrahydroindeno[1,2-d][1,3]dioxine }\end{array}$ & $\begin{array}{l}\mathrm{CC} 1 \mathrm{C} 2 \mathrm{CC} 3=\mathrm{CC}=\mathrm{CC}=\mathrm{C} 3 \mathrm{C} 2 \mathrm{OC}(\mathrm{C}) \mathrm{O} 1 . \mathrm{C} \\
\mathrm{C} 4 \mathrm{C} 5 \mathrm{CC} 6=\mathrm{CC}=\mathrm{CC}=\mathrm{C} 6 \mathrm{C} 5 \mathrm{OC}(\mathrm{C}) \mathrm{O} 4\end{array}$ & 0.00156 & 0.084 \\
\hline 29 & Coumarin & chromen-2-one & $\mathrm{O}=\mathrm{C} 1 \mathrm{OC} 2=\mathrm{CC}=\mathrm{CC}=\mathrm{C} 2 \mathrm{C}=\mathrm{C} 1$ & 0.000657 & 0.035 \\
\hline 30 & Phenethyl Alcohol & 2-phenylethanol & $\mathrm{OCCC} 1=\mathrm{CC}=\mathrm{CC}=\mathrm{C} 1$ & 0.0243 & 1.307 \\
\hline 31 & $\begin{array}{l}\text { (+-)(2,7-dimethyl-1,2,3,4- } \\
\text { tetrahydro-2- } \\
\text { napththalenyl)methanol }\end{array}$ & $\begin{array}{l}\text { (2,7-dimethyl-3,4-dihydro-1 \{H\}- } \\
\text { naphthalen-2-yl)methanol }\end{array}$ & $\mathrm{CC} 1=\mathrm{CC}(\mathrm{C} 2)=\mathrm{C}(\mathrm{CCC} 2(\mathrm{CO}) \mathrm{C}) \mathrm{C}=\mathrm{C} 1$ & $3.21 \mathrm{E}-05$ & 0.002 \\
\hline 32 & 3-phenyl-1-propanol & 3-phenylpropan-1-ol & $\mathrm{OCCCC} 1=\mathrm{CC}=\mathrm{CC}=\mathrm{C} 1$ & 0.00848 & 0.456 \\
\hline 33 & $\begin{array}{l}\text { (+-)-2-METHOXYMETHYL-2,5- } \\
\text { DIMETHYLINDAN }\end{array}$ & $\begin{array}{l}\text { 2-(methoxymethyl)-2,5-dimethyl-1,3- } \\
\text { dihydroindene }\end{array}$ & $\mathrm{CC} 1=\mathrm{CC}(\mathrm{CC}(\mathrm{C})(\mathrm{COC}) \mathrm{C} 2)=\mathrm{C} 2 \mathrm{C}=\mathrm{C} 1$ & 0.00934 & 0.502 \\
\hline 34 & Benzyl formate & benzyl formate & $\mathrm{O}=\mathrm{COCC} 1=\mathrm{CC}=\mathrm{CC}=\mathrm{C} 1$ & 0.31 & 16.672 \\
\hline 35 & 2-methoxynaphthalene & 2-methoxynaphthalene & $\mathrm{COC} 1=\mathrm{CC} 2=\mathrm{C}(\mathrm{C}=\mathrm{C} 1) \mathrm{C}=\mathrm{CC}=\mathrm{C} 2$ & 0.00267 & 0.144 \\
\hline 36 & 3-phenylpropanal & 3-phenylpropanal & $\mathrm{O}=\mathrm{CCCC} 1=\mathrm{CC}=\mathrm{CC}=\mathrm{C} 1$ & 0.0628 & 3.377 \\
\hline 37 & Indole & 1 \{H\}-indole & $\mathrm{C} 1(\mathrm{C}=\mathrm{CC}=\mathrm{C} 2)=\mathrm{C} 2 \mathrm{NC}=\mathrm{C} 1$ & 0.0121 & 0.651 \\
\hline 38 & Wolfwood & $\begin{array}{l}(1 \sim\{S\}, 2 \sim\{R\}, 3 \sim\{R\}, 5 \sim\{R\})-2,6,6- \\
\text { trimethylspiro[bicyclo[3.1.1] } \\
\text { cyclohex-2-ene]-1'-one }\end{array}$ & $\begin{array}{l}\mathrm{CC} 1(\mathrm{C})[\mathrm{C} @ \mathrm{H}] 2 \mathrm{C}[\mathrm{C} @ @ \mathrm{H}] 1 \mathrm{C}[\mathrm{C} @](\mathrm{C}=\mathrm{C} \\
\cdot \mathrm{C} 3=\mathrm{O})(\mathrm{CC} 3)[\mathrm{C} @ \mathrm{H}] 2 \mathrm{C}\end{array}$ & 0.00129 & 0.069 \\
\hline 39 & Transluzone & 7- \{tert\}-butyl-1,5-benzodioxepin-3-one & $\begin{array}{l}\mathrm{CC}(\mathrm{C} 1=\mathrm{CC}=\mathrm{C}(\mathrm{OC} 2) \mathrm{C}(\mathrm{OCC} 2=\mathrm{O})=\mathrm{C} 1)(\mathrm{C} \\
\mathrm{C} C\end{array}$ & $9.41 \mathrm{E}-05$ & 0.005 \\
\hline 40 & Cedroxyde & $\begin{array}{l}\text { 1,4,8-trimethyl-13- } \\
\text { oxabicyclo[10.1.0]trideca-4,8- } \\
\text { diene;1,5,8-trimethyl-13- } \\
\text { oxabicyclo[10.1.0]trideca-4,8-diene }\end{array}$ & $\begin{array}{l}\mathrm{CC} 12 \mathrm{C}(\mathrm{O} 2) \mathrm{CC} / \mathrm{C}=\mathrm{C}(\mathrm{C}) / \mathrm{CC} / \mathrm{C}(\mathrm{C})=\mathrm{ClCC} \\
\text { 1.CC34C }(\mathrm{O} 4) \mathrm{CC} / \mathrm{C}=\mathrm{C}(\mathrm{C}) / \mathrm{CC} / \mathrm{C}=\mathrm{C}(\mathrm{C}) \backslash \mathrm{C} \\
\mathrm{C} 3\end{array}$ & 0.00254 & 0.137 \\
\hline 41 & Isopropyl Quinoline & $\begin{array}{l}\text { 6-propan-2-ylquinoline;8-propan-2- } \\
\text { ylquinoline }\end{array}$ & $\begin{array}{l}\mathrm{CC}(\mathrm{C}) \mathrm{C} 1=\mathrm{CC} 2=\mathrm{C}(\mathrm{C}=\mathrm{C} 1) \mathrm{N}=\mathrm{CC}=\mathrm{C} 2 . \mathrm{CC}( \\
\mathrm{C}) \mathrm{C} 3=\mathrm{CC}=\mathrm{CC} 4=\mathrm{C} 3 \mathrm{~N}=\mathrm{CC}=\mathrm{C} 4\end{array}$ & 0.00227 & 0.122 \\
\hline 42 & Tert-butylphenol, 2- & 2- \{tert\}-butylphenol & $\mathrm{OC} 1=\mathrm{CC}=\mathrm{CC}=\mathrm{C} 1 \mathrm{C}(\mathrm{C})(\mathrm{C}) \mathrm{C}$ & 0.0531 & 2.856 \\
\hline 43 & Violet At & $\begin{array}{l}\text { 4-(2,6,6-trimethylcyclohexen-1-yl)but-3- } \\
\text { en-2-one;4-(2,6,6-trimethylcyclohex-2- } \\
\text { en-1-yl)but-3-en-2-one }\end{array}$ & $\begin{array}{l}C C 1(C) C(/ C=C / C(C)=O)=C(C) C C C 1 . C C \\
2(C) C(/ C=C / C(C)=O) C(C)=C C C 2\end{array}$ & 0.0227 & 1.221 \\
\hline 44 & Caryophyllene oxide & $\begin{array}{l}(1 \sim\{R\}, 4 \sim\{S\}, 6 \sim\{R\}, 10 \sim\{R\})-4,12,12- \\
\text { trimethyl-9-methylidene-5- } \\
\text { oxatricyclo[8.2.0.0^\{4,6\}]dodecane }\end{array}$ & $\begin{array}{l}{[\mathrm{H}][\mathrm{C} @] 1(\mathrm{CC} 2(\mathrm{C}) \mathrm{C})[\mathrm{C} @ @] 2([\mathrm{H}]) \mathrm{CC}[\mathrm{C}} \\
@](\mathrm{O} 3)(\mathrm{C})[\mathrm{C} @] 3([\mathrm{H}]) \mathrm{CCC} 1=\mathrm{C}\end{array}$ & 0.01 & 0.538 \\
\hline 45 & Sclarene & $\begin{array}{l}4,5,6,7,8,9,10,11,12,13- \\
\text { decahydrocyclododeca[d][1,3]oxazole }\end{array}$ & $\mathrm{C} 1(\mathrm{OC}=\mathrm{N} 2)=\mathrm{C} 2 \mathrm{Ccccccccc} 1$ & 0.000965 & 0.052 \\
\hline 46 & Z 11 Crude Dist & 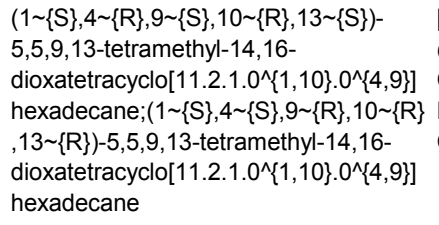 & $\begin{array}{l}{[\mathrm{H}][\mathrm{C} @] 1(\mathrm{C}(\mathrm{C})(\mathrm{C}) \mathrm{CCC} 2)[\mathrm{C} @ @] 2(\mathrm{C})[\mathrm{C}} \\
\text { @@H](CC[C@@ } 9(\mathrm{C}) \mathrm{O} 4)[\mathrm{C} @] 4(\mathrm{CO} 3) \\
\mathrm{CC} 1 . \mathrm{CC} 5(\mathrm{C}) \mathrm{CCC}[\mathrm{C} @ @] 6(\mathrm{C})[\mathrm{C} @ @] 5([ \\
\mathrm{H}]) \mathrm{CC}[\mathrm{C} @] 7(\mathrm{CO})[\mathrm{C} @ @ \mathrm{H}] 6 \mathrm{CC}[\mathrm{C} @] 8( \\
\mathrm{C}) 07\end{array}$ & 0.000196 & 0.011 \\
\hline 47 & Lyral & $\begin{array}{l}\text { 3-(4-hydroxy-4-methylpentyl)cyclohex-3- } \\
\text { ene-1-carbaldehyde;4-(4-hydroxy-4- } \\
\text { methylpentyl)cyclohex-3-ene-1- } \\
\text { carbaldehyde }\end{array}$ & $\begin{array}{l}-O=\operatorname{CC} 1 \operatorname{Cc}(\operatorname{CccC}(C)(C) O)=C \operatorname{Cc} 1.0 C( \\
C)(C) \operatorname{CcCC} 2=\operatorname{CcC}(C=O) \operatorname{Cc} 2\end{array}$ & 2.73E-05 & 0.001 \\
\hline 48 & Cachalox & $\begin{array}{l}(3 \sim\{\mathrm{a}\} \sim\{\mathrm{R}\}, 5 \sim\{\mathrm{a}\} \sim\{\mathrm{R}\}, 9 \sim\{\mathrm{a}\} \sim\{\mathrm{S}\}, 9 \sim\{\mathrm{b}\} \sim\{ \\
\mathrm{R}\})-3 \sim\{\mathrm{a}\}, 6,6,9 \sim\{\mathrm{a}\} \text {-tetramethyl- } \\
2,4,5,5 \sim\{\mathrm{a}\}, 7,8,9,9 \sim\{\mathrm{b}\} \text {-octahydro-1 } 1 \mathrm{H}\} . \\
\text { benzo[e][1]benzofuran }\end{array}$ & $\begin{array}{l}\mathrm{C}[\mathrm{C} @ @] 1([\mathrm{C} @ \mathrm{H}](\mathrm{CCO} 2)[\mathrm{C} @ @] 2(\mathrm{C}) \mathrm{C} \\
\mathrm{C} 3)[\mathrm{C} @] 3([\mathrm{H}]) \mathrm{C}(\mathrm{C})(\mathrm{C}) \mathrm{CCC} 1\end{array}$ & 0.00393 & 0.211 \\
\hline 49 & Bourgeonal & 3-(4- \{tert\}-butylphenyl)propanal & $C C(C)(C) C 1=C C=C(C C C=O) C=C 1$ & 0.00499 & 0.268 \\
\hline 50 & Rose oxide & 4-methyl-2-(2-methylprop-1-enyl)oxane & $\operatorname{cc} 1 \cos (\mathrm{C}=\mathrm{C}(\mathrm{C}) \mathrm{C}) \mathrm{C} 1$ & 0.657 & 35.334 \\
\hline 51 & 2-Phenylethyl acetate & 2-phenylethyl acetate & $\mathrm{O}=\mathrm{C}(\mathrm{C}) \mathrm{OCCC} 1=\mathrm{CC}=\mathrm{CC}=\mathrm{C} 1$ & 0.0683 & 3.673 \\
\hline 52 & Trifernal & 3-phenylbutanal & $\mathrm{CC}(\mathrm{CC}=\mathrm{O}) \mathrm{C} 1=\mathrm{CC}=\mathrm{CC}=\mathrm{C} 1$ & 0.0852 & 4.582 \\
\hline 53 & Satinaldehyde & 2-methyl-3-(4-methylphenyl)propanal & $\mathrm{CC} 1=\mathrm{CC}=\mathrm{C}(\mathrm{CC}(\mathrm{C}=\mathrm{O}) \mathrm{C}) \mathrm{C}=\mathrm{C} 1$ & 0.0329 & 1.769 \\
\hline 54 & Rhubafuran & 2,4-dimethyl-4-phenyloxolane & $\mathrm{CC} 1(\mathrm{C} 2=\mathrm{CC}=\mathrm{CC}=\mathrm{C} 2) \mathrm{CC}(\mathrm{C}) \mathrm{OC} 1$ & 0.0308 & 1.656 \\
\hline 55 & Phenylethyl salicylate & 2-phenylethyl 2-hydroxybenzoate & $\begin{array}{l}\mathrm{OC}(\mathrm{C}=\mathrm{CC}=\mathrm{C} 1)=\mathrm{C} 1 \mathrm{C}(\mathrm{OCCC} 2=\mathrm{CC}=\mathrm{CC}= \\
\mathrm{C} 2)=\mathrm{O}\end{array}$ & $1.39 \mathrm{E}-06$ & 0.000 \\
\hline
\end{tabular}




\begin{tabular}{|c|c|c|c|c|c|}
\hline 56 & Methyl anisate & methyl 4-methoxybenzoate & $\mathrm{COC} 1=\mathrm{CC}=\mathrm{C}(\mathrm{C}(\mathrm{OC})=\mathrm{O}) \mathrm{C}=\mathrm{C} 1$ & 0.0118 & 0.635 \\
\hline 57 & Whiskey Lactone $\mathrm{K}$ & 5-butyl-4-methyloxolan-2-one & $\operatorname{ccccc}(\mathrm{O} 1) \mathrm{C}(\mathrm{C}) \mathrm{CC} 1=\mathrm{O}$ & 0.0154 & 0.828 \\
\hline 58 & 3-methyl-5-phenylpentanal & 3-methyl-5-phenylpentanal & $C C(C C=O) C C C 1=C C=C C=C 1$ & 0.013 & 0.699 \\
\hline 59 & Rosinol Cryst & (2,2,2-trichloro-1-phenylethyl) acetate & $\mathrm{CIC}(\mathrm{Cl})(\mathrm{Cl}) \mathrm{C}(\mathrm{OC}(\mathrm{C})=\mathrm{O}) \mathrm{C} 1=\mathrm{CC}=\mathrm{CC}=\mathrm{C} 1$ & 0.000976 & 0.052 \\
\hline 60 & Plicatone & $\begin{array}{l}(1 \sim\{R\}, 2 \sim\{R\}, 5 \sim\{S\}, 7 \sim\{S\}, 8 \sim\{R\})-5- \\
\left.\text { methyltricyclo[6.2.1. } 0^{\wedge}\{2,7\}\right] \text { undecan-4- } \\
\text { one }\end{array}$ & $\begin{array}{l}\mathrm{O}=\mathrm{C} 1 \mathrm{C}[\mathrm{C} @ @]([\mathrm{C} @ @ \mathrm{H}] 2 \mathrm{C}[\mathrm{C} @ \mathrm{H}] 3 \mathrm{CC} 2 \\
)([\mathrm{H}])[\mathrm{C} @]]([\mathrm{H}]) \mathrm{C}[\mathrm{C} @ @ \mathrm{H}] 1 \mathrm{C} . \mathrm{O}=\mathrm{C} 4 \mathrm{C} \\
{[\mathrm{C} @]([\mathrm{C} @ @ \mathrm{H}] 5 \mathrm{C}[\mathrm{C} @ \mathrm{H}] 6 \mathrm{CC} 5)([\mathrm{H}])[\mathrm{C}} \\
@ @] 6([\mathrm{H}]) \mathrm{C}[\mathrm{C} @ \mathrm{H}] 4 \mathrm{C}\end{array}$ & 0.0166 & 0.893 \\
\hline 61 & Decyl acetate & decyl acetate & $\operatorname{ccccccccccoc}(\mathrm{C})=0$ & 0.0375 & 2.017 \\
\hline 62 & Cashmeran & $\begin{array}{l}\text { 1,1,2,3,3-pentamethyl-2,5,6,7- } \\
\text { tetrahydroinden-4-one }\end{array}$ & $\mathrm{O}=\mathrm{C} 1 \mathrm{CCCC}(\mathrm{C}(\mathrm{C})(\mathrm{C}) \mathrm{C} 2 \mathrm{C})=\mathrm{C} 1 \mathrm{C} 2(\mathrm{C}) \mathrm{C}$ & 0.00403 & 0.217 \\
\hline 63 & Neobutenone alpha & $\begin{array}{l}\text { 1-(5,5-dimethylcyclohexen-1-yl)pent-4- } \\
\text { en-1-one }\end{array}$ & $\operatorname{CC} 1(C) \operatorname{CC}(C(C C C=C)=0)=C C C 1$ & 0.0187 & 1.006 \\
\hline 64 & Cascalone & 7-propan-2-yl-1,5-benzodioxepin-3-one & $\mathrm{CC}(\mathrm{C}) \mathrm{C} 1=\mathrm{CC}(\mathrm{OCC} 2=\mathrm{O})=\mathrm{C}(\mathrm{OC} 2) \mathrm{C}=\mathrm{C} 1$ & 0.000197 & 0.011 \\
\hline 65 & Amyl Phenylacetate & $\begin{array}{l}\text { 2-methylbutyl 2-phenylacetate;3- } \\
\text { methylbutyl 2-phenylacetate }\end{array}$ & $\begin{array}{l}\mathrm{O}=\mathrm{C}(\mathrm{OCCC}(\mathrm{C}) \mathrm{C}) \mathrm{CC} 1=\mathrm{CC}=\mathrm{CC}=\mathrm{C} 1 . \mathrm{O}= \\
\mathrm{C}(\mathrm{OCC}(\mathrm{C}) \mathrm{CC}) \mathrm{CC} 2=\mathrm{CC}=\mathrm{CC}=\mathrm{C} 2\end{array}$ & 0.0068 & 0.366 \\
\hline 66 & Alpha-Damascone & $\begin{array}{l}\text { 1-(2,6,6-trimethylcyclohex-2-en-1-yl)but- } \\
\text { 2-en-1-one }\end{array}$ & $-C_{1}(C) C(C(/ C=C / C)=O) C(C)=C C C 1$ & 0.0186 & 1.000 \\
\hline n.a. & 2-Methylindole & 2-methyl-1H-indole & $\mathrm{CC} 1=\mathrm{CC} 2=\mathrm{CC}=\mathrm{CC}=\mathrm{C} 2 \mathrm{~N} 1$ & - & - \\
\hline n.a. & 3-Methylindole & 3-methyl-1H-indole & $\mathrm{CC} 1=\mathrm{CNC} 2=\mathrm{CC}=\mathrm{CC}=\mathrm{C} 12$ & - & - \\
\hline n.a. & 6-Methylindole & 6-methyl-1H-indole & $\mathrm{CC} 1=\mathrm{CC} 2=\mathrm{C}(\mathrm{C}=\mathrm{C} 1) \mathrm{C}=\mathrm{CN} 2$ & - & - \\
\hline
\end{tabular}

Table S3. List of compounds shown in Figure 2 and 6 and used throughout this study. Related to Figures 2 and 6. Compounds are indexed according to appearance in Figure 2 and 6 and additional information is provided. Isomeric mixtures are described by the IUPAC name and the simplified molecular input line entry system (SMILES). Vapor pressure estimates for all compounds (calculated in EPISuite) and the gas phase concentration at saturation in air are also given (following Raoult's law). 